\title{
Edukatorisches Staatshandeln am Beispiel der Etablierung eines neuen Familienleitbildes ${ }^{\star}$
}

\author{
Eva SchumanN
}

I. Begriffsbestimmungen

II. Voraussetzungen und Grenzen edukatorischen Staatshandelns

III. Etablierung eines neuen Familienleitbildes

1. Die Zwei-Erwerbstätigen-Familie als Leitbild

2. Maßnahmen und Strategien zur Durchsetzung des neuen Familienleitbildes

a) Das Beispiel des Siebten Familienberichts

b) Einkommensabhängiges Elterngeld und „Vätermonate“

c) Regelungen und Anreize zur Nutzung der Angebote frühkindlicher Fremdbetreuung

3. Verstärkung von Edukationseffekten durch wechselbezügliche Gesetzgebung, begleitende Werbekampagnen und gezielte Desinformation

IV. Fazit

In diesem den Tagungsband einleitenden Beitrag soll in drei Schritten zunächst edukatorisches Staatshandeln definiert, sodann eine verfassungsrechtliche Einordnung vorgenommen und schließlich ein aktuelles Beispiel vorgestellt werden.

\section{Begriffsbestimmungen}

Obwohl sich erzieherische Tendenzen in verschiedenen Feldern des Rechts identifizieren lassen, beschränken sich einschlägige Beiträge häufig auf die bloße Benennung des Phänomens; rechtstheoretische und insbesondere verfassungsrechtliche Überlegungen zu diesem Thema bleiben ebenso wie Ausführungen zur historischen oder rechtsvergleichenden Perspektive vereinzelt. ${ }^{1}$ Im Fol-

* Ich danke meinem wiss. Mitarbeiter Carsten Fitting für vielfache Hilfe. Der vorliegende Beitrag ist eine erweiterte und aktualisierte Fassung des Einführungsvortrags auf dem Symposion „Das erziehende Gesetz“ vom 20. Januar 2011. Die in diesem Beitrag angegebenen URL-Adressen wurden zuletzt am 9. August 2013 aufgerufen.

$1 \mathrm{Zu}$ nennen sind insbesondere zwei Dissertationen zum Umweltrecht: JörN LüDEMANN, Edukatorisches Staatshandeln, Steuerungstheorie und Verfassungsrecht am Beispiel der 
genden soll daher der Versuch unternommen werden, eine Definition edukatorischen Staatshandelns auch anhand einer Abgrenzung von anderen Formen staatlicher Einflussnahme auf den freien Willen der Bürger, namentlich vom staatlichen Paternalismus, zu entwickeln.

Erziehung meint eine stetige geistige Einwirkung auf Personen mit dem Ziel, diese so zu prägen, dass sie kraft innerer Überzeugung ihr Verhalten der gewünschten Ideologie anpassen. ${ }^{2}$ Sie soll bewirken, dass Personen auf Dauer nicht mehr aufgrund staatlichen Zwangs oder gesetzter Anreize, sondern aufgrund eines durch Erziehung herbeigeführten Bewusstseinswandels ihr Verhalten an der Zielvorgabe ausrichten. ${ }^{3}$ Bei der Frage, ob staatliches Handeln (insbesondere in Form eines Gesetzes) erzieherischen Charakter hat, wird es freilich nicht genügen, nach einzelnen erzieherischen Elementen zu suchen, vielmehr muss der Erziehungszweck eine wesentliche Rolle spielen, wenngleich er nicht den alleinigen oder überwiegenden Zweck des Staatshandelns darstellen muss. ${ }^{4}$

staatlichen Förderung von Abfallmoral, 2004; Hans-Peter Vierhaus, Umweltbewußtsein von oben, Zum Verfassungsgebot demokratischer Willensbildung, 1994. Vgl. weiter zur historischen Perspektive Christian Hillgruber, Der Schutz des Menschen vor sich selbst, 1992, S. 5-61 (der Schwerpunkt liegt hier auf Staatslehren mit edukatorischen Zielsetzungen); Thomas Simon, Was ist und wozu dient Gesetzgebung?, Kodifikation und Steuerungsgesetzgebung: Zwei Grundfunktionen legislativer Normsetzung, in: Gerald Kohl/Christian Neschwara/Thomas Simon (Hrsg.), Rechtsgeschichte mit internationaler Perspektive, Festschrift für Wilhelm Brauneder, 2008, S. 635 ff. (insbesondere zur Abgrenzung von Steuerungsgesetzgebung und Kodifikationsgesetzgebung).

2 So insbesondere auch Vierhaus (Anm. 1), S. 205: „das Einwirken , auf die Bewußtseinsbildung des Bürgers dient der Einsicht und Verinnerlichung eines, wertmäßigen Vorrangs` des empfohlenen Verhaltens, kurz: es werden ,sozialmoralische Verhaltensstandards` gesetzt."

3 Unter edukatorisches Staatshandeln fallen daher nicht einzelne Maßnahmen gesetzgeberischer Lenkung, mit denen zwar auch ein konkretes Ziel verwirklicht werden soll, eine dauerhafte Bewusstseinsänderung bei den Personen, die aus rationalen Gründen ihr Verhalten in der konkreten Situation an der Zielvorgabe ausrichten, aber nicht intendiert ist. Entscheidend ist für den Staat hier der (gegenwärtige) Erfolg der Maßnahme, während er der Motivation des Bürgers neutral gegenübersteht und auch keine zukunftsbezogene Erwartungshaltung im Hinblick auf eine Verhaltensänderung seiner Bürger hat. Auch Christof Gramm, Aufklärung durch staatliche Publikumsinformationen, Staatshandeln als Aufklärung?, Der Staat 30 (1991), S. 51, 65 stellt auf die mit der staatlichen Maßnahme verfolgte Absicht ab: „Der Staat begnügt sich also nicht nur mit dem äußeren Gehorsam, sondern er will mehr als dies: die innere Zustimmung." Vgl. weiter VierHaus (Anm. 1), S. 428 ff. (zu verschiedenen Fallgruppen staatlicher Erziehung der Bürger) und kritisch S. $447 \mathrm{ff}$.

4 So aber Christiane Wendehorst, in diesem Band, S. 118, die erst bei einer „bestimmten Dominanz" des edukatorischen Charakters eines Gesetzes von edukatorischer Gesetzgebung sprechen will, nämlich dann, wenn der bewusstseinsbildende Zweck eines Gesetzes gegenüber anderen Zwecken überwiegt. 
Edukatorisches Staatshandeln tritt zudem typischerweise in einer Kombination von Gesetzgebung, sog. Informationsinterventionismus (Aufklärungskampagnen, Informationssteuerung, moralische Appelle, Empfehlungen, Warnungen usw. $)^{5}$ und weiterer Lenkungsmaßnahmen ${ }^{6}$ auf, wobei die Kombination verschiedener staatlicher Maßnahmen und Instrumente die rechtsstaatliche Kontrolle der Erziehung der Bürger erschwert. ${ }^{7}$ Ein wesentlicher Vorteil dieses Vorgehens liegt für den Staat darin, dass der durch den Bewusstseinswandel in der Gesellschaft hervorgerufene Erwartungsdruck und die damit einhergehende Kontrolle des sozialen Umfelds die Veränderung von individuellen Einstellungen zusätzlich beeinflusst. ${ }^{8}$ Im Erfolgsfall kann daher aufgrund der bewusstseinsbildenden Kraft der inneren Überzeugung großer Teile der Bevölkerung und dem damit verbundenen sozialen Druck eine stärke „Nachhaltigkeit“ erzeugt werden als mit der alleinigen Steuerung durch Normen (und diese sogar langfristig entbehrlich machen). ${ }^{9}$

So waren beispielsweise im Bereich der Abfalltrennung in privaten Haushalten die Bemühungen des Staates, seine Bürger zur Sozialmoral zu erziehen, ausgesprochen erfolgreich, ${ }^{10}$ denn die deutschen Bürger, die als ,Weltmeister“ im Sortieren von Abfall gelten, tun dies heute nicht, weil es vorgeschrieben ist (wer kennt schon die einschlägigen Regelungen?), sondern weil sie (und zwar $94 \%$ ) kraft innerer Überzeugung die Abfalltrennung für eine gute Sache halten. ${ }^{11} \mathrm{Ganz}$ abgesehen davon, dass sich die Frage, ob der Staat überhaupt ein Mandat zur Er-

5 Dazu Michael Sachs, Informationsinterventionismus und Verfassungsrecht, in: Lerke Osterloh/Karsten Schmidt/Hermann Weber (Hrsg.), Staat, Wirtschaft, Finanzverfassung, Festschrift für Peter Selmer, 2004, S. 209 ff.; Vierhaus (Anm. 1), S. 209 ff., 214 ff. (zur historischen Entwicklung), S. 223 ff. (zu verfassungsrechtlichen Aspekten).

6 Vierhaus (Anm. 1) zeigt ein ganzes Bündel weiterer Maßnahmen für den Bereich des Umweltschutzes auf: Prägung von (Leit-)Begriffen (S. 147 ff.), Einflussnahme auf die Presse (S. 151 ff.), Steuerung durch gezielte Forschungsförderung (S. 163 ff.), administrative Lenkung und finanzielle Unterstützung von Verbänden (S. 166 ff.).

7 So Wolfram Höfling, Rechtliche Mittel, Maßstäbe und Schranken der staatlichen Beeinflussung des Ernährungsverhaltens, ZLR 2006, S. 121, 123. Vgl. weiter Michael Kloepfer, Umweltrecht, 3. Aufl. 2004, \ 5 Rn. 173 ff., 391 ff.

8 So Lüdemann (Anm. 1), S. 105.

9 Zumal nach ThOmas RaIser, Rechtsgefühl, Rechtsbewußtsein, Rechtskenntnis, Rechtsakzeptanz, Einige begriffliche und methodische Bemerkungen zu den Grundlagen der Akzeptanzforschung, in: Johannes W. Pichler (Hrsg.), Rechtsakzeptanz und Handlungsorientierung, 1998, S. 109, 119 ,,das sich überwiegend aus anderen Quellen speisende Rechtsbewußtsein einen wesentlichen größeren Einfluss auf die Akzeptanz [hat] als die Rechtskenntnisse, über die jemand verfügt".

10 Umfassend zum edukatorischen Staatshandeln im Bereich des Umweltschutzes seit den 1970er Jahren Vierhaus (Anm. 1), S. 33 ff., 123 ff., 139 ff., 147 ff., 180 ff.

11 So Lüdemann (Anm. 1), S. 51 f.; Joachim Jahn, Rezension zu Jörn Lüdemann, Edukatorisches Staatshandeln (2004), FAZ vom 6. März 2006, S. 14. 
ziehung seiner Bürger hat, ${ }^{12}$ auch hier aufdrängt, können wir uns angesichts des „fragliche[n] Nutzen[s] für die Ökobilanz"13 auch keineswegs sicher sein, ob es sich um eine gute Sache handelt, ob also die Moral das hält, was sich der Staat von ihr verspricht. ${ }^{14}$

Eine ähnliche Entwicklung zeichnet sich bei der staatlichen Beeinflussung des Ernährungsverhaltens der Bürger ab. Die edukatorischen Intentionen des einschlägigen europäischen Gemeinschaftsrechts führen in Kombination mit nationalen Maßnahmen zu einem umfangreichen ,regulatorischen Instrumentenmix“, der von Verboten im Lebensmittelrecht über das staatliche „Bio-Siegel“ bis hin zu Ratschlägen über gesunde Ernährung reicht. ${ }^{15}$ Auch hier verfügt der Staat mangels gesicherter Wissensbasis nicht über ein überlegenes Wissen, das ihn in die

12 Eine Empfehlung an den Staat, seine Bürger zur Umweltverantwortung zu erziehen, hatte der Rat von Sachverständigen für Umweltfragen bereits in seinem ersten Umweltgutachten von 1974 erteilt (Umweltgutachten 1974 vom 14. November 1974, BTDrucks. 7/2802, S. VIII): „Die Wirksamkeit des Umweltschutzes hängt vom Verantwortungsbewußtsein des Einzelnen ab. Deshalb ist die Wandlung der Einstellung des Bürgers von der Gleichgültigkeit zur Verantwortung gegenüber der Umwelt von entscheidender Bedeutung. Der Rat empfiehlt daher, die Aufklärung der Öffentlichkeit auf allen Gebieten des Umweltschutzes zu verstärken."

13 Jahn (Anm. 11), FAZ vom 6. März 2006, S. 14: „Doch ohne sozialen Druck und zusätzliche moralische Appelle auch von staatlicher Seite wäre es kaum gelungen, die Deutschen zum Weltmeister beim Sortieren von leeren Joghurtbechern und beim Füllen ,gelber Säcke“ mit Verpackungsschachteln, die den ,grünen Punkt' tragen, zu machen - mit durchaus fraglichem Nutzen für die Ökobilanz." Vgl. weiter Jan FleischHauer/ Guido Kleinhubbert/Alexander Neubacher, Die Öko-Falle, Der Spiegel 2011/11, S. $36 \mathrm{ff}$.

14 So Lüdemann (Anm. 1), S. 18 (ähnlich auch die Verlagsankündigung).

15 Höfling (Anm. 7), ZLR 2006, S. 121, 122 ff. Vgl. weiter Sandra Heck, Paradigmenwechsel im Lebensmittelrecht: Vom speziellen Verbot zu Kontrollzwecken zum generellen Verbot mit edukatorischer Intention?, Rechtmäßigkeit der Verordnung (EG) Nr. 1924/2006 über nährwert- und gesundheitsbezogene Angaben über Lebensmittel, 2010 (insbesondere S. 257 ff. zur Erziehung der Bürger durch hoheitliche Informationstätigkeit); Stefren Augsberg, Der Staat als Informationsmittler, Robin Hood oder Parasit der Wissensgesellschaft?, DVBl 2007, S. 733, 735 (zum Verbraucherschutz im Lebensmittelrecht: „Vielmehr lassen sich diesseits der Risikovorsorge Ansätze eines paternalistisch-edukatorischen Staatshandelns ausmachen, wenn unter Inanspruchnahme staatlicher Autorität und/oder öffentlicher Finanzmittel als besonders zweckmäßig oder ideologisch-moralisch für vorzugswürdig erachtete Produkte empfohlen werden oder gar für bestimmte Lebensbilder geworben wird.“). Ein weiteres Beispiel ist die Regulierungsgesetzgebung/-verwaltung in bestimmten Bereichen der Wirtschaft; dazu Frank Schorkopf, Regulierung nach den Grundsätzen des Rechtsstaates, Zielvorstellungen guter Ordnung im neueren Verwaltungsrecht, JZ 2008, S. 20 ff. 
Lage versetzen könnte, für jeden Bürger das jeweils richtige Ernährungsverhalten verbindlich vorzugeben. ${ }^{16}$

Bei diesem zweiten Beispiel, bei dem nicht nur Gemeinwohlaspekte (Reduzierung der Kosten der Sozialsysteme, Schutz der ,,Volksgesundheit“") als Gründe für die Erziehung der Bürger angeführt werden, ${ }^{17}$ sondern es auch um die Gesundheit des Einzelnen geht, drängt sich die Frage auf, wie sich edukatorisches Staatshandeln von paternalistischer Gesetzgebung abgrenzen lässt. Obwohl es reichlich Literatur zum Thema Paternalismus gibt ${ }^{18}$ (auf die hier im Einzelnen nicht eingegangen werden kann), gibt es nur selten Überlegungen zur Abgrenzung zwischen paternalistischem und edukatorischem Staatshandeln. Dies mag auch daran liegen, dass beide Begriffe gelegentlich undifferenziert für dieselben Sachverhalte verwendet oder sogar bewusst gleichgesetzt werden. ${ }^{19}$

16 Kritisch daher Höfling (Anm. 7), ZLR 2006, S. 121, 131 ff. Vgl. weiter Неск (Anm. 15), S. 264 f. zur EG-Verordnung über nährwert- und gesundheitsbezogene Angaben über Lebensmittel: Die den Großteil ausmachenden ,,allgemeinen' gesundheitsbezogenen Angaben und die nährwertbezogenen Angaben [...] üben hingegen keinen Einfluss auf die Gesundheit aus. [...] Zudem widerspricht es dem Gedanken des Verbraucherschutzes, wenn der Verbraucher den hoheitlichen Schutz seiner Gesundheit und seiner wirtschaftlichen Entscheidungsfreiheit mit Freiheitseinbußen bezahlen muss, die zu dem erreichten Schutzniveau in keinem Verhältnis stehen. [...] Wird der Verbraucher aus jeglicher Verantwortung für sein eigenes Leben befreit, [...] entsteht jedoch ein Teufelskreis aus abnehmender Verantwortung und abnehmender Fähigkeiten zum Selbstschutz. “

17 Kritisch zu dieser Argumentation (und zum Begriff der „Volksgesundheit“) STEFAn HuSter in diesem Band, S. 221 f.; Hillgruber (Anm. 1), S. 163; Kai Fischer, Die Zulässigkeit aufgedrängten staatlichen Schutzes vor Selbstschädigung, 1997, S. 170 f., 274 f. Zum Einsatz des Begriffes der „Volksgesundheit“ bzw. der „Gesundheit der Bevölkerung“ in der Rechtsprechung des BVerfG vgl. Eike Michael Frenzel, Die „Volksgesundheit“ in der Grundrechtsdogmatik - Schlaglicht auf einen aufhaltbaren Aufstieg, DÖV 2007, S. $243,244 \mathrm{ff}$.

18 Innerhalb der Paternalismusdebatte wird zwischen verschiedenen Formen differenziert: zwischen „Paternalismus im weiteren und im engeren Sinne“, zwischen „direktem und indirektem Paternalismus, zwischen „reinem und gemischtem“, „echtem und unechtem“ sowie „weichem und hartem Paternalismus“ usw. Vgl. nur Wolfgang ENDERLEIN, Rechtspaternalismus und Vertragsrecht, 1996, S. 15 ff.; KAI Möller, Paternalismus und Persönlichkeitsrecht, 2005, S. 15 ff.; Anne van Aaken, Begrenzte Rationalität und Paternalismusgefahr: Das Prinzip des schonendsten Paternalismus, in: Michael Anderheiden/Peter Bürkli/Hans Michael Heinig/Stephan Kirste/Kurt Seelmann (Hrsg.), Paternalismus und Recht, 2006, S. 109, 122 ff. Zur historischen Dimension vgl. Thomas Gutmann, Paternalismus - eine Tradition deutschen Rechtsdenkens?, ZRG-GA 122 (2005), S. $150 \mathrm{ff}$.

19 Vgl. zu den Schwierigkeiten einer Abgrenzung von Paternalismus und edukatorischem Staatshandeln zum Schutz ,überragend wichtiger Gemeinwohlbelange“ (BVerfG NJW 2008, S. 2409, 2413: Schutz vor Gesundheitsgefährdungen durch Passivrauchen; kritisch zu diesem Urteil Rolf Gröschner, Vom Ersatzgesetzgeber zum Ersatzerzieher, Warum das Bundesverfassungsgericht zu einem „absoluten Rauchverbot“ besser geschwiegen hätte, ZG 2008, S. 400 ff., 405 ff.) etwa die abweichende Meinung des BVerfG-Richters 
Ein Wesensmerkmal staatlichen Paternalismus liegt darin, dass entscheidungsfähige erwachsene Bürger vor sich selbst und den Folgen ihrer Entscheidung geschützt werden sollen. ${ }^{20}$ Typische Beispiele paternalistischer Gesetzgebung sind etwa die Gurtanlegepflicht in Fahrzeugen, die Schutzhelmpflicht für Kraftradfahrer oder das Verbot von Drogenkonsum, wenngleich es in diesen Fällen regelmäßig nicht nur darum geht, den Bürger zum eigenen Wohl vor sich selbst, ${ }^{21}$ sondern auch die Gesellschaft vor den Kosten des selbstschädigenden Verhaltens des Einzelnen zu schützen. ${ }^{22}$ Die Verknüpfung von Selbstschutz und

JohanNes MAsing, NJW 2008, S. 242I, 2422 zur „Radikallösung eines absoluten gaststättenrechtlichen Rauchverbots“: „Mit ihr wird vielmehr ein Weg edukatorischer Bevormundung vorgezeichnet, der sich auf weitere Bereiche ausdehnen könnte und dann erstickend wirkt.“ Auf S. 2421 spricht Masing hingegen von der „Gefahr paternalistischer Bevormundung" [Hervorhebungen durch Verf.]. Auch in der Literatur wird teilweise nicht klar zwischen Erziehung und Paternalismus differenziert, vgl. etwa Aldo Legnaro, Disziplin und Kontrolle als Parameter von Drogenpolitik: Das Beispiel des New Paternalism, Krim Journal 2007, S. 5, 10; Paul Kevenhörster/Adrienne Windhoff-Héritier, Öffentliche Erziehung zwischen Sozialstaatspostulat und Freiheitsgebot, ZfP 1981, S. 239, 247, die von ,erzieherischem Paternalismus“ sprechen.

20 So die Definition von Gutmann (Anm. 18), ZRG-GA 122 (2005), S. 150, Fn. 1. Ähnlich Möller (Anm. 18), S. 219: „Unter staatlichem Paternalismus versteht man ein Verhalten des Staates, das den Zweck hat, dem Einzelnen Schutz aufzuzwingen, und zwar unabhängig davon, ob dieser Schutz erwünscht ist oder nicht." Vgl. weiter Frank Grunert, Paternalismus in der politischen Theorie der deutschen Aufklärung, Das Beispiel Christian Wolff, in: Michael Anderheiden/Peter Bürkli/Hans Michael Heinig/ Stephan Kirste/Kurt Seelmann (Hrsg.), Paternalismus und Recht, 2006, S. 9. Vgl. auch VAN AAKEN (Anm. 18), S. 109, 110.

$21 \mathrm{Zu}$ Gesetzen, die ausschließlich den Schutz des Individuums vor sich selbst bezwecken, BVerfG NJW 1982, S. 691 (Unterbringung eines Geisteskranken aus fürsorgerischen Gründen ist verfassungsgemäß); BVerfG NJW 1982, S. 2061 (starre Altersgrenze für Personenstandsänderung bei Transsexuellen ist nicht verfassungsgemäß). Kritisch dazu INGO VON MüNCH, Grundrechtsschutz gegen sich selbst?, in: Rolf Stödter/Werner Thieme (Hrsg.), Hamburg, Deutschland, Europa, Beiträge zum deutschen und europäischen Verfassungs-, Verwaltungs- und Wirtschaftsrecht, Festschrift für Hans Peter Ipsen zum siebzigsten Geburtstag, 1977, S. 113, 114 ff. (vON MüNCH kommt zu dem Ergebnis, dass man einen Grundrechtsschutz gegen sich selbst nicht anerkennen könne, denn dies wäre eine „Umkehrung der Grundrechtsidee“, die dazu führe, dass das Grundrecht „dem Grundrechtsträger nicht dient, sondern über ihn herrscht"). So (mit ausführlicher Begründung) auch Hillgruber (Anm. 1), S. 126 ff.

22 So etwa BVerfG NJW 1994, S. 1577, 1578 (unerlaubter Umgang mit Cannabisprodukten): „Die Freiheit der Person, die das Grundgesetz als ,unverletzlich' bezeichnet, ist ein so hohes Rechtsgut, daß in sie aufgrund des Gesetzesvorbehalts des Art. 2 II 3 GG nur aus besonders gewichtigen Gründen eingegriffen werden darf. Unbeschadet dessen, daß solche Eingriffe unter bestimmten Voraussetzungen auch in Betracht kommen mögen, wenn sie den Betroffenen daran hindern sollen, sich selbst einen größeren persönlichen Schaden zuzufügen $[\ldots]$, sind sie im allgemeinen nur zulässig, wenn der Schutz anderer oder der Allgemeinheit dies unter Berücksichtigung des Verhältnismäßigkeitsgrundsatzes erfordert.“ Ähnlich BVerfG NJW 1982, S. 1276 (Schutzhelmpflicht): „Die ange- 
Gemeinwohlbelangen hat das BVerfG inzwischen mit der Formel zementiert, dass ,es grundsätzlich ein legitimes Gemeinwohlanliegen [sei], Menschen davor zu bewahren, sich selbst leichtfertig einen größeren persönlichen Schaden zuzufügen". 23

Während Paternalismus als echte Bevormundung keinen Lernprozess beim Bürger auslösen möchte, sondern davon ausgeht, dass dieser in bestimmten Konstellationen zu seinem Wohle gezwungen werden muss, gegen seinen Willen zu handeln, ${ }^{24}$ will Erziehung überzeugen, d.h. der Erzogene soll sein Verhalten an den Grundeinstellungen und Wertungen des Erziehenden kraft innerer Überzeugung ausrichten. Daher tritt staatlicher Paternalismus typischerweise in Form von gesetzlichen Geboten oder Verboten auf, während im Rahmen edukatorischen Staatshandelns regelmäßig eine ganze Palette an staatlichen Maßnahmen zur Überzeugungsbildung eingesetzt wird.

Die eingesetzten Mittel und die zu erreichenden Ziele unterscheiden sich somit, wenngleich auch beim edukatorischen Staatshandeln die Zwecksetzung (ebenso wie beim staatlichen Paternalismus) darin bestehen kann, dass der Einzelne vor sich selbst geschützt wird und gleichzeitig wichtige Gemeinwohlziele verfolgt werden. Allerdings steht beim Paternalismus regelmäßig der Selbstschutz

griffene Vorschrift stellt auch keine unzulässige Bevormundung des Bürgers dar. Nach dem Grundgesetz muß der einzelne sich diejenigen Schranken seiner Handlungsfreiheit gefallen lassen, die der Gesetzgeber zur Pflege und Förderung des sozialen Zusammenlebens in den Grenzen des bei dem gegebenen Sachverhalt allgemein Zumutbaren zieht, vorausgesetzt, daß dabei die Eigenständigkeit der Person gewahrt bleibt [...]. Ein Kraftradfahrer, der ohne Schutzhelm fährt und deshalb bei einem Unfall eine schwere Kopfverletzung davonträgt, schadet keineswegs nur sich selbst. [...] Daß Unfälle mit schweren Kopfverletzungen weitreichende Folgen für die Allgemeinheit haben (z.B. durch Einsatz der Rettungsdienste, ärztliche Versorgung, Rehabilitationsmaßnahmen, Versorgung von Invaliden), steht außer Frage." Vgl. weiter BVerfG NJW 1987, S. 180 (Gurtanlegepflicht); BVerfG NJW 1967, S. 1795, 1800 (zwangsweise Anstalts-/Heimunterbringung eines Erwachsenen). Dazu auch Hillgruber (Anm. 1), S. 97 ff., 158 ff. (kritisch zur Sozialpflichtigkeit des Einzelnen als Kehrseite sozialstaatlicher Daseinsvorsorge); vON Münch (Anm. 21), S. 113, 115 ff.; van Aaken (Anm. 18), S. 109, 125; Hans Michael Heinig, Paternalismus im Sozialstaat, Nutzen und Grenzen des Paternalismusdiskurses für eine Verfassungstheorie des Sozialstaates, in: Michael Anderheiden/Peter Bürkli/ Hans Michael Heinig/Stephan Kirste/Kurt Seelmann (Hrsg.), Paternalismus und Recht, 2006, S. 157, $175 \mathrm{ff}$.

23 BVerfG NJW 2012, S. 1062, 1063 (gesetzliches Sonnenstudioverbot für Minderjährige), wobei das BVerfG vor allem mit dem Jugendschutz (Schutz der Minderjährigen aufgrund ihrer mangelnden Einsichtsfähigkeit und Reife) argumentierte (S. 1064). Vgl. aber auch BVerfG NJW 1999, S. 3399, 3403 zum Verbot einer fremdgerichteten altruistischen Lebendorganspende bei Erwachsenen. Kritisch dazu Thomas Gutmann, Gesetzgeberischer Paternalismus ohne Grenzen? Zum Beschluss des Bundesverfassungsgerichts zur Lebendspende von Organen, NJW 1999, S. 3387, 3388.

24 Ähnlich Christiane Wendehorst, in diesem Band, S. $117 \mathrm{ff}$. 
des Individuums im Vordergrund, während beim edukatorischen Staatshandeln tendenziell die Verbesserung der Gesellschaft, ${ }^{25}$ insbesondere die Verfolgung wichtiger Gemeinwohlbelange wie z.B. der Umwelt- oder Gesundheitsschutz, als Gründe für die Erziehung der Bürger überwiegen. ${ }^{26}$ Anhand dieser Kriterien (Mittel, Ziele, betroffene Schutzgüter) lassen sich Schutzhelm- und Gurtanlegepflicht oder das Verbot einer fremdgerichteten altruistischen Lebendorganspende der paternalistischen Gesetzgebung zuordnen, während die staatliche Einflussnahme in den Bereichen der Abfalltrennung oder des Ernährungsverhaltens als edukatorisches Staatshandeln einzuordnen ist.

\section{Voraussetzungen und Grenzen edukatorischen Staatshandelns}

Edukatorisches Staatshandeln bedarf wie jede staatliche Maßnahme, die in eine grundrechtlich geschützte Position eingreift, einer verfassungsrechtlichen Rechtfertigung. Wie bereits erwähnt tritt edukatorische Gesetzgebung typischerweise in Kombination mit staatlicher Informationstätigkeit auf, die sich als ,entformalisiertes staatliches Handeln“ nur schwer rechtlich fassen lässt. ${ }^{27}$ Informales Staatshandeln durch staatliche Information der Öffentlichkeit hat worauf FRIEDRICH SCHOCH zu Recht hinweist - ,im Zeitalter der sogenannten Informationsgesellschaft signifikant zugenommen“. ${ }^{28}$ Dieses Handlungsinstrument ermöglicht es heute dem Staat, mit geringem (steuerfinanziertem) Auf-

$25 \mathrm{Zu}$ diesem Ziel kann es auch gehören, den Einzelnen zu bessern. Hierzu hat das BVerfG früh festgestellt, dass Eingriffe in die Freiheit des Einzelnen zwar zu dessen Schutz, nicht aber zur Erziehung bzw. Besserung des Einzelnen zulässig sind (BVerfGE 22, S. 180, 219 f.). Dazu auch Hillgruber (Anm. 1), S. 64 f., 69 ff.

26 Thomas Simon (in diesem Band, S. 70 f.) differenziert hingegen innerhalb der erzieherischen Gesetzgebung zwischen solcher, „die primär der Verbesserung der Gesellschaft dienen soll, und einer solchen, die ausschließlich auf den Schutz des Individuums vor selbstschädigendem Verhalten ausgerichtet ist, " wobei er die frühneuzeitliche Polizeigesetzgebung der erstgenannten Kategorie zuordnet.

27 Dazu umfassend Friedrich Sсносн, $\mathbb{S} 37$ Entformalisierung staatlichen Handelns, in: Josef Isensee/Paul Kirchhof (Hrsg.), Handbuch des Staatsrechts der Bundesrepublik Deutschland, Bd. 3, 3. Aufl. 2005, der konstatiert (Rn. 23), dass die „Schwierigkeiten der rechtlichen Erfassung [...] dadurch noch gesteigert [werden], daß informales Staatshandeln rechtswissenschaftlich nur punktuell erforscht ist und daher über keine verläßliche Dogmatik verfügt."

28 Sсносн (Anm. 27), \37 Rn. 53. So auch schon Gramm (Anm. 3), Der Staat 30 (1991), S. 51 zur Herrschaftsausübung in Form geistiger Einflussnahme: ,Tatsächlich ist der Staat der Bundesrepublik als informierender Staat nahezu omnipräsenter Diskursteilnehmer in der modernen, mediengeprägten Lebenswelt." 
wand erhebliche verhaltenssteuernde Wirkungen zu erzielen ${ }^{29}$ und hat aus der Perspektive des handelnden Staates zudem den Vorteil, dass das BVerfG bei der verfassungsrechtlichen Kontrolle zurückhaltend ist. ${ }^{30}$ Dies mag auch damit zusammenhängen, dass sich der ,ohne Befehl und Zwang arbeitende Staat [...] als der freundschaftliche, partnerschaftliche und kooperative Staat [geriert], der für die Einhaltung von sozialmoralischen Verhaltensstandards wirbt", wobei dies für den Bürger zur Folge hat, dass ,die weitgehend auf den ordnungsrechtlichen Zwang zugeschnittenen Rechtsschutzverfahren faktisch zurückgedrängt“ werden. $^{31}$

29 Beispiele aus den Bereichen des Lebensmittel-, Arzneimittel-, Gesundheits-, Verbraucherschutz- und Umweltrechts sowie auf dem Gebiet der Religion finden sich bei Sсносн (Anm. 27), \37 Rn. 58 ff. Vgl. weiter zur staatlichen Aids-Aufklärungskampagne Christoph Gramm, Rechtsfragen der staatlichen Aids-Aufklärung, NJW 1989, S. 2917 ff. Vgl. aber auch Vierhaus (Anm. 1), S. 418 ff.

30 So auch SсHоch (Anm. 27), \37 Rn. 56: ,Allerdings stellt die mit dem Einsatz staatlicher Autorität verbundene staatliche Informationstätigkeit, die eines gewissen Vertrauensvorschusses des Publikums gewiß sein darf, staatliche Herrschaftsausübung dar. Es ist deshalb rechtstatsächlich und rechtsnormativ verfehlt, wenn das Bundesverfassungsgericht - eine Ebene der Gleichordnung zwischen den Teilnehmern am öffentlichen Diskurs suggerierend - die ,staatliche Teilhabe an öffentlicher Kommunikation " von den wesentlichen verfassungsrechtlichen Bindungen des Staatshandelns freistellt." Vgl. weiter Rn. 97: „Hinzu kommt, daß das Bundesverfassungsgericht die Informationstätigkeit der Regierung entgegen Art. 20 Abs. 3 GG weitgehend von den Bindungen der Rechtsordnung freigestellt hat, worin das Regierungshandeln durch Information auch einen taktischen Vorteil zu erblicken vermag." Kritisch auch schon UDO DI FABIO, Grundrechte im präzeptoralen Staat am Beispiel hoheitlicher Informationstätigkeit, JZ 1993, S. 689, 691, der folgende Wesensmerkmale des präzeptoralen Staates nennt: ,,neue mit Wissen und Information arbeitende staatliche Steuerungsmittel sowie neue vorsorgende und umsorgende Zwecksetzungen - Staat als besorgter, ermahnender und erziehender pater familias“. Abschließend (S. 697) fordert Di FABIO, dass die „Grundrechtsdogmatik [...] auf Möglichkeiten und Gefahren präzeptoraler Staatstätigkeit eingestellt werden“ müsse.

31 Michael Kroepfer, Staatliche Information als Lenkungsmittel, dargestellt insbesondere am Problem behördlicher Warnungen und Empfehlungen im Umweltrecht, 1998, S. 18, 19, der zu Recht darauf hinweist (S. 19 f.), dass diese Folge ,nicht nur die (unbeabsichtigte) Nebenfolge einer mit ,freiwilligen' Entscheidungen der Bürger arbeitenden informationellen Steuerung [sein muss], sondern [...] sehr wohl auch deren funktionale Intention sein“ kann. Und weiter: „Dem sanft vorgehenden Staat kann sich der Bürger nicht selten schwerer entziehen als gegenüber dem imperativen Staat, insbesondere wenn das der indirekten Verhaltenssteuerung immanente Element der Freiwilligkeit durch Markt, Politik und öffentliche Meinung zum ,freiwilligen Zwang' denaturiert. Das moderne Verwaltungs- und Verwaltungsprozeßrecht (einschließlich) der verfassungsrechtlichen Grundrechtsordnung haben mit staatlichem Zwang umzugehen [...] gelernt, kaum aber mit den motivierenden Steuerungsmitteln des ,sanften' Staates. Hier ist das Öffentliche Recht eher noch am Anfang." 
Eine besondere Form öffentlichkeitsbezogener Informationstätigkeit ${ }^{32}$ ist das staatliche Berichtswesen. Dieses zeichnet sich dadurch aus, dass der Staat (meist die Bundesregierung oder ein Bundesministerium) entweder auf gesetzlicher Grundlage ${ }^{33}$ oder kraft Auftrags des Bundestags ${ }^{34}$ in regelmäßigen Abständen zu gesellschaftlich relevanten Bereichen Berichte vorlegt, ${ }^{35}$ die mehrere Aufgaben erfüllen können: Sie geben einen Überblick über die bisherige Tätigkeit des Staates in dem jeweiligen Bereich, sie können die Grundlage für Reformen und Verwaltungshandeln sein und sie versorgen die Bevölkerung mit Informationen, ${ }^{36}$ wobei Letzteres den Effekt einer verhaltensbeeinflussenden Wirkung haben kann und wohl auch regelmäßig haben soll.

Weiterhin sind hier alle im Rahmen staatlicher Informationstätigkeit als Regierungsaufgabe ergehenden Verlautbarungen zu nennen, unabhängig davon, in welcher Form sie auftreten (Aufklärung, Auskunft, Empfehlung, Hinweis, Warnung, Appell, Information usw.). Das BVerfG geht davon aus, dass die allgemeine Information der Öffentlichkeit als Annex zur Regierungstätigkeit erlaubt sei und verlangt daher selbst bei grundrechtsrelevanten Maßnahmen keine gesetzliche Ermächtigungsgrundlage. ${ }^{37}$ Dies ist in der Literatur zu

$32 \mathrm{Zu}$ verschiedenen Formen öffentlichkeitsbezogener Informationstätigkeit wie Berichterstattung, Öffentlichkeitsarbeit oder informationelle Steuerung vgl. KLOEPfER (Anm. 31), S. 12 ff. Vierhaus (Anm. 1), S. 202 ff. unterscheidet zwischen selbstdarstellerischer und edukatorischer Öffentlichkeitsarbeit.

33 So etwa $\int 84$ SGB VIII für die von der Bundesregierung vorzulegenden Jugendberichte. Vgl. weiter die jährlichen Berichte der Bundesregierung zur Evaluation des Kinderförderungsgesetzes nach $₫ 24$ a Abs. 5 SGB VIII.

34 So bei den Familienberichten aufgrund eines Bundestags-Beschlusses von 1965, siehe Anm. 93.

35 Beispiele und weitere Nachweise bei Sсносн (Anm. 27), \37 Rn. 65 ff.

36 So Sсносн (Anm. 27), \ 37 Rn. 67, der kritisch hervorhebt, dass angesichts ,der politischen und gesellschaftlichen Breitenwirkung des staatlichen Berichtswesens [...] das dazu bestehende rechtswissenschaftliche Forschungsdefizit erstaunlich" sei.

37 BVerfGE 105, S. 252, 269 f. (Glykol): „So gehört es in einer Demokratie zur Aufgabe der Regierung, die Öffentlichkeit über wichtige Vorgänge auch außerhalb oder weit im Vorfeld ihrer eigenen gestaltenden politischen Tätigkeit zu unterrichten. In einer auf ein hohes Maß an Selbstverantwortung der Bürger bei der Lösung gesellschaftlicher Probleme ausgerichteten politischen Ordnung ist von der Regierungsaufgabe auch die Verbreitung von Informationen erfasst, welche die Bürger zur eigenverantwortlichen Mitwirkung an der Problembewältigung befähigen. Dementsprechend erwarten die Bürger für ihre persönliche Meinungsbildung und Orientierung von der Regierung Informationen, wenn diese andernfalls nicht verfügbar wären. Dies kann insbesondere Bereiche betreffen, in denen die Informationsversorgung der Bevölkerung auf interessengeleiteten, mit dem Risiko der Einseitigkeit verbundenen Informationen beruht und die gesellschaftlichen Kräfte nicht ausreichen, um ein hinreichendes Informationsgleichgewicht herzustellen. Von der Staatsleitung in diesem Sinne wird nicht nur die Aufgabe erfasst, durch rechtzeitige öffentliche Information die Bewältigung von Konflikten in 
Recht kritisiert worden, ${ }^{38}$ denn Information kann auch ,als staatliches Mittel zur Verhaltensbeeinflussung “39 und damit ,,als Instrument der ,weichen“ Verhaltensbeeinflussung im Sinne eines Mittels zur Erfüllung einer Sachaufgabe“ eingesetzt werden. SсHосH folgend ist daher zu differenzieren zwischen „Information ,über" Staatstätigkeit“" einerseits und ,Wahrnehmung von Staatsaufgaben ,durch“ Information“" andererseits. ${ }^{40}$ In der zweiten Fallgruppe liegt immer dann ein Grundrechtseingriff vor, wenn aufgrund des staatlichen Informationshandelns faktisch ,ein grundrechtlich geschütztes Verhalten unmöglich gemacht wird oder wesentlich erschwert wird“".

Die Frage, wann die Schwelle eines Grundrechtseingriffs bei faktischen Beeinträchtigungen durch staatliches Handeln erreicht ist, ist zwar in Rechtspre-

Staat und Gesellschaft zu erleichtern, sondern auch, auf diese Weise neuen, oft kurzfristig auftretenden Herausforderungen entgegenzutreten, auf Krisen schnell und sachgerecht zu reagieren sowie den Bürgern zu Orientierungen zu verhelfen. Aktuelle Krisen im Agrar- und Lebensmittelbereich haben beispielhaft gezeigt, wie wichtig öffentlich zugängliche, mit der Autorität der Regierung versehene Informationen sind, um solche spannungsgeladenen Situationen angemessen meistern zu können. Würde die Regierung sich in solchen Lagen der Aufgabe entziehen, den Bürgern durch Aufklärung, Beratung und Verhaltensempfehlungen Orientierung zu geben, und sich stattdessen auf Gesetzesinitiativen beschränken oder auf administrative Maßnahmen anderer Staatsorgane warten, würde ein wichtiges Element schneller, wirkungsvoller und auf möglichst geringe Beeinträchtigungen Dritter gerichteter Krisenbewältigung fehlen." Entsprechend BVerfGE 105, S. 279, $300 \mathrm{ff}$.

38 Kritisch Sсносн (Anm. 27), \ 37 Rn. 72 ff., 111 ff., 114 ff., 134; Ders., Die Schwierigkeiten des BVerfG mit der Bewältigung staatlichen Informationshandelns, NVwZ 2011, S. 193 ff.; Dietrich Murswiek, Das Bundesverfassungsgericht und die Dogmatik mittelbarer Grundrechtseingriffe, $\mathrm{Zu}$ der Glykol- und der Osho-Entscheidung vom 26.6.2002, NVwZ 2003, S. 1, 3 ff.

39 So SсHосн (Anm. 27), \37 Rn. 74, der ,zwischen staatlichen Informationshandlungen, die der individuellen Verhaltenslenkung dienen und final auf die Freiheitsausübung einwirken (z.B. konkrete Warnungen oder Empfehlungen), und einem auf andere Ziele gerichteten staatlichen Informationsverhalten (z.B. staatliche Öffentlichkeitsarbeit, staatliche Unterrichtung der Öffentlichkeit)“ differenziert. Dazu auch Rn. 76 ff.

40 Sсносн (Anm. 27), \37 Rn. 79.

41 Sсносн (Anm. 27), \37 Rn. 165 m.w.N. und mit Hinweis darauf, dass dies in der Schweiz bereits so praktiziert werde und auch die Rechtsprechung des EuGH (sog. Dassonville-Formel, EuGH Rs. 8/74, Slg. 1974, S. 837) zur Bestimmung von „Maßnahmen gleicher Wirkung“ im Bereich der Warenverkehrsfreiheit in diese Richtung weise: In der Schweiz werde geprüft, „ob der infolge staatlicher Wissenserklärung bewirkte tatsächliche Erfolg grundrechtliche Freiheit durch den Einsatz staatlicher Autorität verkürz[e]“, während der EuGH deutlich mache, dass „,die Grundfreiheit nicht nur durch staatliche Rechtsvorschriften beeinträchtigt wird, sondern auch durch staatliche Verwaltungspraktiken, Empfehlungen und sonstige Informationsmaßnahmen, die von einer staatlichen Stelle ausgehen und in ihrer freiheitsverkürzenden Wirkung Rechtsakten vergleichbar" seien. 
chung und Literatur im Einzelnen umstritten, ${ }^{42}$ Einigkeit besteht aber insoweit, dass eine eingriffsgleiche Beeinträchtigung jedenfalls dann vorliegt, wenn es sich um eine zielgerichtete staatliche Maßnahme mit einer gewissen Intensität handelt, die mit den Worten des BVerfG, ,in der Zielsetzung und in ihren Wirkungen Eingriffen gleichkomm[t]". ${ }^{43}$ Sobald der Staat zielgerichtet durch Information steuert, um auf diese Weise einen bestimmten Erfolg herbeizuführen, und dabei Grundrechtspositionen beeinträchtigt, ist somit ein Grundrechtseingriff anzunehmen. ${ }^{44}$ Dabei kann es nicht darauf ankommen, dass sich sämtli-

42 Sсносн (Anm. 27), \37 Rn. 87 ff. kritisiert diese unbefriedigende Rechtslage. Denn nach seiner Ansicht dürften die „Folgen des, weichen“ Informationshandelns des Staates nicht unterschätzt werden“, weil mit diesem „durch einen bestimmten Informationsund Wissenstransfer dergestalt auf die Individuen [eingewirkt werde], daß diese aus eigenem Willensentschluß ihr Verhalten so einrichten und gegebenenfalls ändern, daß staatlicherseits erwünschte gesellschaftliche Effekte erzielt" würden (Rn. 91). Hinzu komme, dass die „Praxis des informalen staatlichen Handelns [...] sich ständig fort[entwickle], die positive Rechtsordnung [...] hierauf nur punktuell [reagiere] und die Rechtsprechung [...] keine Hilfe bei der Problembewältigung“ verspreche. „Der inzwischen eingetretene Rechtszustand [sei] teilweise bereits durchaus alarmierend, weil in immer mehr Bereichen die eingetretene Faktizität die durch die Rechtsordnung gestiftete Normativität zu ersticken [drohe]. Vor diesem Hintergrund [sei] die Rechtswissenschaft [...] aufgefordert, Konzepte zur rechtsstaatlich (noch) verantwortbaren und dennoch legitimen praktischen Bedürfnissen Rechnung tragenden Domestizierung entformalisierten staatlichen Handelns zu entwickeln“ (Rn. 119 f.).

43 BVerfGE 116, S. 202, 222: „Der Grundrechtsschutz ist nicht auf Eingriffe im herkömmlichen Sinne beschränkt (zu diesem Eingriffsbegriff vgl. BVerfGE 105, 279 [300]). Vielmehr kann der Abwehrgehalt der Grundrechte auch bei faktischen oder mittelbaren Beeinträchtigungen betroffen sein, wenn diese in der Zielsetzung und in ihren Wirkungen Eingriffen gleichkommen (vgl. BVerfGE 105, 279 [303]; 110, 177 [191]; 113, 63 [76]). Durch die Wahl eines solchen funktionalen Äquivalents eines Eingriffs entfällt die Grundrechtsbindung nicht (vgl. BVerfGE 105, 252 [273]). "Vgl. auch Kloepfer (Anm. 31), S. 27 ff., insb. S. 29 f.: „Gezielte Grundrechtseingriffe tatsächlicher Art müssen insoweit imperativen Eingriffen regelnder Art grundsätzlich gleichgestellt werden. [...] Staatliche Informationen sind demnach als Eingriff zu qualifizieren, wenn sie final auf die Verwirklichung eines Verhaltenserfolges im Schutzbereich eines Freiheitsrechts gerichtet sind. [...] Die gezielte Vereitelung oder Erschwerung der Verwirklichung von grundrechtlich geschützten Interaktionschancen ist regelmäßig als Eingriff zu werten." Vgl. weiter Schoch (Anm. 38), NVwZ 2011, S. 193, 195; Sophie-Charlotte Lenski, Staatliches Informationshandeln als Grundrechtseingriff, Zur Anwendung der OshoRechtsprechung in der verwaltungsgerichtlichen Praxis, ZJS 2008, S. 13, 14 ff.; ToBIAS LeIdinger, Hoheitliche Warnungen, Empfehlungen und Hinweise im Spektrum staatlichen Informationshandelns - Zum aktuellen Stand der Diskussion in Rechtsprechung und Literatur, DÖV 1993, S. 925, 928 ff. Das BVerwG NJW 1997, S. 1996, 1998 bejaht einen Eingriff, wenn durch eine staatliche Stellungnahme ein erheblicher faktischer oder moralischer Druck ausgeübt wird.

44 Vgl. etwa Paul Kirchiof, $\$ 99$ Mittel staatlichen Handelns, in: Josef Isensee/Paul Kirchhof (Hrsg.), Handbuch des Staatsrechts der Bundesrepublik Deutschland, Bd. 5, 3. Aufl. 2007, Rn. 214: „Wenn der informierende Staat mit seiner verfassungsstaatlichen Au- 
che Adressaten der Steuerungswirkung nicht mehr entziehen können, vielmehr muss es genügen, wenn die intendierte Wirkung darauf abzielt, einen möglichst großen Teil der Adressaten durch die Information zu einem bestimmten Verhalten $\mathrm{zu}$ veranlassen. Insbesondere steht der Erhalt des Letztentscheidungsrechts auf Seiten des Adressaten dann der Annahme einer eingriffsgleichen Wirkung nicht entgegen, wenn die Nichtbefolgung der empfohlenen Verhaltensweise zu einer Stigmatisierung oder einem Gewissenszwang führt. ${ }^{45}$

torität vor Jugendsekten, vor dem Verzehr eines Weines oder vor Meditationsvereinen warnt, so ist dieses ein Informationseingriff in den Schutzbereich von Grundrechten, nicht bloße Verbreitung von Allgemeinwissen. Die Information ist eine Handlungsform des Staates, die wie alle anderen den Bindungen des Verfassungsstaates unterliegt." Vgl. auch Dietrich Murswiek, Staatliche Warnungen, Wertungen, Kritik als Grundrechtseingriffe - Zur Wirtschafts- und Meinungslenkung durch staatliches Informationshandeln, DVBl 1997, S. 1021, 1022 f.: „Auch diese gezielte Einwirkung auf die EntschlieBungsfreiheit ist eine Freiheitseinschränkung. " Soweit Verhaltenssteuerungsmaßnahmen „den Betroffenen weniger stark in seiner Freiheit einschränken als Ge- oder Verbote, wirkt sich das nicht auf die Frage aus, ob ein Grundrechtseingriff vorliegt; vielmehr kann dies erst eine Rolle spielen im Zusammenhang mit der Rechtfertigung des Eingriffs am Maßstab des Verhältnismäßigkeitsprinzips." Vgl. weiter Wiebke Spaeth, Grundrechtseingriff durch Information, Zur Verfassungsmäßigkeit von verhaltenssteuernden Warnungen und Empfehlungen der Bundesregierung, 1995, S. 79, $81 \mathrm{f}$.

45 Insoweit liegt ein Rückgriff auf die Rechtsprechung des BGH zum Aufopferungsanspruch bei Impfschäden nahe; BGHZ 24, S. 45 f.: „Ein Aufopferungsanspruch bei einem Impfschaden kann auch dann gegeben sein, wenn der Staat, um eine allgemeine Schutzimpfung herbeizuführen, nicht einen gesetzlichen Zwang, wohl aber (durch entsprechende Merkblätter) auf die Eltern der zu impfenden Kinder einen Gewissenszwang ausübt, der ihnen eine eigene Entschließung über die Impfung ihrer Kinder nur noch der Form nach zugesteht." Erweitert durch BGHZ 31, S. 187, 190 f. (Annahme einer zur Entschädigung verpflichtenden Aufopferungslage bei Durchführung einer empfohlenen Schutzimpfung ohne gesetzlichen Zwang): „Das entspricht der Entwicklung, die der moderne Staat und das moderne Leben genommen haben. Das staatliche hoheitliche Handeln beschränkt sich nicht mehr wie ehedem im wesentlichen auf die Geltendmachung obrigkeitlichen Zwanges, auf den Erlaß von Geboten und Verboten, sondern tritt in besonderem Ausmaß in Planung, Vorsorge und Fürsorge in Erscheinung. [...] Hinzu kommt: Im demokratischen und sozialen Rechtsstaat erfährt das Verhältnis des Bürgers zu seinem Staat eine besondere Färbung: Wo es um politische Entwicklungen und politische Macht geht, mag Wachsamkeit, wo es um obrigkeitliches Handeln geht, mag mutiges Bestehen auf dem Recht am Platze sein; diesem Staat gegenüber ist aber im Bereich des Fürsorgerischen nicht Skepsis und Ressentiment am Platze, sondern Vertrauen und Bereitschaft zur freiwilligen und verantwortungsvollen Einordnung. Das bedeutet, daß man davon auszugehen hat, der Bürger dieses Staates wird, wenn ihm die zuständigen, für das Gemeinwohl verantwortlichen, sachkundigen Stellen in Rücksicht auf die öffentliche Wohlfahrt - beispielsweise aus Gründen der Sozialhygiene - einen Rat geben, den sie für ungefährlich halten, ihm folgen. [...] Das bedeutet: Der Staat hat in dem Bewußtsein, daß der Bürger sich unter den obwaltenden Umständen dem Merkblatt füge und sein Kind der [...] Impfung zuführen werde, einem Kinde, das durch die Impfung eine schwere Gesundheitsschädigung davontrug, zwar nicht durch Ausübung 
Darüber hinaus wird in der Literatur eine eingriffsgleiche Beeinträchtigung auch dann angenommen, wenn mit einer gezielten Desinformation durch den Staat (,Manipulation durch Auswahl und Inhalt“ der Information) eine Verhaltensänderung der Bürger erreicht werden soll. ${ }^{46}$ Wenn der Staat „Grundlagen des Wissens vermittel[e], müss[t]en diese als Befähigung zur Freiheit, nicht als Bevormundung zum Irrtum angelegt sein“. ${ }^{47}$ Man mag die Verhaltenssteuerung durch gezielte Manipulation bereits als Propaganda bezeichnen, wenngleich die Formel, die ,Verbreitung von Wahrheiten“ als Erziehung und die ,Verbreitung von Unwahrheiten “ als Propaganda zu begreifen, nicht unbestritten ist. ${ }^{48}$ In jedem Fall ist eine staatliche ,,Verhaltenslenkung durch bewusste Fehlinformation als schlechthin unzulässig“" einzuordnen. ${ }^{49}$

Nach der Rechtsprechung des BVerfG müssen staatliche Informationen sachlich und objektiv (bezogen auf Werturteile) sowie richtig und vollständig (im Hinblick auf den Inhalt) sein. ${ }^{50}$ Bei der Einhaltung dieser Kriterien sind hohe Standards zu verlangen, weil eine Bewusstseinsänderung (bei Teilen) der Bevölkerung aufgrund staatlicher Informationen nicht bzw. nur schwer rever-

eines gesetzlichen Impfzwanges, wohl aber vermittels eines psychologischen Abforderns der Impfung von den für das Kind handelnden Eltern ein besonders Opfer auferlegt."

46 Dazu Lüdemann (Anm. 1), S. 106 ff., insb. S. $113 \mathrm{ff}$.

47 So Kirchiof (Anm. 44), \ 99 Rn. 215.

48 So insbesondere Peter Robert Hofstätter, Einführung in die Sozialpsychologie, 5. Aufl. 1973, S. 280. Nach Hofstätter (S. 283) gehe es bei Propaganda vielmehr ,stets um den Versuch [...], ein bereits erziehungsmäßig fixiertes normatives Equilibrium zu verschieben“. Gemeinsam sei aber beiden (S. 284), „daß sie die Uniformität der Individuen in einer Kultur vergrößern“ und „,dem Individuum die Gewinnung einer zweckentsprechenden Haltung zu den Geschehnissen in der Welt nur in sehr begrenztem Umfange aus eigenem [Wissen] möglich“ sei. Vgl. auch Gertrude LübBe-Wolf, Rechtsprobleme der behördlichen Umweltberatung, NJW 1987, S. 2705, 2711 (Fn. 35), die Propaganda als eine ,nicht sach-, sondern rein darstellungsorientiert[e] und primär auf andere Mittel als das der rationalen Überzeugung setzend[e]" Bewusstseinsbeeinflussung definiert. Vierhaus (Anm. 1), S. 374 spricht von „inszenierter Information“, wenn die lenkende Wirkung vor allem auf der ,inhaltlichen Gestaltung der Information“ beruht, wozu er insbesondere die ,unvollständige, unrichtige, tendenziöse Information“ rechnet.

49 Sachs (Anm. 5), S. 220. So auch Imke SchneIder, Staatliche Informationstätigkeit als Steuerungsmittel im Umweltrecht, 2012, S. 79.

50 BVerfGE 105, S. 252, 272 ff.; BVerfGE 105, S. 279, 305 ff. Dazu Sсносн (Anm. 27), \ 37 Rn. 143 f.; Bardo Fassbender, \ 76 Wissen als Grundlage staatlichen Handelns, in: Josef Isensee/Paul Kirchhof (Hrsg.), Handbuch des Staatsrechts der Bundesrepublik Deutschland, Bd. 4, 3. Aufl. 2006, Rn. 72; Kirchноғ (Anm. 44), \ 99 Rn. 215 („Das Rechtsstaatsprinzip und das in den Grundrechten angelegte Freiheitsprinzip verpflichten staatliches Informieren, Beraten und Appellieren zu Wahrheit, Objektivität, zu Neutralität und Sachkundigkeit."). 
sibel ist. ${ }^{51}$ Neben dem Grundsatz staatlicher Neutralität ${ }^{52}$ gilt es zudem das Übermaßverbot auch für informelles Staatshandeln zu beachten, d.h. die staatliche Informationstätigkeit muss ,,zur Verfolgung eines (verfassungs)legitimen Ziels geeignet, erforderlich und verhältnismäßig sein" ${ }^{53}$ Auch dies ist ein wichtiger Aspekt, denn gerade weil sich staatliches Informationshandeln so schwer mit dem Recht einfangen lässt und häufig unter dem Deckmantel ,bloßer“ (Sozial-),,Moral“ daherkommt, bedarf es klarer (verfassungsrechtlicher) Grenzen, um staatlicher Edukation entgegenzuwirken. ${ }^{54}$ Denn: ,Jede Information trägt ihre Botschaft in sich“"55 - und damit die Gefahr einer Beeinträchtigung der staatsfreien Meinungsbildung (zu diesem Aspekt siehe unten S. 20 f.).

Sofern edukatorisches Staatshandeln (auch in Form einer Informationssteuerung) einen Grundrechtseingriff begründet, stellt sich die Frage, ob und gegebenenfalls wie ein solcher Eingriff (Beeinflussung der Überzeugungen der Bürger mit dem Ziel einer Veränderung ihrer Einstellungen) gerechtfertigt werden kann. ${ }^{56}$ Hier könnte sich ein Rückgriff auf die breit geführte Paternalismusdebatte anbieten: Ein Teil der Befürworter eines begrenzten Paternalismus hält der Idee vom selbstbestimmt und rational handelnden Menschen entgegen, dass die Verhaltensökonomik und die Psychologie zeigten, dass ,,in vielen Lebensbereichen [...] den Menschen klare und wohlgeordnete Präferenzen [fehlten, weil ihre] Wahlhandlungen [von] dem Fluss der Informationsgenerierung“

51 Zur Problematik auch Sсносн (Anm. 27), \& 37 Rn. 107.

52 Zum Neutralitätsgebot gehört auch das Verbot staatlicher Identifikation; dazu Gramm (Anm. 3), Der Staat 30 (1991), S. 51, 75.

53 Friedrich SCHOCH, Information und Kommunikation im Lebensmittelrecht: Europarechtliche und verfassungsrechtliche Grundlagen staatlichen Informationshandelns und privater Informationspflichten, ZLR 2010, S. 121, 137 m.w.N.

54 In diesem Sinne auch kritisch Murswiek (Anm. 44), DVBl 1997, S. 1021 f.: „Der mit rechtlich unverbindlichen Warnungen und Empfehlungen agierende Staat mag als der freundliche, kooperative, dienstleistende Staat in Erscheinung treten und sich - als Gegenbild des obrigkeitlich-imperativ agierenden Staates - als bürgernah und partnerschaftlich empfehlen. Aber solche Selbstempfehlungen können trügerisch sein. [...] Der ,präzeptorale Staat', der mit den Mitteln seines ,weichen', aber schwer greifbaren ,Informationshandelns' dem Bürger das erwünschte Verhalten auf allen möglichen Gebieten aufzudrängen sucht, kann unter Umständen weit weniger freiheitlich sein, als ein verbindlich regelnd und insofern, obrigkeitlich auftretender Staat, der sich auf die Wahrnehmung notwendiger Aufgaben beschränkt und in die Freiheit der Bürger nur in berechenbarer und kontrollierbarer Weise eingreift."

55 Gramm (Anm. 3), Der Staat 30 (1991), S. 51, 60 zerlegt daher die staatliche Information in fünf Teile: ,a) Sachlicher Informationsgehalt; b) Verhaltenssteuerung; c) Die Wertebene; d) Psychologische Ebene; e) Die eigentlich rechtliche Intention."

56 Bislang gibt es nur wenig Literatur zu den verfassungsrechtlichen Rahmenbedingungen für edukatorisches Staatshandeln; vgl. Lüdemann (Anm. 1), S. 102 ff.; Vierhaus (Anm. 1), S. $359 \mathrm{ff} ., 447 \mathrm{ff}$. 
abhingen. ${ }^{57}$ Die Vertreter dieses Ansatzes folgern somit aus einer begrenzten Rationalität des Individuums (Rationalitätsdefizit im Entscheidungsverhalten) die Legitimität eines begrenzten Paternalismus des Staates, d.h. für die verbindliche Vorgabe der (vermeintlich) rationalen Entscheidung. Der staatliche Paternalismus wird hier damit gerechtfertigt, dass die Intervention nicht als Bevormundung, sondern aufgrund des irrationalen Verhaltens des Einzelnen als Autonomieförderung zu bewerten sei. ${ }^{58}$ Denn die mangelnde Rationalität bei der Entscheidung belege, dass das Individuum nicht in der Lage sei, eine selbstbestimmte (von der Verfassung geschützte) Entscheidung zu treffen. ${ }^{59}$

Dieser Ansatz kann auch bei edukatorischem Staatshandeln eine Rolle spielen, beispielsweise als Bestandteil der seit den 1990er Jahren zunächst in den USA und dann auch in Deutschland verfolgten sozialstaatlichen Konzeption im Umgang mit Erwerbslosen, die den Blickwinkel auf die Unterschichten ,,von der sozialen Einbettung zum individuellen Verhalten, von der ökonomischen Ungleichheit zur persönlichen Inkompetenz" verschiebt. ${ }^{60} \mathrm{Im}$ Mittelpunkt dieses Ansatzes steht eine ,,moralisierende Delegitimierung nichterwerbstätiger Lebensformen“;61 als Mittel zur Behebung der bei den Unterschichten angeblich vorhandenen Defizite dienen u.a. ,fürsorglich gemeint[e]

57 van Aaken (Anm. 18), S. 109, 114 (auf S. 115 ff. führt van Aaken Beispiele von kognitiver Schwäche und von Willensschwäche an).

58 Dazu van Aaken (Anm. 18), S. 109, 140; Enderlein (Anm. 18), S. 52 ff., 68 ff., 241 ff. Vgl. aber auch Heinig (Anm. 22), S. 157, 167 ff.

59 Dazu Stephan Kirste, Harter und weicher Rechtspaternalismus, Unter besonderer Berücksichtigung der Medizinethik, JZ 2011, S. 805, 806. Kirste, S. 813 hält dem zu Recht entgegen, dass eine autonome Entscheidung nur die Fähigkeit zur Selbstbestimmung, nicht hingegen ,voll rationale Begründbarkeit und [...] moralische Werthaftigkeit" voraussetze. Entsprechende Begründungsmuster finden sich auch beim weichen bzw. liberalen Paternalismus, vgl. Jan Schnellenbach, Wohlwollendes Anschubsen: Was ist mit liberalem Paternalismus zu erreichen und was sind seine Nebenwirkungen?, Perspektiven der Wirtschaftspolitik 12 (2011), S. 445, 447 (liberaler Paternalismus unternehme „den Versuch, Entscheidungssituationen bewusst zu gestalten und so Individuen in ihrem Handeln zu lenken“, wobei „aber die Freiheit erhalten bleib[e], bewusst eine abweichende Entscheidung zu treffen"). Kritisch auch Gramm (Anm. 3), Der Staat 30 (1991), S. 51, 72 f. m.w.N.

60 Legnaro (Anm. 19), Krim. Journal 2007, S. 5, 7. Vgl. aber auch schon Kevenhörster/ Windhoff-Héritier (Anm. 19), ZfP 1981, S. 239, 245, 247 (als spezifische Schwachstellen einer Erziehung durch den Staat identifizieren die Verfasser nicht nur die Einschränkung individueller Freiheit, sondern auch die „Stigmatisierung“ der Adressaten staatlicher Erziehungs-/Dienstleistungsprogramme).

61 Stephan Lessenich, Der Arme in der Aktivgesellschaft - zum sozialen Sinn des „Förderns und Forderns“, WSI-Mitteilungen 2003, S. 214, 218. Dies zeigt sich auch in der politischen Debatte um das Betreuungsgeld (von führenden Politikern der Opposition auch als „Herdprämie“ bezeichnet), bei der die Kritik an dieser Leistung im Wesentlichen in einer Delegitimation des Wertes von Familienarbeit besteht. Dazu unten S. 56 f. 
Erziehungsprogramm[e]“ und insgesamt ,eine Politik der Aktivierung“. ${ }^{62}$ Dabei liegt die Annahme nicht fern, dass sich mit dem Übergang vom protektiv-paternalistisch handelnden Staat zum aktivierenden Staat ${ }^{63}$ auch ein Übergang von einer Bevormundung hin zur Erziehung des Bürgers vollzogen hat. ${ }^{64}$

Neben dem offen formulierten Motiv des Ausgleichs von Rationalitätsdefiziten wird das „klassische“ Motiv für paternalistisches Staatshandeln heute weniger stark gemacht, nämlich dass individuelle Präferenzen, die „Werten widersprechen, von deren universeller Geltung der paternalistisch Intervenierende überzeugt ist", eingeschränkt werden, um den objektiven Gehalt dieser Werte zu erhalten. ${ }^{65}$ Dass auch diese Argumentation als Rechtfertigung für edukatorisches Staatshandeln dienen könnte, liegt bei den bislang genannten Beispielen der Einflussnahme im Bereich der Abfallentsorgung (Umweltschutz) oder der Beeinflussung des Ernährungsverhaltens der Bürger (Gesundheitsschutz) nicht fern - die hohe „Wertigkeit“ des angestrebten Ziels bei gleichzeitig geringer Intensität der staatlichen Maßnahme spräche dann für die Zulässigkeit der staatlichen Edukation. ${ }^{66}$

Einer solchen Sichtweise, bei der der Hinweis auf das (vermeintlich) „gute“ oder ,richtige“ Ziel, das mit einem (scheinbar) relativ milden Instrument verwirklicht wird ${ }^{67}$ als Rechtfertigung für die Einschränkung verfassungsrechtlich

62 Legnaro (Anm. 19), Krim. Journal 2007, S. 5, 7, der jedoch unter Berufung auf LawRence M. Mead, The Rise of Paternalism, in: ders. (Hrsg.), The New Paternalism, Supervisory Approaches to Poverty, 1997, S. 1, 6 („,Paternalism is an effort to control the lifestyle of the poor."), die sozialstaatlichen Maßnahmen als Paternalismus und nicht als Edukation einordnet.

63 Dazu etwa Horst Bossong, Suchtpolitik im paternalistischen, aktivierenden oder ermöglichenden Staat: Versuch einer Entwirrung, ORDO 62 (2011), S. 177 ff. (S. 182 ff. mit Kritik an den Mitteln und Zielen der aktivierenden Suchthilfepolitik).

64 Nach Bossong (Anm. 63), ORDO 62 (2011), S. 177, 186 ziele der aktivierende Staat auf ,die Erzeugung und Beförderung der ,richtigen“ Einstellung und des ,richtigen“ Verhaltens“ und damit letztlich auf „die Formung des ,neuen Menschen““ ab.

65 Gleichwohl ist dieses Motiv nach wie vor vorhanden, vgl. Kirste (Anm. 59), JZ 2011, S. 805, 806; Horst Eidenmüller, Liberaler Paternalismus, JZ 2011, S. 814, 815. Kritisch zur Diskussion um die aus der Verfassung abgeleitete objektive Wertordnung auch Hillgruber (Anm. 1), S. 126 ff., 134, 158 ff., 162 ff., 165 ff.

66 Nach Schorkopf (Anm. 15), JZ 2008, S. 20, 25 ff. lässt sich eine vergleichbare Zielsetzung auch bei der sog. Regulierungsverwaltung nachweisen. Mit dem dahinter stehenden Konzept setzt er sich kritisch auseinander und weist zu Recht darauf hin, dass diesem „Regulierungskonzept [...] die Differenz von Staat und Gesellschaft [...], die als gedankliche Trennung die Freiheitssphäre des Bürgers ermöglicht", fern sei (S. 26), und dass sich der ,berechtigte Wohlfahrtszweck des Staates [...] nicht gegen, sondern nur mit dem Rechtsstaat verwirklichen" lasse (S. 28).

67 Dazu Lüdemann (Anm. 1), S. 104 f. 
gewährleisteter Freiheiten genügen soll, ${ }^{68}$ ist jedoch im Rechtsstaat eine klare Absage zu erteilen. ${ }^{69}$ Ungeachtet dessen, dass schon die zugrundeliegende Annahme, die jeweilige Regierung wäre nach fachkundiger Beratung und aufgrund der Abwägung sämtlicher relevanter Informationen kraft überlegenen Wissens in der Lage, jedem Bürger die ,richtigen“ Vorgaben für eine rationale (d.h. meist für eine ökonomisch sinnvolle) Entscheidung machen zu können, höchst fragwürdig ist ${ }^{70}$ entspricht auch die Vorstellung eines ohne staatliche Hilfestel-

68 Diese Sichtweise lässt sich zunehmend beobachten: So wird mit der Zielsetzung eines (präventiven) Kinderschutzes zunehmend im Vorfeld einer Kindeswohlgefährdung in das verfassungsrechtlich geschützte Elternrecht eingegriffen, wobei die Vorverlagerung der Eingriffsschwelle damit gerechtfertigt wird, dass es sich um einen niedrigschwelligen Eingriff handele. Ein Beispiel hierfür ist das richterliche („Erziehungs“-)Gespräch nach $\ 157$ FamFG, mit dem ausweislich der Drucksachen im Vorfeld einer Kindeswohlgefährdung auf die Eltern eingewirkt werden soll; Entwurf eines Gesetzes zur Erleichterung familiengerichtlicher Maßnahmen bei Gefährdung des Kindeswohls vom 24. Oktober 2007, BT-Drucks. 16/6815, S. 17: „Dem Familiengericht steht damit bereits im Vorfeld und unabhängig von Maßnahmen nach den $\$ S$ 1666, 1666a BGB - ein wirksames Instrument zur Verfügung, um auf die Eltern und die Kinder einzuwirken." Vgl. weiter S. 1: „Insbesondere sollen Möglichkeiten geschaffen werden, frühzeitiger und stärker auf die Eltern einzuwirken, um diese anzuhalten, notwendige öffentliche Hilfen zur Wiederherstellung ihrer Elternkompetenz in Anspruch zu nehmen. In diesem Sinne sieht der Entwurf verschiedene Änderungen vor, die eine frühzeitige Anrufung des Familiengerichts und ein frühes, aber ggf. niedrigschwelliges Eingreifen durch das Familiengericht födern sollen." [Hervorhebungen durch Verf.] Dazu Eva Schumann, in: Thomas Rauscher (Hrsg.), Münchener Kommentar zum FamFG, 2. Aufl. 2013, S 157 FamFG Rn. 2, 4 f. m.w.N. Vgl. weiter Matthias Jestaedt, in diesem Band, S. 165 ff.

69 So auch Höfling (Anm. 7), ZLR 2006, S. 121, 131. Vgl. auch Thomas Simon, in diesem Band, S. 73.

70 Abgesehen davon, dass der Staat nicht die Deutungshoheit über das, was für den Einzelnen (unter Heranziehung einer Vielzahl von Kriterien und Präferenzen) rational ist, beanspruchen kann, ist „Rationalität“ auch nicht der einzige (bzw. oberste) Zweck, an dem menschliches Verhalten ausgerichtet werden kann und sollte (zu nennen sind etwa die dem religiösen Bereich zugeschriebenen Motive menschlichen Verhaltens wie das Handeln aus Nächstenliebe, Barmherzigkeit, Mitgefuihl oder die den familiären Solidarleistungen zugrundeliegenden Motive wie Liebe, Zuneigung, Fürsorge, Verantwortung). Fraglich ist zudem, ob der paternalistisch handelnde Staat überhaupt die nötigen Kompetenzen hat, um entscheiden zu können, ,,welches Element einer widersprüchlichen Präferenzordnung unvernünftig und welches vernünftig ist"; so Schnellenbach (Anm. 59), Perspektiven der Wirtschaftspolitik 12 (2011), S. 445, 450. Schnellenbach (S. 451 ff., 455 f.) legt dar, dass das von paternalistischer Seite zugrunde gelegte (vernünftige) Verhaltensmuster häufig nur dem allgemeinen Zeitgeist folge und zu Standardisierungen neige, wobei die normative Basis der ,richtigen“ Vorgaben ausgesprochen schwach sei. Zudem bestehe „auf der gesellschaftlichen Ebene [...] die Gefahr, dass das Lernen aus Versuch und Irrtum behindert und verlangsamt" werde. Schließlich werde die in der psychologischen Literatur gut dokumentierte Tatsache vernachlässigt, „,dass Autonomie und individuelle Handlungskompetenz eine wichtige Quelle von Lebenszufriedenheit sind“". Vgl. weiter Heck (Anm. 15), S. 265. 
lung nicht selbständig handlungsfähigen Bürgers nicht dem Menschenbild des Grundgesetzes. ${ }^{71}$ Dieses setzt vielmehr die Garantie auf den je eigenen Lebensentwurf voraus, ${ }^{72}$ mit der Folge, dass Entscheidungen für das Unvernünftige und das Unnütze vom Staat - solange das friedliche Zusammenleben und die Werteordnung der Verfassung nicht gefährdet sind - genauso zu respektieren sind wie die für das Individuum vernünftigste und für das Gemeinwohl nützlichste Entscheidung. ${ }^{73}$ Das Menschenbild des Grundgesetzes setzt staatliche Neutralität voraus, mit der Folge, dass sich der Staat bei der Bewertung der Konzeptionen des für den Einzelnen oder das Gemeinwohl „Guten“ oder „Richtigen“ weitgehend zurückzuhalten hat; ${ }^{74}$ jede staatliche Präferenzbeeinflussung muss daher rechtsstaatlichen Grundsätzen genügen ${ }^{75}$ und die Freiheit des Einzelnen achten. ${ }^{76}$

71 Vgl. dazu auch Vierhaus (Anm. 1), S. $381 \mathrm{ff}$.

72 Dazu etwa BVerfG NJW 1976, S. 947, 948: „Der, ethische Standard“ des Grundgesetzes ist vielmehr die Offenheit gegenüber dem Pluralismus weltanschaulich-religiöser Anschauungen angesichts eines Menschenbildes, das von der Würde des Menschen und der freien Entfaltung der Persönlichkeit in Selbstbestimmung und Eigenverantwortung bestimmt ist. In dieser Offenheit bewahrt der freiheitliche Staat des Grundgesetzes seine religiöse und weltanschauliche Neutralität." Vgl. auch BVerfG NJW 2003, S. 3111, 3113; Wolfram Höfling, in: Michael Sachs (Hrsg.), Grundgesetz, 6. Aufl. 2011, Art. 1 GG Rn. 36 f.; Ders. (Anm. 7), ZLR 2006, S. 121, 131 f.; Peter Häberle, Das Menschenbild im Verfassungsstaat, 4. Aufl. 2008, S. 63 ff.

73 Anderenfalls wäre, so GutMANn (Anm. 18), ZRG-GA 122 (2005), S. 150, 192, „Schutzgut des Rechts [...] nur noch , der noumenale, vernünftige Wille' der Individuen, und nicht mehr die freiheitsgeschützte individuelle Entscheidungsmacht, die diesseits der Fremdschädigung oder -gefährdung das Recht umfassen muß, ,nicht ganz rational zu sein [...].“ Zudem verlören ,subjektive Freiheitsrechte ihren Sinn und [...] das Recht [wäre] nicht nur erlaubterweise, sondern notwendigerweise ein paternalistisches."

74 Nach Stefan Huster, Die ethische Neutralität des Staates, Eine liberale Interpretation der Verfassung, 2002, S. 12 verlangt die staatliche Neutralität, dass der Staat auf eine Bewertung der Konzeptionen des für den Einzelnen oder das Gemeinwohl „Guten“ oder „Richtigen“ grundsätzlich verzichtet und sich darauf beschränkt, lediglich eine Ordnung für das friedliche und gerechte Zusammenleben der unterschiedlichen Überzeugungen und Lebensformen zu gewährleisten. Vgl. weiter Hillgruber (Anm. 1), S. 119 f.; Vierhaus (Anm. 1), S. 464 ff.

75 So auch ऽсносн (Anm. 27), \ 37 Rn. 114 f.: „Der Verfassungsstaat neuzeitlicher Prägung ist in seinem Kern ein Rechtsstaat. Verfassungsstaatlichkeit bedeutet demnach im wesentlichen Rechtstaatlichkeit. Dies impliziert die Rechtsbindung einer jeden Form der Ausübung von Staatsgewalt. Die Rechtsbindung gilt folglich auch für informales Staatshandeln [...]. Art. 20 Abs. 3 GG verfügt für die vollziehende Gewalt - wozu [...] auch die Regierung gehört - und die Rechtsprechung die Bindung an Gesetz und Recht. Folglich ist informales Staatshandeln nach geltendem Verfassungsrecht kein rechtsfreies Handeln - auch wenn den zur Informalität neigenden Akteuren damit gewisse Schwierigkeiten gemacht werden (müssen).“

76 Dabei ist nicht zu verkennen, dass der Sozialstaat (insbesondere eine staatliche Fürsorge nach dem Prinzip „Fördern und Fordern“) die Gefahr eines Rückfalls in frühneuzeitliche Strukturen der „Guten Policey“ unter Rückgriff auf kameralistische Ordnungs- 
Entscheidend ist somit allein, ob staatliche Erziehung durch Gesetz und/ oder durch Information mit dem Grundgesetz, insbesondere mit der Verfassungsgarantie einer freien Entfaltung der Persönlichkeit (Art. 2 Abs. 1 GG i.V.m. Art. 1 Abs. 1 GG), aber auch mit anderen Garantien, ${ }^{77}$ vereinbar ist. Da staatliche Erziehung im Erfolgsfalle (Erzielung einer Bewusstseinsänderung bei Teilen der Bevölkerung) auch massiv die öffentliche Meinungsbildung beeinflussen kann, wäre zudem zu prüfen, ob eine nicht gerechtfertigte Einwirkung auf den staatsfreien Meinungsbildungsprozess als ein konstituierendes Element

ziele in sich trägt. Vgl. etwa zur kameralistischen Staatslehre nach JoHann HeInRICH Gottlieb von Justi (und der Verbindung von ,individueller Glückserwartung“ und „Wohlsein des Staates“) Hillgruber (Anm. 1), S. 32 f.: „Es versteht sich daher von selbst, daß Verschwendung, Arbeitsscheu und Müßiggang als Pflichtvergessenheit nach v. Justi staatlicherseits nicht geduldet werden können, sondern mit polizeilichem Zwang zu bekämpfen sind. [...] Soll der Staat als ,Vereinigung der Willen und Kräfte' seiner Bürger öffentliche Wohlfahrt befördern, so muß jedes Mitglied des Gemeinwesens nach Maßgabe seiner Fähigkeiten zur Prosperität des Staates beitragen. Die individuelle Arbeitsmoral und die Ethik der Ökonomie erhalten auf diese Weise einen Gemeinschaftsbezug mit der Folge einer Grenzverschiebung zwischen Moral und Recht: ,Bürgerliche“ Tugenden werden zur Rechtspflichten gegenüber der staatlichen Gemeinschaft.“ Zu den gegenläufigen Prinzipien von Rechts- und Sozialstaat, ebd., S. 46 f., 53 ff. (zu Recht weist Hillgruber, S. 48 auch darauf hin, dass der Vorrang des Gemeinwohls zu einer grenzenlosen Einschränkung der Freiheit des Einzelnen führen kann, weil „,im Grunde sämtliche Verhaltensweisen des Menschen von irgendeiner Relevanz für das zu befördernde gemeine Wohl sind“.). Vgl. auch Thomas Simon, „Gute Policey“, Ordnungsleitbilder und Zielvorstellungen politischen Handelns in der Frühen Neuzeit, 2004, S. 426 ff., 455 ff., 488 ff. (mit Hinweis auf S. 546 ff., 553 ff., dass die kameralistischen Ordnungsziele, insbesondere die Wohlstandsmaximierung und die Steigerung der Produktivität, typischerweise durch eine „Vervielfältigung der Steuerungsinstrumente“, einschließlich der Setzung positiver Anreize sowie der Beeinflussung von Motivation und Willen, verwirklicht wurden). Zur aktuellen Entwicklung vgl. Reinhold Zippelius, Verhaltenssteuerung durch Recht und kulturelle Leitideen, 2004, S. 111 f.: „Das Ausufern der Sozial- und Wohlfahrtsstaatlichkeit macht den Staat fortschreitend wieder, wie einst den Polizeistaat des achtzehnten Jahrhunderts, zum Vormund seiner Bürger. Gewiß steckt hinter den vielfältigen Reglementierungen des Sozial-, Wohlfahrt- und Umweltschutzstaates oft die Absicht, die Bürger vernünftig zu ihrem Besten zu leiten. [...] Man beginnt zu begreifen, daß nicht nur der autoritäre Staat, sondern auch der Rechtsstaat totalitäre Züge annehmen kann, wenn er sich anschickt, das Leben einer Gemeinschaft umfassend in seine Regie zu nehmen. Wieviel Freiheit der Einzelne im Staate hat, bemißt sich auch danach, in welchem Maße die sozialen Lebensprozesse überhaupt einer staatlichen Regulierung unterworfen werden oder aber einer Selbstregulierung durch Privatautonomie überlassen bleiben." Vgl. weiter Heinz Holzhauer, Aktuelles Familienrecht vor rechtsgeschichtlichem Hintergrund, JZ 2000, S. 1076, 1077 f.

77 Vgl. etwa zu den Anforderungen an eine marktbezogene Information des Staates, die für betroffene Unternehmen zu einer Existenzgefährdung führt, BVerfGE 105, S. 252 ff. (Glykol); Sсносн (Anm. 27), \$ 37 Rn. 85 ff. Vgl. weiter Kirchноғ (Anm. 44), \$ 99 Rn. 214. 
der Demokratie vorliegt. ${ }^{78}$ Die Gefahr einer Einwirkung liegt auch deshalb nahe, weil der Staat in der Mediengesellschaft ,,kein Diskursteilnehmer wie jeder andere“ ist, sondern ihm seine staatliche Autorität einen ,Vertrauensvorschuß [verleiht], was den sachlichen Wahrheitsgehalt" der Information angeht, ${ }^{79}$ wobei dieser noch gesteigert wird, wenn der Staat die Information als wissenschaftlich fundierte Expertise ausgibt. ${ }^{80}$

Im Folgenden sollen ein weiteres Feld edukatorischen Staatshandelns aus der aktuellen Familienpolitik vorgestellt und die Voraussetzungen und Grenzen staatlicher Edukation am konkreten Beispiel ausgelotet werden.

\section{Etablierung eines neuen Familienleitbildes}

\section{Die Zwei-Erwerbstätigen-Familie als Leitbild}

Nachdem das Familienleitbild der Bundesrepublik jahrzehntelang vom Ernährer-Modell mit traditioneller Rollenverteilung (Hausfrauenehe) geprägt war, ${ }^{81}$

78 Dazu LüDEMAnN (Anm. 1), S. 131 ff. Zum Staatsfreiheitsprinzip öffentlicher Meinungsbildung BVerfGE 20, S. 56, 99 f.: „In einer Demokratie muß sich diese Willensbildung aber vom Volk zu den Staatsorganen, nicht umgekehrt von den Staatsorganen zum Volk hin, vollziehen. Die Staatsorgane werden durch den Prozeß der politischen Willensbildung des Volkes, der in die Wahlen einmündet, erst hervorgebracht (Art. 20 Abs. 2 GG). Das bedeutet, daß es den Staatsorganen grundsätzlich verwehrt ist, sich in bezug auf den Proze $\beta$ der Meinungs- und Willensbildung des Volkes zu betätigen, daß dieser Proze $\beta$ also grundsätzlich ,staatsfrei“ bleiben muß." Vgl. weiter Vierhaus (Anm. 1), S. 236 ff., $291 \mathrm{ff} ., 311 \mathrm{ff} ., 359 \mathrm{ff}$.

79 Gramm (Anm. 3), Der Staat 30 (1991), S. 51, 52. Vgl. auch Ders. (Anm. 29), NJW 1989, S. 2917, 2925; Sсносн (Anm. 27), \37 Rn. 56; Vierhaus (Anm. 1), S. 378 f. (,erhöhter Wirkungsgrad staatlich-autorisierter Information"). Hinzu kommt der Vorteil, zur Finanzierung der Informationskampagnen auf Steuermittel zurückgreifen zu können, sodass die Kampagnen besonders breit angelegt werden können (dazu unten S. 36 f., 39 f.).

80 Dazu insgesamt auch Anke Engelbert/Martin Kutscha, Staatliche Öffentlichkeitsarbeit und Demokratieprinzip, NJW 1993, S. 1233, 1235 ff., insb. S. 1236 f.: „Regierungsamtliche Öffentlichkeitsarbeit wird sich stets der Versuchung erwehren müssen, nicht nur parteipolitisch neutrale sachbezogene Aufklärung der Bevölkerung [...] zu betreiben, sondern ihre Amtsautorität und ihre sächlichen Mittel auch dazu einzusetzen, die politischen Anschauungen der die Regierung tragenden Mehrheitsparteien zu propagieren. Indem Öffentlichkeitsarbeit diese [...] Grenze überschreitet, verstößt sie gegen das demokratische Prinzip des Grundgesetzes, wonach die politische Willensbildung sich grundsätzlich vom Staatsvolk zu den Staatsorganen vollziehen muß.“

81 Die Förderung des Ein-Ernährer-Modells schloss die Übernahme der Familienarbeit durch den Vater zwar nicht aus, in der Praxis übernahmen jedoch ganz überwiegend Frauen diese Rolle (so wurden noch im Jahr 2003 ca. 97 \% der Anträge auf Erziehungsgeld von Müttern gestellt, dazu Kirsten Scheiwe/Christine Fuchsloch, Rechtspo- 
haben die Regierungen in den letzten zehn Jahren einen Politikwechsel hin zur Zwei-Erwerbstätigen-Familie (adult worker model) vollzogen. ${ }^{82}$ Dieser Wandel darf als Reaktion auf folgende Faktoren betrachtet werden: (1) auf die immer dringender werdende Aufgabe, sich den Problemen des demographischen Wandels zu stellen, wobei ein zentraler Bestandteil aller Konzepte die Steigerung der Geburtenrate ist; (2) auf die durch sozialwissenschaftliche Studien nahegelegte Annahme eines positiven Zusammenhangs zwischen einer hohen Müttererwerbsbeteiligung und der Fertilität in anderen europäischen Ländern; (3) auf die Notwendigkeit des Einsatzes aller gut ausgebildeten Arbeitskräfte (insbesondere auch von Müttern) für den Erhalt der Wirtschaftskraft in Deutschland; (4) auf die als Folge des PISA-Schocks entstandene Idee einer stärkeren frühkindlichen Bildung und Sozialisation von Kindern außerhalb der Familie; (5) auf die Zielsetzung der Verwirklichung der ökonomischen Gleichstellung von Mann und Frau durch Sicherstellung der Vollerwerbstätigkeit von Frauen und insbesondere auch von Müttern. ${ }^{83}$

litische Ziele und rechtliche Gestaltungsmöglichkeiten eines Elterngeldes, ZRP 2006, S. 37, 38). Im Vorfeld der Einführung des Erziehungsgeldes im Jahre 1986 wurde vor allem die Notwendigkeit der Betreuung des Kindes durch einen Elternteil als Motiv für die Stützung dieses Modells stark gemacht (BR-Drucks. 350/85, S. 13): „Das Erziehungsgeld fördert die Betreuung und Erziehung eines Kindes in der ersten Lebensphase. Seit Jahren ist anerkannt, wie sehr die ganze spätere Entwicklung eines Kindes von der ersten Lebensphase abhängt und wie wichtig es ist, daß die Mutter oder der Vater in dieser Zeit für das Kind da sein können. Erziehungsgeld ermöglicht oder erleichtert es, daß [...] die Mutter oder der Vater ganz oder teilweise [...] auf eine Erwerbstätigkeit verzichten können. Dadurch kann die Mutter weiterhin vorrangig zu Hause bleiben, um sich neben der Betreuung des Kindes gesundheitlich zu regenerieren.“

82 Kritisch dazu Thorsten Kingreen, Rezension zu Frauke Brosius-Gersdorf, Demografischer Wandel und Familienförderung (2011), JZ 2012, S. 39 f.: „Das neue Leitbild ist die Doppelverdienerfamilie; die nicht berufstätige Mutter verblasst zum ,Heimchen am Herd ' - eine wohl unvermeidliche Gegenbewegung zu den konservativen Leitbildern der Vergangenheit und gleichwohl hoffentlich nur eine Zwischenstation zu einer Familienpolitik, die sich als Sozialpolitik begreift und auf überschießende Zwecksetzungen verzichtet."

83 Dazu umfassend Eva Schumann, Die Ökonomisierung der Familie, Jahrbuch der Akademie der Wissenschaften zu Göttingen 2011, 2012, S. 444, 447 f. m.w.N. Im Folgenden wird auf den pronatalistischen Aspekt dieser Politik (Ziff. 1 im Text: Steigerung der Geburten) nicht näher eingegangen (dazu Schumann, S. 454 f.), es soll aber darauf hingewiesen werden, dass die familienpolitischen Maßnahmen der letzten zehn Jahre nicht zu einer Steigerung der Geburtenrate geführt haben (die Fertilitätsrate bleibt in Deutschland seit Jahren konstant unter 1,4 Geburten pro Frau). Der Vergleich zwischen Ost- und Westdeutschland deutet zudem darauf hin, dass die Vereinbarkeit von Familie und Beruf höchst unterschiedlich gelöst wird, was erklären könnte, warum die einseitige Förderung bestimmter Familientypen nicht zu einer Steigerung der Geburtenrate führt: In ostdeutschen Familien herrscht nämlich die Zwei-Erwerbstätigen-Familie mit ein bis zwei Kindern vor, während in Westdeutschland berufsorientierte Frauen häufiger keine 
Der mit dem Siebten Familienbericht der Bundesregierung von $2006^{84}$ verbundene Politikwechsel sowie die Ziele und Handlungslogiken der neuen Familienpolitik können hier nicht im Einzelnen dargestellt werden, vielmehr muss der Hinweis genügen, dass die genannten bevölkerungs-, arbeitsmarkt-, bildungs- und gleichstellungspolitisch motivierten Interessen des Staates an der Familie mit dem neuen Leitbild der Zwei-Erwerbstätigen-Familie passgenau umgesetzt werden können. ${ }^{85}$ Hier soll es vielmehr darum gehen, mit welchen Maßnahmen und Strategien der Staat die Bürger zur Verinnerlichung dieses Leitbildes bewegt.

Die Herausforderung für den Staat bei der Durchsetzung des neuen Familienleitbildes bestand zunächst darin, dass die Mehrzahl der Eltern in Deutschland auch noch zu Beginn des 21. Jahrhunderts die traditionelle Rollenverteilung der Zwei-Erwerbstätigen-Familie in den ersten Jahren nach der Geburt eines Kindes vorzog. Für das Jahr 2005 stellte das Statistische Bundesamt fest, dass in Familien mit Kindern unter 3 Jahren ,die ,traditionelle' Rollenverteilung, in der ausschließlich der Vater erwerbstätig ist, [...] die von den Eltern am häufigsten gewählte Form der Balance von Familie und Beruf" sei. ${ }^{86}$ Statt sich mit den hinter diesem gesellschaftlich noch immer bevorzugten Modell stehenden Gründen auseinanderzusetzen, hat die Bundesregierung (beraten von Experten aus den Bereichen der Wirtschafts-, Arbeitsmarkt-, Berufs- und Geschlechterforschung) ${ }^{87}$ eine arbeitsmarktorientierte Neujustierung der Fami-

Kinder haben und die von Eltern überwiegend praktizierte traditionelle Rollenverteilung zu mehr Familien mit zwei und mehr Kindern führt. Dazu Norbert F. Schneider/ Jürgen Dorbritz, Wo bleiben die Kinder? Der niedrigen Geburtenrate auf der Spur, Aus Politik und Zeitgeschichte 10-11/2011, S. 26, 30 ff., die zu dem Ergebnis kommen, dass das Geburtenniveau nur durch eine bessere Gewährleistung der Wahlfreiheit der Lebensführung angehoben werden könne (S. 34). Kritik an der pronatalistischen Familienpolitik übt auch Diana Auth, Pronatalistischer Aktionismus: von der bevölkerungspolitischen Instrumentalisierung und Ökonomisierung der Familienpolitik in Deutschland, in: dies./Barbara Holland-Cunz (Hrsg.), Grenzen der Bevölkerungspolitik, Strategien und Diskurse demographischer Steuerung, 2007, S. 81, $92 \mathrm{ff}$.

84 Siebter Familienbericht „Familie zwischen Flexibilität und Verlässlichkeit - Perspektiven für eine lebenslaufbezogene Familienpolitik" und Stellungnahme der Bundesregierung vom 26. April 2006, BT-Drucks. 16/1360.

85 Dazu umfassend Schumann (Anm. 83), S. 444, 446 ff. Zum Politikwechsel vgl. auch Ilona Ostner, „Auf den Anfang kommt es an“ - Anmerkungen zur „Europäisierung“ des Aufwachsens kleiner Kinder, RdJB 2009, S. 44, 57 ff.

86 Statistisches Bundesamt (Hrsg.), Leben und Arbeiten in Deutschland, Sonderheft 2: Vereinbarkeit von Familie und Beruf, Ergebnisse des Mikrozensus 2005, 2006, S. 17. Vgl. auch Scheiwe/Fuchsloch (Anm. 81), ZRP 2006, S. 37, 38.

87 Dazu unten Anm. 96. 
lienpolitik vorgenommen. ${ }^{88}$ Im Koalitionsvertrag vom 18. November 2005 wird dieser Paradigmenwechsel auf die Formel gebracht: „Kinder dürfen nicht länger ein Hindernis für Beruf und Karriere sein. "689

\section{Maßnahmen und Strategien zur Durchsetzung des neuen Familienleitbildes}

Es wurde schon darauf hingewiesen, dass bei edukatorischem Staatshandeln typischerweise die (erziehende) Gesetzgebung durch Informationsinterventionismus begleitet wird. HöFLING spricht bezogen auf das Regulierungssystem im Lebensmittelrecht von „wechselbezüglichen Verstärkungstendenzen“ und weist auf die Gefahr hin, dass die ,vielschichtige[n] Kombinationen zwischen Zwekken und Instrumenten die rechtsstaatliche Kontrolle“ erschwerten. ${ }^{90}$ Der von HöFLING für die staatliche Beeinflussung des Ernährungsverhaltens entwickelte Ansatz lässt sich auch für die vorliegende Fragestellung fruchtbar machen; die staatlichen Maßnahmen zur Beeinflussung von Eltern mit Kleinkindern bei der Entscheidung über die Aufteilung von Familien- und Erwerbstätigkeit stellen sich dann folgendermaßen dar:

88 In ihrer Stellungnahme zum Siebten Familienbericht 2006 hat sich die Bundesregierung der Empfehlung, „dass ein Familienmodell, das die ökonomische Verantwortung für die Familie allein beim Mann als Haupternährer sieht und die Erziehungsleistungen der Familie im Wesentlichen auf die Frau konzentriert, einer nachhaltigen Familienpolitik nicht entspricht", angeschlossen (Siebter Familienbericht, BT-Drucks. 16/1360, S. 246).

89 Koalitionsvertrag zwischen CDU, CSU und SPD „Gemeinsam für Deutschland. Mit Mut und Menschlichkeit" vom 18. November 2005, S. 112 (http://www.cducsu.de/ upload/koavertrag0509.pdf). Diese Aussage ist auch deshalb bemerkenswert, weil der besondere staatliche Schutz der Familie in Art. 6 Abs. 1 GG die umgekehrte Zielvorgabe nahelegen müsste, nämlich dass die Rahmenbedingungen für erwerbstätige Eltern so ausgestaltet werden müssten, dass sie kein Hindernis für die Gründung einer Familie und für die - innerhalb eines Erwerbslebens zeitlich begrenzte - Wahrnehmung der damit verbundenen Aufgaben darstellen. Kritisch daher auch Dieter Schwab, Familie und Staat, FamRZ 2007, S. 1, 6.

90 Höfling (Anm. 7), ZLR 2006, S. 121, 123. 
Edukatorisches Staatshandeln zur Etablierung der Zwei-Erwerbstätigen-Familie

\begin{tabular}{|c|c|c|}
\hline \multicolumn{2}{|c|}{ Rechtliche Formen staatlichen Handelns } & \multirow{2}{*}{$\begin{array}{c}\text { Informelles Staatshandeln } \\
\text { Informationssteuerung durch } \\
\text { Berichte, Aufklärung, Appelle }\end{array}$} \\
\hline $\begin{array}{c}\text { Steuerung durch } \\
\text { verbindliches Recht }\end{array}$ & $\begin{array}{c}\text { Steuerung durch } \\
\text { Setzung finanzieller Anreize }\end{array}$ & \\
\hline & $\begin{array}{l}\text { seit 2005: subventionierter } \\
\text { Ausbau der Kleinkindbe- } \\
\text { treuung (seit 2008: Verdrei- } \\
\text { fachung der Plätze als Ergebnis } \\
\text { des „Krippengipfels“) }\end{array}$ & $\begin{array}{l}\text { seit 2003: Informations-/Werbe- } \\
\text { kampagnen der Bundesregierung/ } \\
\text { des BMFSFJ } \\
\text { - Werbemaßnahmen im Vorfeld und } \\
\text { begleitend zur Gesetzgebung } \\
\text { - gezielte Desinformation }\end{array}$ \\
\hline & $\begin{array}{l}\text { seit 2006: Berücksichtigung } \\
\text { der Betreuungskosten als Son- } \\
\text { derausgaben nach } \$ 10 \text { Abs. } 1 \\
\text { Nr. } 5 \text { EStG }\end{array}$ & $\begin{array}{l}\text { seit 2005/2006: Leitbilder des } \\
\text { Siebten Familienberichts (und des } \\
\text { 12. Kinder- und Jugendberichts) } \\
\text { - frühkindliche Bildung in der } \\
\text { Krippe } \\
\text { - finanzielle Absicherung von Müt- } \\
\text { tern durch kurze Erwerbsunter- } \\
\text { brechung }\end{array}$ \\
\hline $\begin{array}{l}\text { seit 2008: Begrenzung des } \\
\text { Betreuungsunterhalts bis } \\
\text { zum 3. Lebensjahr des } \\
\text { Kindes nach } \$ 1570 \\
\text { Abs. } 1 \text { BGB als gesetzli- } \\
\text { cher Regelfall }\end{array}$ & $\begin{array}{l}\text { seit 2007: Elterngeld als Ein- } \\
\text { kommensersatzleistung für } \\
\text { erwerbstätige Eltern nach } ₫ 1 \\
\text { Abs. } 1 \text { Nr. } 4 \text { BEEG und zu- } \\
\text { sätzliche Vätermonate nach } \\
\$ 4 \text { Abs. } 3 \text { BEEG }\end{array}$ & \\
\hline $\begin{array}{l}\text { seit August 2013: Er- } \\
\text { werbsobliegenheit eines } \\
\text { erwerbsfähigen Hilfebe- } \\
\text { dürttigen trotz Erziehung } \\
\text { eines Kindes unter drei } \\
\text { Jahren (\$ } 10 \text { Abs. } 1 \text { Nr. } 3 \\
\text { SGB II i.V.m. \$ } 24 \text { Abs. } 3 \\
\text { S. } 1 \text { Nr. 2c und Abs. } 2 \\
\text { S. } 1 \text { SGB VIII) }\end{array}$ & $\begin{array}{l}\text { seit August 2013: Anspruch } \\
\text { auffrühkindliche Förderung } \\
\text { nach \24 Abs. 2 S. } 1 \\
\text { SGB VIII }\end{array}$ & \\
\hline
\end{tabular}

Soweit sich der Staat bei den genannten Maßnahmen als leistender und nicht als lenkender Staat präsentiert, liegen zwar Eingriffe in Art. 2 Abs. 1 i.V.m. Art. 1 Abs. 1 GG nicht nahe, jedoch könnte die durch Art. 6 Abs. 1 und 2 GG i.V.m. dem allgemeinen Gleichheitssatz gewährleistete Wahlfreiheit der Eltern bezüglich der Ausgestaltung des Familienlebens (freie Entscheidung über die Aufteilung von Familien- und Erwerbsarbeit) verletzt sein. Das BVerfG hat schon sehr früh die Grenzen edukatorisch motivierter Gesetzgebung im Wirkungsbereich des Art. 6 
Abs. 1 GG klar abgesteckt und den durch eine gesetzgeberische Maßnahme erzeugten Edukationseffekt (erhöhte steuerrechtliche Belastung, um die Ehefrau und Mutter im Haus zu halten) für verfassungswidrig erklärt. ${ }^{91}$ Heute müssen wir fragen, ob der Staat, wenn er durch eine ganze Reihe von Gesetzen den umgekehrten Effekt einer (Voll-)Erwerbstätigkeit beider Eltern zu erzielen sucht, ebenfalls in verfassungswidriger Weise in die Gestaltungsfreiheit der Familie eingreift.

Da es in dem hier zu untersuchenden Feld zudem nicht nur um einen Edukationseffekt geht, sondern eine Effektverstärkung durch das Zusammenwirken zahlreicher staatlicher Maßnahmen erzeugt wird, liegt es nahe, bei der verfassungsrechtlichen Bewertung in Anlehnung an die Figur des additiven Grundrechtseingriffs ${ }^{92}$ die Maßnahmen nicht nur einzeln zu betrachten, sondern

91 BVerfGE 6, S. 55, 80 ff. zur Zusammenveranlagung der Ehegatten nach dem EStG 1951: „Dem Ziel, ,die Ehefrau ins Haus zurückzuführen“, dem sogenannten Edukationseffekt, soll die Zusammenveranlagung dadurch dienen, daß die damit verknüpfte erhöhte steuerliche Belastung die Ehefrau von der Berufstätigkeit zurückhält [...]. An sich bestehen keine verfassungsrechtlichen Bedenken, mit einer Steuer außer der Erzielung von Einkünften auch andere Zwecke mit zu verfolgen. [...] Im Fall der Zusammenveranlagung von Ehegatten [...] betrifft der Erziehungszweck selbst ein Gebiet, das bereits durch verfassungsgesetzliche Entscheidung umgrenzt ist, auf dem also der einfache Gesetzgeber nicht mehr völlig frei Wertentscheidungen treffen kann: Das ergibt sich sowohl aus Art. 6 Abs. 1 GG selbst wie auch aus Art. 3 Abs. 2 und 3 GG. Wie bereits oben dargelegt, ist Art. 6 Abs. 1 GG im Sinne der klassischen Grundrechte ein Bekenntnis zur Freiheit der spezifischen Privatsphäre für Ehe und Familie; es entspricht damit einer Leitidee unserer Verfassung, nämlich der grundsätzlichen Begrenztheit aller öffentlichen Gewalt in ihrer Einwirkungsmöglichkeit auf das freie Individuum. Aus diesem Gedanken folgt allgemein die Anerkennung einer Sphäre privater Lebensgestaltung, die staatlicher Einwirkung entzogen ist [...]. Das zur Rechtfertigung der Zusammenveranlagung angeführte Ziel, die erwerbstätige Ehefrau ,ins Haus zurückzuführen', entspricht einer bestimmten Vorstellung von der besten Art der Ehegestaltung. Das Gebot des Schutzes von Ehe und Familie in Art. 6 Abs. 1 GG aber bezieht sich auf jede Ehe und Familie [...]. Der Gesetzgeber dürfte daher eine bestimmte Gestaltung der privaten Sphäre der Ehe nicht unmittelbar erzwingen. Ist aber ein solcher unmittelbarer Zwang verfassungswidrig, so kann dasselbe Ziel auch nicht geeignet sein, eine Maßnahme zu legitimieren, die, wie die $\mathrm{Zu}$ sammenveranlagung, mittelbar diesem Ziel dienen soll." Dazu auch Huster (Anm. 74), S. 530 f.; Anne Röthel, Institution und Intimität: Die Ehe, ihre Leitbilder und ihr Recht, in: dies./Martin Löhnig/Tobias Helms (Hrsg.), Ehe, Familie, Abstammung Blicke in die Zukunft, Schriften zum deutschen und ausländischen Familien- und Erbrecht, Bd. 1, 2010, S. 9, 18.

92 Dazu Jörg LüCKe, Der additive Grundrechtseingriff sowie das Verbot der übermäßigen Gesamtbelastung des Bürgers, DVBl 2001, S. 1469 ff. Das BVerfG verwendet die Figur des ,additiven Grundrechtseingriffs" bislang sehr zurückhaltend; BVerfGE 112, S. 304, 319 f.; BVerfGE 114, S. 196, 247. Vgl. weiter Jan Hendrik Klement, Die Kumulation von Grundrechtseingriffen im Umweltrecht, AöR 134 (2009), S. 35, 41 f., der anstelle des additiven Grundrechtseingriffs von einer „Kumulation von Grundrechtseingriffen“ bzw. von einer „Belastungskumulation“ sprechen möchte. Nach KLEment, S. 54 f. ist die ,gewollte Belastungskumulation [...] das Kind einer weit greifenden Veränderung 
eine Gesamtbetrachtung vorzunehmen (dazu unten Ziff. 3). Denn die Edukationseffekte, die von mehreren Einzelmaßnahmen ausgehen, können erhebliche Wirkung haben, insbesondere im Falle der Prägung von edukativen Leitbildern, die auf die innere Überzeugung der Bürger einwirken, was wiederum eine hohe Normkonformität verspricht. Aus verfassungsrechtlich noch zulässigen erzieherischen Tendenzen einzelner Gesetze auf einem bestimmten Gebiet kann so in der Summe eine verfassungsrechtlich unzulässige Erziehung des Bürgers durch den Staat werden. Doch zunächst gilt es, die Edukationseffekte der einzelnen Maßnahmen und als deren Grundlage den Siebten Familienbericht darzustellen.

\section{a) Das Beispiel des Siebten Familienberichts}

Die Familienberichte, die aus einem Bericht einer vom Bundesministerium für Familie, Senioren, Frauen und Jugend beauftragten Sachverständigenkommission zur aktuellen Lage der Familien in Deutschland sowie einer Stellungnahme der Bundesregierung zu diesem Bericht bestehen, werden aufgrund einer Entschließung des Deutschen Bundestags aus dem Jahre $1965^{93}$ in regelmäßigen Abständen vorgelegt. Der Siebte Familienbericht „Familie zwischen Flexibilität und Verlässlichkeit - Perspektiven für eine lebenslaufbezogene Familienpolitik" von 2006 war der letzte von insgesamt vier der inzwischen acht vorgelegten Familienberichte, der sich umfassend mit der Situation der Familien in Deutschland auseinandersetzen sollte. ${ }^{94}$ In dem rund 350 Seiten umfassenden Siebten Familienbericht wurden fast 80 weitere Gutachten verarbeitet; zudem entstehen typischerweise im Umfeld der Familienberichte weitere, auf den jeweiligen Familienbericht bezogene Expertisen, die vom Familienministerium in Auftrag gegeben und anschließend verbreitet werden. Die insoweit generierte wissenschaftliche Expertise wird dann zur Grundlage der Familienpolitik gemacht, wobei sich die Argumentationsmuster aus dem Familienbericht und den

im Verhältnis von Staat und Gesellschaft. Der Wohlfahrts- und Umweltstaat beschränkt sich nicht darauf, in Einzelfällen und in präzise vorherbestimmtem Maß grundrechtliche Freiheit zu beschneiden. Will er den selbst definierten Erwartungen gerecht werden, muss er das Verhalten der Privaten mit komplexen Arrangements aus materiellen und verfahrensbezogenen Regeln beeinflussen."

93 Die Entschließung des Bundestags von 1965 (BT-Drucks. IV/3474, S. 1 f.) wurde seitdem mehrfach ergänzt und präzisiert (BT-Drucks. VI/834, S. 1 f.; BT-Drucks. 9/1286, S. 1 ff.; BT-Drucks. 12/5811, S. 1 ff.).

94 Umfassend in diesem Sinne waren auch der Erste, Dritte und Fünfte Familienbericht, während der Zweite, Vierte, Sechste und der seit 2012 vorliegende Achte Familienbericht sich mit spezifischen Fragen zur Familie beschäftigt haben. 
sonstigen Gutachten in den Gesetzesmaterialien, aber auch in den staatlichen Informationskampagnen wiederfinden. ${ }^{95}$

Der Gesetzgeber erweckt auf diese Weise erstens den Eindruck, dass er nicht (allein) aufgrund parteipolitischer Entscheidungsprozesse, sondern gestützt auf die eingeholte Expertise wissenschaftlich basiert und damit „sachlich“ geleitet agiert. Zweitens macht sich die Bundesregierung diese Expertise durch die Stellungnahme zum Familienbericht zu Eigen und stellt sie mittels breit angelegter Werbekampagnen als sachliche, objektive, richtige und vollständige Information den Bürgern zur Verfügung, sodass auch außerhalb einzelner Gesetze, die sich auf den Familienbericht stützen, dessen Inhalt Bestandteil staatlicher Informationstätigkeit ist.

Die Annahme, dass der Siebte Familienbericht unabhängige Expertisen abbildet, ist jedoch insoweit verfehlt, als die von der Politik gewünschten Ergebnisse durch den konkreten Auftrag an die Kommission und die Auswahl der Experten vorgezeichnet waren; ${ }^{96}$ der Siebte Familienbericht sollte den geplanten Politikwechsel lediglich legitimieren. ${ }^{97}$

Wie die Bundesregierung die „Expertisen“ des Familienberichts und der darauf bezogenen Gutachten für die Stützung gesetzgeberischer Maßnahmen und darüber hinaus für die Verbreitung unvollständiger und damit einseitiger Informationen nutzt, wird im Folgenden zu zeigen sein.

95 Dazu umfassend Schumann (Anm. 83), S. 444, 446 f., 448 ff. (mit zahlreichen Beispielen).

96 Die am Siebten Familienbericht beteiligten Sachverständigen kamen überwiegend aus den Bereichen der Wirtschafts-, Arbeitsmarkt-, Berufs- und Geschlechterforschung. Dazu Bundesministerium für Familie, Senioren, Frauen und Jugend (Hrsg.), Zukunft: Familie, Ergebnisse aus dem 7. Familienbericht, 2005, S. 16 ff. (Besetzung der Sachverständigenkommission und Auflistung der eingeholten Expertisen). Zudem wurde der Sachverständigenkommission - entgegen dem Ziel des Berichts, umfassend zur Lage der Familien in Deutschland Stellung zu nehmen - der Auftrag erteilt, Empfehlungen ,zur demografischen Entwicklung, zu den Veränderungen von Arbeitswelt und Wirtschaft, den Geschlechterrollen und auch zum Zusammenhalt der Gesellschaft" vorzulegen (Siebter Familienbericht, BT-Drucks. 16/1360, S. XXIII). Kritisch dazu ScHUMANN (Anm. 83), S. 444, 446 f. Vgl. auch Achter Familienbericht „Zeit für Familie, Familienzeitpolitik als Chance einer nachhaltigen Familienpolitik" und Stellungnahme der Bundesregierung vom 15. März 2012, BT-Drucks. 17/9000, S. 1 (auch hier war unter den acht Sachverständigen, die überwiegend den Bereichen der Arbeitsmarkt- und Bildungspolitik, Personalentwicklung und Berufsforschung zuzuordnen sind, nur eine Sachverständige aus dem Bereich der Frühpädagogik).

97 So auch Ilona Ostner, Sozialwissenschaftliche Expertise und Politik, Das Beispiel des Siebten Familienberichts, ZfS 2007, S. 385 ff. 
b) Einkommensabhängiges Elterngeld und „Vätermonate“

Mit der Ablösung des Erziehungsgeldes durch das Elterngeld zum 1.1.2007 98 verkürzte sich die bezahlte Elternzeit von 24 Monaten nach der Geburt des Kindes auf zwölf Monate. Mit dieser Verkürzung der Bezugsdauer bei gleichzeitiger Anhebung der Höhe der Leistung für erwerbstätige Eltern (67 \% des im Jahr vor der Geburt des Kindes erzielten Einkommens, mindestens 300 Euro und maximal 1.800 Euro, $\$ 2$ Abs. 1 S. 1, Abs. 4 S. 1 BEEG $)^{99}$ sollten zwei Effekte erreicht werden: So sollten einerseits die finanziellen Risiken für Eltern, die ihre Erwerbstätigkeit nach der Geburt des Kindes unterbrechen, gemindert und damit die Entscheidung für ein Kind erleichtert werden. Andererseits sollte die Kürzung der Unterstützung auf ein Jahr eine frühere Rückkehr vor allem von Müttern in den Beruf bewirken. ${ }^{100} \mathrm{Im}$ Gegensatz zum Erziehungsgeld soll mit dem Elterngeld somit nicht primär die Betreuung des Kindes als Leistung für die Gesellschaft honoriert bzw. ein Ausgleich für Erziehungsarbeit geleistet

98 Gesetz zur Einführung des Elterngeldes vom 5. Dezember 2006, BGBl. I, S. 2748.

99 Das Elterngeld stellt eine Kombination von Einkommensersatzleistung für erwerbstätige Eltern und Sozialleistung für nicht erwerbstätige Eltern dar, die aber in beiden Fällen aus Steuern finanziert wird. Die Gesetzgebungskompetenz des Bundes aus Art. 74 Abs. 1 Nr. 7 GG (konkurrierende Gesetzgebungskompetenz des Bundes auf dem Gebiet der „öffentlichen Fürsorge“) erscheint daher fraglich. Zwar wird der Begriff der „öffentlichen Fürsorge" weit verstanden (BVerfGE 97, S. 332, 341; BVerfGE 106, S. 62, 94 ff., insb. S. 100; BVerfGE 108, S. 186, 213 f.), jedoch lässt sich die Auszahlung einer am früheren Erwerbseinkommen orientierten „Lohnersatzleistung“ kaum noch dem Bereich der Fürsorge zuordnen. Vgl. dazu Schumann (Anm. 83), S. 444, 475 ff. m.w.N. Zweifel an der Gesetzgebungskompetenz äußern auch Christian Seiler, Das Elterngeld im Lichte des Grundgesetzes, NVwZ 2007, S. 129, 130 f.; Dagmar Felix, Das neue Elterngeld - ein probates Mittel im Kampf gegen den demografischen Wandel?, RdJB 2008, S. 165, $172 \mathrm{f}$.

100 Entwurf eines Gesetzes zur Einführung des Elterngeldes vom 20. Juni 2006, BT-Drucks. 16/1889, S. 2 und weiter S. 18: Das Elterngeld diene der „Verbesserung der finanziellen Situation von Familien“ und solle ,als Teil des insgesamt 25 Mrd. Euro umfassenden Programms der Bundesregierung zur Stärkung von Innovation, Investition, Wachstum und Beschäftigung Wachstumsimpulse" geben. Zum frühzeitigen Einstieg von Müttern in den Beruf heißt es: „Eine steigende Erwerbsbeteiligung von Frauen hilft, ein ansonsten aufgrund der demographischen Veränderungen sinkendes Angebot insbesondere von Fachkräften auf dem Arbeitsmarkt auszugleichen." Dazu ausführlich und kritisch SCHUMANN (Anm. 83), S. 444, 449 ff., 456 ff. m.w.N. Kritik äußert auch SeIler (Anm. 99), NVwZ 2007, S. 129, 132: „Art. 6 I GG verbürgt ein subjektives Abwehrrecht, welches das Familieninternum gegen staatliche Einflussnahmen abschirmt. Insbesondere ist der Staat zur Neutralität gegenüber der innerfamiliären Aufteilung von Familien- und Erwerbsarbeit verpflichtet, auf die er weder unmittelbar noch mittelbar Einfluss nehmen dürfte. Folglich darf ein Elterngeld lediglich als unterstützendes Angebot ausgestaltet werden, die Freiheitsberechtigten aber nicht zu einer bestimmten Freiheitswahrung drängen. Vor diesem Hintergrund ist der verhaltensbezogene Ansatz des Elterngeldes zu untersuchen $[\ldots] . “$ 
werden, vielmehr geht es primär um die Förderung von Eltern, die ein bestimmtes Familienmodell, nämlich das der Doppelverdienerfamilie, praktizieren. Hingegen werden Familien, die das traditionelle Modell bevorzugen oder auf einen ausschließlich in der Familie tätigen Elternteil nicht verzichten können (etwa kinderreiche Familien oder Familien, in denen zusätzlich die Pflege von Angehörigen geleistet wird), benachteiligt. ${ }^{101}$

Auch wenn die gesetzliche Elternzeit von drei Jahren nach der Geburt eines Kindes ( $\int 15$ Abs. 2 S. 1 BEEG) nach wie vor besteht, ${ }^{102}$ bedeutet die Einführung des Elterngeldes im Verhältnis zum Erziehungsgeld vor allem eine Halbierung der Anspruchsdauer auf ein Jahr und setzt damit einen Anreiz, die Elternzeit nicht voll auszuschöpfen, sondern bereits nach Auslaufen des Elterngeldes die Erwerbstätigkeit wieder aufzunehmen. ${ }^{103}$ Dieser Edukationseffekt der gesetzlichen Regelung wird dabei durch eine staatliche Werbekampagne zum Elterngeld geschickt verstärkt (siehe unten S. 39 f.). So verheißt beispielsweise das Bundesfamilienministerium den Müttern, dass der schnelle Wiedereinstieg in die Erwerbstätigkeit zu einer Belohnung von durchschnittlich 40.000 Euro führe, ${ }^{104}$ während ein Wiedereinstieg nach erst drei Jahren nicht nur zu wirt-

101 Solche Familien erhalten ein pauschaliertes Elterngeld, dessen Bezugsdauer sich im Verhältnis zum Erziehungsgeld halbiert hat. Kritisch daher SeILER (Anm. 99), NVwZ 2007, S. 129, 131; Felix (Anm. 99), RdJB 2008, S. 165, 168 ff., insb. S. 170 f.

102 Es dürfte kaum überraschen, dass im Achten Familienbericht, BT-Drucks. 17/9000, S. 126 angeregt wird, die Elternzeit zu verkürzen, wobei auch hier allein auf die Interessen der Wirtschaft abgestellt wird: „Insgesamt fragwürdig ist die gesetzliche Dauer der Elternzeit von 3 Jahren. Sie bedeutet nicht selten eine große organisatorische und finanzielle Belastung für die Unternehmen. [...] Zu erwägen ist daher eine Verkürzung der Elternzeit auf zwei Jahre."

103 So die Begründung zum Elterngeldgesetz, BT-Drucks. 16/1889, S. 23: „Damit wird erreicht, dass jede anspruchsberechtigte Person nur für einen auf zwölf Monate begrenzten Zeitraum das Elterngeld erhält. Insoweit ergibt sich eine Anreizwirkung, sich bis zu diesem Zeitpunkt um die Aufnahme einer Erwerbstätigkeit für eine eigenständige Sicherung der Lebensgrundlage zu bemühen."

104 Vgl. nur Bundesministerium für Familie, Senioren, Frauen und Jugend (Hrsg.), Familienreport 2010, Leistungen, Wirkungen, Trends, 2010, S. 99 zu den Einkommenseinbußen durch Erwerbsunterbrechungen von Müttern: „Zu den direkten Lohnverlusten während des Erwerbsausstiegs und der Teilzeitphase [...] treten weitere Lohnverluste nach der Rückkehr auf Vollzeitarbeit aufgrund von fehlender Arbeitserfahrung und mangelnder Humankapitalentwicklung hinzu. Insgesamt hat eine Frau mittleren Bildungsniveaus mit nur einjähriger Erwerbsunterbrechung und anschließender Teilzeitphase bis zum sechsten Lebensjahr des Kindes etwa 40.000 Euro weniger Einkommenseinbußen als eine Frau mit dreijähriger Erwerbsunterbrechung und anschließender Teilzeitphase. Hier zeigen sich die positiven Effekte des Elterngeldes, das einen frühen beruflichen Wiedereinstieg belohnt.“ Vgl. auch S. 96: „Das Elterngeld basiert auf dem Erwerbseinkommen vor der Geburt des Kindes und ,belohnt diejenigen, die ein eigenes Erwerbseinkommen erzielen." [Hervorhebungen durch Verf.] 
schaftlichen Nachteilen führe, sondern darüber hinaus auch eine „Entwertung von Humankapital“" bedeute. ${ }^{105}$

Auch mit der Einführung der sog. Vätermonate verbindet der Gesetzgeber einen Edukationseffekt: Denn nur das nach seiner Ansicht ,richtige“ Familienleben (Beteiligung des Vaters an der Betreuung des Kindes durch Unterbrechung/ Herabsetzung der Erwerbstätigkeit für einen Zeitraum von zwei Monaten) wird zusätzlich prämiert ( $\int 4$ Abs. 2, 3 BEEG). ${ }^{106}$ Nach Auffassung des Landessozialgerichts Niedersachsen-Bremen ist die Regelung zu den Partnermonaten verfassungswidrig, ${ }^{107}$ weil der Staat ,die ihm durch Art. 6 Abs. 1 und 2 GG auferlegte Verpflichtung [missachte], die Familiengemeinschaft sowohl im immateriell-persönlichen als auch im materiell-wirtschaftlichen Bereich in ihrer jeweiligen eigenständigen und selbstverantwortlichen Ausgestaltung zu respektieren, wenn er (bezogen auf den Regelfall) einen Anspruch auf Elterngeld für den 13. und 14. Bezugsmonat von einer spezifischen Ausgestaltung der innerfamiliären

105 Vgl. nur die vom Bundesministerium für Familie, Senioren, Frauen und Jugend initiierte und als Broschüre herausgegebene Studie von Bert Rürup/SAndra Gruescu, Nachhaltige Familienpolitik im Interesse einer aktiven Bevölkerungsentwicklung, 2003, S. 52 (die Studie wurde auch für den Siebten Familienbericht verwendet): „Einer Entwertung von Humankapital aufgrund der Unterbrechung der Erwerbstätigkeit kann entgegengewirkt werden, wenn diese Unterbrechung möglichst kurz gehalten wird. Das Humankapital einer Mutter, die nach einigen Monaten wieder in ihren Beruf zurückkehrt, bleibt eher erhalten. Bei einem Fernbleiben von 3 Jahren bzw., wenn ein zweites Kind geboren wird, bis zu 6 Jahren dürfte das Wissen zu einem höheren Prozentsatz abgeschrieben sein." Auf S. 53 des Gutachtens heißt es weiter, dass Mütter, die eine ihrer Qualifikation nicht entsprechende Teilzeittätigkeit annehmen, um mehr Zeit mit ihren Kindern verbringen zu können, einen „Teil [ihres] Humankapitals [...] verschwende[n].“ Dazu insgesamt kritisch ScHumanN (Anm. 83), S. 444, 448 ff. m.w.N.

106 Auch Seiler (Anm. 99), NVwZ 2007, S. 129, 132 f. kritisiert diesen ,sozialinterventionistischen Ansatz“ des Elterngeldes; dieses erweise sich ,als Prämie für ein dem Leitbild des Gesetzgebers entsprechendes ,richtiges" Familienleben“. Kritisch auch Ralf MüLLER-TerPITZ, Vätermonate und Kindergartenpflicht - wie viel Staat verträgt die Familie?, JZ 2006, S. 991 ff.; Felix (Anm. 99), RdJB 2008, S. 165, 174. Vgl. weiter Scheiwe/ Fuchsloch (Anm. 81), ZRP 2006, S. 37, 39 m.w.N.

107 Insgesamt wurden erhebliche verfassungsrechtliche Bedenken gegen zahlreiche Einzelregelungen des Elterngeldes geltend gemacht; vgl. nur MüLler-Terpitz (Anm. 106), JZ 2006, S. 99i, 994; Felix (Anm. 99), RdJB 2008, S. 165, 172 ff.; Seiler (Anm. 99), NVwZ 2007, S. 129 ff.; Stefanie Salaw-Hanslmaier, Diskriminiert das Elterngeld die Mehrkindfamilie?, ZRP 2008, S. 140 ff.; Katarina WeIlert, Verfassungsrechtliche Überlegungen zur Berechnung des Elterngeldes, DVBl 2010, S. 164 ff.; EntschlieBungsantrag der FDP zum Entwurf eines Gesetzes zur Einführung des Elterngeldes, BT-Drucks. 16/2809. Das BVerfG hat bislang sämtliche geltend gemachten Verfassungsbeschwerden nicht zur Entscheidung angenommen und sämtliche Normenkontrollanträge als unzulässig abgewiesen: BVerfG NJW 2012, S. 214; BVerfG NJW 2012, S. 216; BVerfG FamRZ 2012, S. 188; BVerfG FamRZ 2011, S. 959; BVerfG NJW 2011, S. 2869; BVerfG FamRZ 2011, S. 1645; BVerfG ArbuR 2011, S. 268. 
Aufgabenverteilung im Sinne der Inanspruchnahme sog. Partner- bzw. Partnerinnenmonate abhängig mach[e]“. ${ }^{108}$ Auch wenn der Normenkontrollantrag des Landessozialgerichts Niedersachsen-Bremen vom Bundesverfassungsgericht als unzulässig abgewiesen wurde (der Vorlagebeschluss habe den Anforderungen an das Begründungserfordernis nach $\int 80$ Abs. 2 S. 1 BVerfGG nicht genügt), so nimmt auch das BVerfG an, dass der Gesetzgeber mit Hilfe der Partnermonate die ,überkommene Rollenverteilung“ in der Familie überwinden und ,zu einer partnerschaftlicheren Rollenverteilung“ beitragen wolle ${ }^{109}$ und insoweit auch einen Bewusstseinswandel bei Eltern herbeiführen könnte; ein möglicher Eingriff in Art. 6 Abs. 1 GG könnte dabei durch den Auftrag in Art. 3 Abs. 2 S. 2 GG gerechtfertigt sein (dazu unten S. 50 ff.). ${ }^{110}$

c) Regelungen und Anreize zur Nutzung der Angebote frühkindlicher Fremdbetreuung

Impulse für eine möglichst frühe Aufnahme der Erwerbstätigkeit nach der Geburt eines Kindes setzt auch die Unterhaltsrechtsreform von 2008: Die deutliche Kürzung des Anspruchs auf nachehelichen Betreuungsunterhalt (der Anspruch besteht seit der Reform im Regelfall nur noch bis zum 3. Lebensjahr des Kindes, $\int 1570$ Abs. 1 S. 1 BGB) wurde u.a. damit gerechtfertigt, dass ein Rechtsanspruch auf einen Kindergartenplatz ab diesem Zeitpunkt bestehe. ${ }^{11}$

108 LSG Niedersachsen-Bremen BeckRS 2011, 73185, Leitsatz 1.

109 Zur Erzeugung eines Bewusstseinswandels durch die Einführung von zwei Partnermonaten heißt es in BT-Drucks. 16/1889, S. 23: „Zugleich erleichtert diese Regelung eine partnerschaftliche Teilung von Erwerbs- und Familienarbeit. Denn sie schafft einen Anreiz, nicht allein einem Elternteil die Erwerbsarbeit und dem anderen Teil die Betreuungsarbeit zu übertragen. [...] Ziel der Regelung ist es, die einseitige Zuweisung der Betreuungsarbeit an die Frauen mit den diskriminierenden Folgen auf dem Arbeitsmarkt aufzubrechen. Damit entspricht sie dem Auftrag zur Förderung der Gleichberechtigung aus Artikel 3 Abs. 2 Satz 2 GG." Bei dieser Argumentation wird übersehen, dass ein frühzeitiger Wiedereinstieg in die Erwerbstätigkeit nicht die Diskriminierung von teilzeittätigen bzw. länger die Erwerbstätigkeit unterbrechenden Eltern im Hinblick auf die berufliche Karriere ,,aufbricht“, sondern diese Nachteile für Eltern mit kurzer Babypause gar nicht erst entstehen, für alle anderen Eltern aber fortbestehen.

110 BVerfG FamRZ 2011, S. 1645, 1646 ff.

111 Entwurf eines Gesetzes zur Änderung des Unterhaltsrechts vom 15. Juni 2006, BTDrucks. 16/1830, S. 18. Die Reform wurde mit einem (nicht näher dargelegten) gesellschaftlichen Wandel begründet (S. 17): „Die Möglichkeiten der Fremdbetreuung von Kindern haben [...] insgesamt stark zugenommen; die Ausübung insbesondere einer Teilzeittätigkeit neben der Kindererziehung ist heute vielfach Realität." Daher müsse das Unterhaltsrecht an die „veränderten gesellschaftlichen Verhältniss[e] angepasst“ werden (Beschlussempfehlung und Bericht des Rechtsausschusses zum Entwurf eines Gesetzes zur Änderung des Unterhaltsrechts vom 7. November 2007, BT-Drucks. 16/6980, S. 1). Vgl. dazu Birgit Grundmann, Die Reform des Unterhaltsrechts kommt, FF 2005, 
Die Effekte liegen auch hier auf der Hand: Wenn Mütter damit rechnen müssen, dass sie im Falle einer Trennung vom Vater Betreuungsunterhalt nur bis zum 3. Lebensjahr des jüngsten Kindes erhalten, wird dies ihre Bereitschaft erhöhen, auch schon während intakter Partnerschaft ihr Kind rechtzeitig vor Ablauf der Elternzeit in einer Einrichtung einzugewöhnen. Zudem wird die Kürzung des Betreuungsunterhalts in den Gesetzesmaterialien euphemistisch als Stärkung der (nachehelichen) Eigenverantwortung (in erster Linie von Frauen) gefeiert ${ }^{112}$ und so bei Müttern mit Kleinkindern das Bewusstsein erzeugt, dass sie das „Richtige" tun, wenn sie möglichst schnell der ökonomischen Abhängigkeit vom (Ehe-)Mann durch eigene Erwerbstätigkeit entkommen.

Darüber hinaus steht zu erwarten, dass die seit 2004 an den Rechtsanspruch auf einen Betreuungsplatz für Kinder ab drei Jahren gekoppelte Erwerbsobliegenheit eines erwerbsfähigen Hilfebedürftigen nach $\ 10$ Abs. $1 \mathrm{Nr} .3$ SGB II ${ }^{113}$ mit der Verwirklichung eines Rechtsanspruchs auf frühkindliche Förderung dahingehend verschärft wird, dass diese Obliegenheit auch für erwerbslose Eltern mit Kindern unter drei Jahren besteht bzw. dass die Norm ab August 2013 so interpretiert werden wird. ${ }^{114}$ Jedenfalls legt die seit 1. August 2013 geltende Neuregelung des $\$ 24$ Abs. 2 S. 1 SGB VIII dies nahe, denn dort wird der Rechtsanspruch auf frühkindliche Förderung ab dem ersten Lebensjahr garantiert, wobei Erziehungsberechtigte, die Leistungen zur Eingliederung in Arbeit im Sinne des SGB II erhalten ( $\$ 24$ Abs. 1 S. 1 Nr. 2c SGB VIII), auch schon vor Vollendung des ersten Lebensjahres des Kindes auf eine Fremdbetreuung verwiesen werden können. ${ }^{115}$ In der Literatur finden sich bereits erste Stimmen, die

S. 213 f., 216 f. Kritisch Eva Schumann, Einführende Überlegungen zur Unterhaltsrechtsreform, in: Volker Lipp/Eva Schumann/Barbara Veit (Hrsg.), Reform des Unterhaltsrechts, 2007, S. 1, 2 (Fn. 4); ANNE Röthel, JZ 2009, S. 9I4, 9I6 (Anmerkung zur Grundsatzentscheidung des BGH zum Altersphasenmodell): „Man mag bezweifeln, ob sich die gesellschaftlichen Verhältnisse im Hinblick auf die persönliche Betreuung des Kindes derart einschneidend verändert haben - fest steht, dass sie sich infolge der Neuregelung verändern werden."

112 BT-Drucks. 16/1830, S. 16 f. Kritisch dazu Lore Maria Peschel-Gutzeit, Kritische Überlegungen zur geplanten Reform des Unterhaltsrechts, ZRP 2005, S. 177, 179.

113 Nach $\$ 10$ Abs. 1 Nr. 3 SGB II ist die Aufnahme einer Beschäftigung in der Regel zumutbar, wenn die Fremdbetreuung des Kindes sichergestellt ist (BT-Drucks. 15/1728, S. 5). Vgl. dazu auch Ostner (Anm. 85), RdJB 2009, S. 44, 56 f.

$114 \mathrm{Zu}$ der bis Juli 2013 geltenden Regelung Schumann (Anm. 83), S. 444, $465 \mathrm{f}$.

115 Seit 1 . August 2013 haben $\$ 24$ Abs. 1 S. 1 Nr. 2 c und Abs. 2 S. 1 SGB VIII folgenden Wortlaut: „Ein Kind, das das erste Lebensjahr noch nicht vollendet hat, ist in einer Einrichtung oder in Kindertagespflege zu fördern, wenn [...] die Erziehungsberechtigten [...] Leistungen zur Eingliederung in Arbeit im Sinne des Zweiten Buches erhalten. [...] Ein Kind, das das erste Lebensjahr vollendet hat, hat bis zur Vollendung des dritten Lebensjahres Anspruch auf frühkindliche Förderung in einer Tageseinrichtung oder in Kindertagespflege.“ Dazu BT-Drucks. 16/9299, S. 15: „Für Kinder, die das erste Le- 
auf die Möglichkeit einer Neuinterpretation der Zumutbarkeit einer Erwerbstätigkeit des betreuenden Elternteils eines unter dreijährigen Kindes gemäß $\int 10$ Abs. 1 Nr. 3 SGB II ab August 2013 hinweisen. ${ }^{116}$

Beeindruckend ist aber vor allem der finanzielle Umfang der neu geschaffenen Anreizstrukturen für erwerbstätige Eltern mit Kleinkindern: Den geringsten Posten macht dabei die Neuregelung zur Abzugsfähigkeit von Kinderbetreuungskosten nach $\int 10$ Abs. 1 Nr. 5 EStG aus. ${ }^{117}$ Für den Wechsel vom Erziehungs- zum Elterngeld war ursprünglich eine jährliche Erhöhung der Ausgaben von einer Mrd. Euro eingeplant (das Erziehungsgeld kostete drei Mrd. jährlich, das Elterngeld sollte ca. vier Mrd. kosten); ${ }^{118}$ im Jahr 2011 beliefen sich die jährlichen Kosten für das Elterngeld auf 4,7 Mrd. und seit 2012 wird mit jährlichen Kosten von fast fünf Mrd. gerechnet. ${ }^{119}$ Es steht somit zu erwarten, dass das Elterngeld jährlich zwei Mrd. mehr als das Erziehungsgeld kostet, wobei hier aufgrund der umgekehrt sozial gestaffelten Leistung (im Verhältnis zur Rechtslage bis 2007) eine Subventionierung der Besserverdienenden durch eine mit dem Sozialstaatsprinzip kaum zu vereinbarende Umverteilung von unten nach oben stattfindet. ${ }^{120}$

Geradezu gigantisch sind aber die Kosten, die der Staat in den Ausbau der Tagesbetreuung für Kinder unter drei Jahren steckt - und zwar sowohl im Hinblick auf die einmaligen Kosten für den Ausbau selbst als auch bezogen auf die laufenden Betriebskosten. Der verstärkte Ausbau der Tagesbetreuung für Kinder unter drei Jahren begann zwar schon 2005, ${ }^{121}$ entscheidend war

bensjahr noch nicht vollendet haben, bleibt es bei einer objektiv-rechtlichen Verpflichtung zur Vorhaltung von Plätzen. Diese wird jedoch an erweiterte Kriterien geknüpft (Absatz 1)." Vgl. weiter BT-Drucks. 16/10173, S. 10, 16.

116 Wolfgang Spellbrink, in: Ralf Kreikebohm/Wolfgang Spellbrink/Raimund Waltermann (Hrsg.), Kommentar zum Sozialrecht, 2. Aufl. 2011, \ 10 SGB II Rn. 6, 8. A.A. Christoph Kapp, in: Christian Rolfs/Richard Giesen/Ralf Kreikebohm/Peter Udsching (Hrsg.), Beck'scher Online-Kommentar zum Sozialrecht, 30. Edition, Stand 01.03.2013, \ 10 SGB II Rn. $44 \mathrm{ff}$.

117 Eingeführt mit dem Gesetz zur steuerlichen Förderung von Wachstum und Beschäftigung vom 26. April 2006 (BGBl. I, S. 1091). Die steuerliche Berücksichtigung von Kinderbetreuungskosten war zunächst in $\int 4$ f EStG (bis 31. August 2009), danach in $\$ 9$ c EStG (bis 31. Dezember 2011) und ist jetzt in $\$ 10$ Abs. 1 Nr. 5 EStG geregelt.

118 BT-Drucks. 16/1889, S. 17; Bundesministerium für Familie, Senioren, Frauen und Jugend (Hrsg.), Dossier Elterngeld als Teil nachhaltiger Familienpolitik, 3. Auflage 2008, S. 13.

119 Bericht des Haushaltsausschusses vom 18. November 2011, BT-Drucks. 17/7125, S. 42; Gesetz über die Feststellung des Bundeshaushaltsplans für das Haushaltsjahr 2013 vom 20. Dezember 2012 (BGB1. I, S. 2757), Einzelplan 17, Titel 68102 Elterngeld.

120 Dazu umfassend und kritisch Schumann (Anm. 83), S. 444, $475 \mathrm{ff}$.

121 Tagesbetreuungsausbaugesetz vom 27. Dezember 2004 (BGBl. I, S. 3852). Ausweislich der Gesetzesbegründung vom 6. September 2004 (BT-Drucks. 15/3676, S. 1 f., 21 ff.) 
aber die auf dem „Krippengipfel“ am 2. April 2007 zwischen Bund, Ländern und Gemeinden getroffene Vereinbarung, die Zahl der Krippenplätze bis 2013 zu verdreifachen, um für ein Drittel der unter dreijährigen Kinder Plätze zur Verfügung zu stellen. ${ }^{122}$ Dies entspricht 750.000 Plätzen bundesweit, wobei ca. 500.000 Plätze in Kindertagesstätten und ca. 250.000 Plätze über die Tagespflege bei einer Tagesmutter zur Verfügung gestellt werden sollten (zur nunmehrigen Aufstockung dieser Plätze siehe unten S. 38). Die staatlichen Subventionen für diese Maßnahme belaufen sich auf mindestens 6 Mrd. Euro jährlich an reinen Betriebskosten; ${ }^{123}$ hinzu kommen die Kosten für den Ausbau der Tagesbetreuung seit 2008 (12,6 Mrd. Euro finanziert von Bund und Ländern). ${ }^{124}$ Insgesamt beläuft sich die staatliche Förderung des Doppelverdienermodells (und erwerbstätiger Alleinerziehender) unter Berücksichtigung der Zahlung eines Betreuungsgeldes seit August 2013 an Eltern, die keine subventionierte Fremdbetreuung in den ersten drei Jahren nach der Geburt ihres Kindes in Anspruch nehmen, ${ }^{125}$ auf das Drei- bis Vierfache pro Kind, wobei die finanziellen Vorteile aufgrund der Berücksichtigung der Betreuungskosten bis zur Höhe von 4.000 Euro pro

werden mit dem Ausbau der Kindertagesbetreuung in erster Linie bildungspolitische (notwendige frühe Förderung und Sozialisation von Kindern außerhalb der Familie zur Verwirklichung der Chancengleichheit), gleichstellungspolitische (mehr Geschlechtergerechtigkeit) sowie demographische Ziele (Erleichterung der Entscheidung für Kinder, um auch der Gesellschaft bessere Entwicklungschancen zu geben) verfolgt.

122 Umgesetzt wurde diese Vereinbarung mit dem Gesetz zur Förderung von Kindern unter drei Jahren in Tageseinrichtungen und in Kindertagespflege vom 10. Dezember 2008 (BGBl. I, S. 2403); BT-Drucks. 16/10173, S. 1.

123 Zur Berechnung der Kosten vgl. Schumann (Anm. 83), S. 444, 482 ff. (insb. Fn. 163165). Im letzten Jahr hat die Bundesregierung die Kosten im Bereich der Kindertagespflege weiter nach oben korrigiert; Entwurf eines Gesetzes zur Einfuhrung eines Betreuungsgeldes vom 12. Juni 2012, BT-Drucks. 17/9917, S. 7: „Für die öffentliche Förderung in Tageseinrichtungen sind im Kinderförderungsgesetz jährliche Bruttobetriebskosten von 12000 Euro pro Platz in Ansatz gebracht worden; für einen Platz in der Kindertagespflege sind dies 9450 Euro (Bundestagsdrucksache 16/9299 S. 22). Diese Förderung erhalten alle Eltern unabhängig von ihrer finanziellen Situation, da die Beiträge der Eltern nicht kostendeckend sind.“

124 Entwurf eines Gesetzes zur Förderung von Kindern unter drei Jahren in Tageseinrichtungen und in der Kindertagespflege, BT-Drucks. 16/9299, S. 4; Pressemitteilung des Bundesministeriums für Familie, Senioren, Frauen und Jugend vom 20. August 2012, Gesetzliche Grundlagen für den Ausbau der Kinderbetreuung (http://www.bmfsfj.de/ BMFSFJ/kinder-und-jugend,did=118992.html).

125 Seit 1. August 2013 wird ein Betreuungsgeld von zunächst 100 Euro pro Monat und ab 2014 von 150 Euro pro Monat im Anschluss an das Elterngeld bis zum dritten Lebensjahr des Kindes gewährt; Gesetz zur Einführung eines Betreuungsgeldes vom 15. Februar 2013 (BGBl. I, S. 254). Nach der neuen Eltern-Studie „Wenn Eltern die Wahl haben“ vom 9. April 2013 befürworten 54 \% aller Befragten eine Verlängerung des Betreuungsgeldes bis zum dritten Geburtstag des Kindes (forsa, Familie und Wahl, Ergebnisbericht, 2013, S. 9; http://www.eltern.de/c/images/pdf/forsa_ergebnisbericht\%202013.pdf). 
Jahr als Sonderausgaben im Rahmen der Einkommensteuer noch hinzuzurechnen sind (ganz abgesehen davon, dass Doppelverdienerfamilien durch das zweite Einkommen finanziell ohnehin deutlich besser gestellt sind als Familien mit nur einem Einkommen). ${ }^{126} \mathrm{Zu}$ Recht wird daher gefragt, ob dies noch sozial gerecht sei ${ }^{127}$ denn das Sozialstaatsprinzip (Art. 20 Abs. 1 GG) scheint hier ins Gegenteil verkehrt zu werden. ${ }^{128}$

\section{Verstärkung von Edukationseffekten durch wechselbezügliche Gesetzgebung, begleitende Werbekampagnen und gezielte Desinformation}

Die seit dem Jahr 2005 in kurzer Folge erlassenen Gesetze (subventionierter Ausbau der Betreuungsplätze für Kleinkinder; Berücksichtigung von Kinderbetreuungskosten im EStG; Umstieg vom Erziehungsgeld auf das Elterngeld durch das BEEG; zeitliche Begrenzung des nachehelichen Betreuungsunterhalts bis zum dritten Lebensjahr des Kindes im BGB) fördern unter Einsatz immenser Mittel aus Steuern ausschließlich ein Modell der Vereinbarkeit von Familie und Beruf, nämlich den möglichst frühzeitigen Wiedereinstieg des betreuenden Elternteils in den Beruf nach einer kurzen Babypause verbunden mit einer frühzeitigen Fremdbetreuung des Kleinkindes. ${ }^{129}$

Unterstützt wird diese Gesetzgebung seit gut zehn Jahren durch (steuerfinanzierte) Werbekampagnen, ${ }^{130}$ deren wesentliche Inhalte bezogen auf die Mutter darin bestehen, die volle Ausschöpfung der gesetzlichen Elternzeit von drei Jahren nach der Geburt des Kindes als Verschwendung von Humankapital verbunden mit erheblichen finanziellen Verlusten, als Risiko für die Karriere und

126 Dazu Schumann (Anm. 83), S. 444, 483 f.

127 Auth (Anm. 83), S. 81, 96 f.; Felix (Anm. 99), RdJB 2008, S. 165, 170 ff., 173 ff. Vgl. dazu auch Schumann (Anm. 83), S. 444, 477 f.

128 Das Sozialstaatsprinzip, das die verfassungsrechtliche Legitimation für steuerfinanzierte Sozialleistungen darstellt, untersagt erstens dem Staat, Steuergelder ohne Anknüpfung an persönliche Lebensumstände oder gesellschaftliche Benachteiligung und ohne sachliche Differenzierung zu verteilen, und verpflichtet zweitens den Gesetzgeber dazu, für einen Ausgleich der sozialen Gegensätze zu sorgen und die Idee der materiellen Gerechtigkeit zu beachten; so BVerfGE 100, S. 271, 284; BVerfGE 102, S. 254, 298 f.

129 Das seit 1. August 2013 auszuzahlende Betreuungsgeld ist die erste gesetzgeberische Maßnahme nach acht Jahren, mit der auch andere Familienmodelle gefördert werden. Zur Diskussion um die Einführung eines Betreuungsgeldes vgl. Schumann (Anm. 83), S. 444, 460 ff. m.w.N.

130 Hierbei handelt es sich keineswegs um eine neue Entwicklung; auch andere Gesetze (im Bereich des Umweltschutzes oder im Zusammenhang mit der Wiedervereinigung) wurden von (kostspieligen) Werbekampagnen begleitet; dazu Vierhaus (Anm. 1), S. 224 ff., $232 \mathrm{f}$. 
als Indikator für Altersarmut sowie als Verfestigung der überkommenen Rollenverteilung und der ökonomischen Abhängigkeit der Frau vom Mann zu qualifizieren. ${ }^{131}$ Gleichzeitig werden in Bezug auf das Kleinkind unter drei Jahren die Ausschöpfung der Elternzeit und die damit verbundene Betreuung des Kindes durch einen Elternteil als „bildungspolitische Katastrophe“ (so u.a. die ehemalige Bundesfamilienministerin URSULA VON DER LEYEN) bezeichnet ${ }^{132}$ und den Eltern wird suggeriert, dass ein Verzicht auf Fremdbetreuung eines unter drei Jahre alten Kindes eine Vorenthaltung frühkindlicher Förderung und Bildung bedeute, wobei insbesondere für Kinder aus bildungsfernen Elternhäusern eine frühkindliche Fremdbetreuung zum Ausgleich unterstellter Defizite der Eltern für notwendig erachtet wird, um Chancengleichheit herzustellen. ${ }^{133}$

Beruhen diese durch den Siebten Familienbericht und weitere Berichte sowie durch die Aufklärungskampagnen der Bundesregierung und des Bundesfamilienministeriums verbreiteten Empfehlungen, Warnungen und Appelle auf sachlich, objektiv, richtig und vollständig dargestellten Informationen?

Beginnen wir mit den Daten: Im Jahr 2004/2005 betrug der ermittelte Betreuungsbedarf für Kinder unter drei Jahren $35 \%$; inzwischen ist dieser Anteil möglicherweise bereits aufgrund eines durch die Edukationseffekte ausgelösten Bewusstseinswandels in der Bevölkerung ${ }^{134}$ - auf $39 \%$ gestiegen (dieser Bedarf ist allerdings seit drei Jahren konstant). ${ }^{135}$ Als Reaktion darauf wurde die auf dem „Krippengipfel“ 2007 vereinbarte finanzielle Förderung von 750.000 Betreu-

131 Nachweise bei Schumann (Anm. 83), S. 444, 449 ff., 467 f.

132 Von der Leyen gibt nach, Süddeutsche.de vom 17. Mai 2010 (http://www.sueddeutsche.de/politik/betreuungsgeld-von-der-leyen-gibt-nach-1.348863). Vgl. weiter SEBAStian Fischer, Betreuungsgeld, Spiegel Online vom 24. November 2009 (http://www. spiegel.de/politik/deutschland/betreuungsgeld-csu-giftet-gegen-gutschein-loesunga-663201.html); Bundestag beschließt umstrittenes Betreuungsgeld, Zeit Online vom 9. November 2012 (http://www.zeit.de/politik/deutschland/2012-11/steinbrueck-betreuungsgeld-bundestag).

133 Nachweise bei Schumann (Anm. 83), S. 444, 462 f., 465 ff., 470 ff.

134 In welchem Umfang die Steigerung der bundesweiten Inanspruchnahme von Betreuungsplätzen für unter Dreijährige (inkl. Tagespflege) von 2006 um 304.314 Kinder (120\%) auf 558.208 Kinder in 2012 die Folge eines von statlicher Seite ausgelösten Bewusstseinswandels bzw. nur Folge der Behebung eines erheblichen Unterangebots an Betreuungsplätzen ist, muss hier offen bleiben. Zu den Zahlen Thomas Rauschenbach/Matтhias Schilling/Eva Strunz, Der U3-Ausbau im Endspurt - und danach, Kommentierte Daten der Kinder- und Jugendhilfe 2012, Heft 3, S. 1; Thomas Rauschenbach/Matthias Schilling, Die Trägerstruktur der Arbeitgeber in der Kinder- und Jugendhilfe - ein wenig beachtetes Thema, Kommentierte Daten der Kinder und Jugendhilfe 2012, Heft 2, S. 1, 3.

135 Bericht der Bundesregierung über den Stand des Ausbaus für ein bedarfsgerechtes Angebot an Kindertagesbetreuung für Kinder unter drei Jahren für das Berichtsjahr 2011 (Dritter Zwischenbericht zur Evaluation des Kinderförderungsgesetzes) vom 31. Mai 2012, BT-Drucks. 17/9850, S. 4, 15. 
ungsplätzen durch Bund und Länder im Jahr 2012 um weitere 30.000 Plätze auf 780.000 Betreuungsplätze für unter Dreijährige aufgestockt (der Bund stellt hierfür nochmals 580,5 Mio. Euro zur Verfügung). ${ }^{136}$ Da in den Jahren 2009 bis 2011 in Deutschland durchschnittlich 668.586 Kinder pro Jahr und insgesamt 2.005.758 Kinder geboren wurden, ${ }^{137}$ scheint das Angebot auch dem tatsächlichen Bedarf von $39 \%$ zu entsprechen.

Die Bedarfsberechnung geht jedoch von einer Ganztagsbetreuung der Kinder aus, tatsächlich wünschen sich aber nur $11 \%$ der Eltern eine Ganztagsbetreuung, $25 \%$ der Eltern bevorzugen Betreuungszeiten von 25 bis 35 Stunden und fast zwei Drittel der Eltern (64\%) wollen eine Betreuung von weniger als 25 Stunden für ihr Kind in Anspruch nehmen. ${ }^{138}$ Bei einer stärkeren Berücksichtigung der gewünschten Betreuungszeiten unter Nutzung der vorhandenen Ressourcen, insbesondere einer stärkeren Vergabe von Halbtagsplätzen, könnte der Bedarf mit dem vorgesehenen Angebot problemlos gedeckt werden. ${ }^{139}$

Als nächstes ist zu fragen, ob sich die behaupteten positiven Effekte auBerfamiliärer Betreuung unter Dreijähriger auf deren Bildung und soziale Entwicklung nachweisen lassen, weil diese Information für viele Eltern bei der Entscheidung für eine Fremdbetreuung eine nicht unwesentliche Rolle spielen dürfte. Denn wer möchte seinen Kindern spätere Bildungserfolge und eine gute Sozialisation vorenthalten? Im Siebten Familienbericht heißt es dazu mit Bezug auf die PISA-Studie, dass ,,in keinem anderen der untersuchten Länder die Schichtzugehörigkeit der Eltern für die Kompetenzen von Jugendlichen so ent-

136 Pressemitteilung des Bundesministeriums für Familie, Senioren, Frauen und Jugend vom 16. August 2012 (http://www.bmfsfj.de/BMFSFJ/kinder-und-jugend,did=187954.html).

137 Statistisches Bundesamt, Destatis, Bevölkerung Deutschland, Geburten 2009-2011 (http://www.destatis.de/DE/ZahlenFakten/Indikatoren/LangeReihen/Bevoelkerung//Irbev04.html).

138 Dritter Zwischenbericht zur Evaluation des Kinderförderungsgesetzes, BT-Drucks. 17/9850, S. $15 \mathrm{ff}$.

139 Dennoch wird ein weiterer Ausbau der Kindertagespflege gefordert. So wird die Ablehnung des Betreuungsgeldes durch die SPD-Fraktion im Antrag „Frühkindliche Bildung und Betreuung verbessern - Für Chancengleichheit und Inklusion von Anfang an" vom 9. Juni 2010 damit begründet, dass mögliche negative bildungs- und gleichstellungspolitische Auswirkungen nicht auszuschließen seien, und die Mehrausgaben für das Betreuungsgeld (1,4 - 1,9 Mrd. Euro pro Jahr) stattdessen in den Ausbau der frühkindlichen Infrastruktur investiert werden sollten (BT-Drucks. 17/1973, S. 5): „Eine gute und bedarfsgerechte Infrastruktur der frühkindlichen Bildung und Betreuung [sei] eine wichtige Voraussetzung, um Kindern ein gelingendes Aufwachsen [...] zu ermöglichen.“ (S. 1). Vgl. zuletzt die Stellungnahme von Kanzlerkandidat Peer Steinbrück (Steinbrück warnt SPD vor falschen Versprechen, Zeit Online vom 6. Dezember 2011; http://www. zeit.de/politik/deutschland/2011-12/steinbrueck-spd-rede): Das Betreuungsgeld sei eine „dämliche und skandalöse Fernhalteprämie“. 
scheidend [sei] wie in Deutschland“ und daher „gerade Kinder bildungsferner Eltern zukünftig bereits in der frühkindlichen Entwicklung wesentlich besser zu fördern [seien] als bisher", um ,ausgesprochen negative Folgen [...] für Chancengerechtigkeit und (für die persönliche, soziale und wirtschaftliche Entwicklung dringend benötigt[e]) Kompetenzen“ zu vermeiden. ${ }^{140}$ An anderer Stelle des Berichts zeigt sich, dass sich diese Schlussfolgerung keineswegs auf wissenschaftliche Erkenntnisse stützen kann, sondern auf bloßen Vermutungen beruht:

„Da es v.a. Kinder mit Migrationshintergrund oder aus sozial benachteiligten Familien sind, die vorschulische Einrichtungen seltener besuchen, scheint es [sic!], als ob der Grundstein für die ebenso in der PISA Studie nachgewiesene starke Abhängigkeit des Bildungserfolges von der sozialen Herkunft schon im vorschulischen Alter angelegt wird." ${ }^{141}$

Auch im Zwölften Kinder- und Jugendbericht von 2005 wird ohne empirische Nachweise behauptet, dass heute die große Mehrheit der Kinder von ihren Familien nicht mehr mit den nötigen Ressourcen ausgestattet werde, um später den gesellschaftlichen Anforderungen gewachsen zu sein. ${ }^{142}$ Die Bundesregierung hat sich die Empfehlungen der Sachverständigen des Zwölften Kinder- und Jugendberichts zu Eigen gemacht, einen erheblichen Handlungsbedarf im Bereich der frühen Förderung, Bildung und Erziehung der unter Dreijährigen anerkannt und damals angekündigt, nicht nur ,den Rechtsanspruch auf eine öffentlich verantwortete Kindertagesbetreuung auf Kinder unter drei Jahren auszudehnen“, sondern den Ausbau der Kindertagesbetreuung für unter Dreijährige auch durch eine (noch unter Bundesfamilienministerin Renate Schmidt gestartete) „,bundesweite Informationskampagne“ mit dem Titel „KINDER KRIEGEN mehr ...!“ zu begleiten. ${ }^{143}$ Noch breiter angelegt war die 2006 durchgeführte Werbekampagne „Vorteil Familie“ unter Bundesfamilienministerin Ursula von DER LeYen, mit

140 Siebter Familienbericht, BT-Drucks. 16/1360, S. 157.

141 Siebter Familienbericht, BT-Drucks. 16/1360, S. 95 (Fn. 55).

142 Bericht über die Lebenssituation junger Menschen und die Leistungen der Kinder- und Jugendhilfe in Deutschland (Zwölfter Kinder- und Jugendbericht) und Stellungnahme der Bundesregierung vom 10. Oktober 2005, BT-Drucks. 15/6014, S. 89 f.: ,Kinder werden in Familien und den Herkunftsmilieus nicht mehr in der Selbstverständlichkeit mit den Ressourcen ausgestattet - jedenfalls im Schnitt gesprochen bzw. für die große Mehrheit der Kinder und Jugendlichen -, die moderne Gesellschaften benötigen, um den Anforderungen an die individuelle Selbstregulierung durchschnittlich gerecht werden zu können." Kritisch dazu auch Ostner (Anm. 85), RdJB 2009, S. 44, 50 ff.

143 Zwölfter Kinder- und Jugendbericht, BT-Drucks. 15/6014, S. 9 ff. (Zitat auf S. 10). Auf S. 10 heißt es weiter: Die Bundesregierung ,wird den Ausbau im Rahmen ihrer Möglichkeiten durch Informationsmaßnahmen unterstützen. Durch die bundesweite Informationskampagne ,KINDER KRIEGEN mehr ...!' sollen Eltern über die Möglichkeiten für eine gute Betreuung und frühe Förderung informiert [...] werden." Die breit angelegte Informationskampagne startete im Jahr 2005. 
der mehr als 55 Mio. Menschen über das Elterngeld informiert wurden: Neben Anzeigen, Fernsehspots und Plakaten (mit dem Titel „Krabbeln lerne ich bei Mama, laufen dann bei Papa“) „hat das Ministerium die Einführung des Elterngelds auch mit sendefertigen Radiobeiträgen und druckreifen Zeitungsartikeln begleitet“, wobei der Eindruck vermittelt wurde, ,,es handele sich um Berichte unabhängiger Journalisten" (tatsächlich stammten die Texte von der vom Bundesfamilienministerium beauftragten PR-Agentur A\&B One). ${ }^{144}$

Für einen radikalen Perspektivwechsel in Bezug auf die außerfamiliäre Betreuung von unter Dreijährigen hatte das Bundesfamilienministerium allerdings schon 2003 geworben:

„Die präventive Funktion außerunterrichtlicher Betreuungsangebote sowie deren Rolle bei der Reduktion sozialer Kosten und der Vermeidung kindlicher Fehlentwicklung (z.B. jugendliche Delinquenz) sind stärker als bisher hervorzuheben und als Argument für den Ausbau dieser Angebote heranzuziehen. [...] Im Bildungswesen generell und in den ersten 10 Jahren der kindlichen Entwicklung insbesondere verdienen Übergänge im Bildungsprozess besonderer fachlicher wie politischer Aufmerksamkeit: der Übergang von der Familie in die Krippe, von der Krippe in den Kindergarten, vom Kindergarten in die Grundschule und von dort in die weiterfuhhrenden Schulen. [...] Die Förderung von Kindern von 0 Jahren bis zum Schuleintritt stellt [...] die erste Stufe im Bildungsprozess dar. [...] Die Auffassung in Deutschland, wonach das System lediglich familienergänzenden Charakter haben soll, muss [...] aufgegeben werden zugunsten der Definition eines genuinen Bildungs- und Erziehungsauftrags mit Blick auf die kindliche Entwicklung. " 145

144 Carsten Volkery, Von der Leyens dubiose PR, Gratis-Reklame für die Ministerin - von der Ministerin, Spiegel Online vom 29. August 2007 (http://www.spiegel.de/politik/ deutschland/von-der-leyen-dubiose-pr-gratis-reklame-fuer-die-ministerin-von-derministerin-a-502566.html). Im Internetauftritt der Agentur A\&B One (http://www.ab-one.de/referenzen/alle/politische-kommunikation-bmfsfj.html) heißt es, dass es im Rahmen der bundesweiten Informationskampagne „Vorteil Familie“ gelungen sei, „die zentralen Kampagnenbotschaften in den Medien, auf Plakaten und in Informationsmaterialien“ erfolgreich zu platzieren: „Schnell erzielte die von uns umgesetzte Kampagne eine hohe Aufmerksamkeit und verstärkte damit das Medienecho auf die Gesetzgebung. So haben wir schließlich mitgeholfen, das Elterngeld populär zu machen und die politische Intention dahinter zu vermitteln. Dies wurde auch durch eine Wirkungsanalyse belegt." Vgl. weiter Antwort der Bundesregierung auf die Kleine Anfrage der Fraktion DIE LINKE, BT-Drucks. 16/6548, S. 1.

145 Bundesministerium für Familie, Senioren, Frauen und Jugend (Hrsg.), Perspektiven zur Weiterentwicklung des Systems der Tageseinrichtungen für Kinder in Deutschland, Zusammenfassung und Empfehlungen, 2003, S. 24, 33 f. [Hervorhebungen durch Verf.] Bezeichnenderweise wird die Familie an den Anfang einer Reihe öffentlicher Einrichtungen, die jeweils einen zeitlich abgeschlossenen Bereich der kindlichen Entwicklung erfassen, gestellt. Dadurch wird der Eindruck vermittelt, dass die Bildungsfunktion der Familie auf die ersten Lebensmonate des Kleinkindes zu beschränken sei. Vgl. WassiLıos FthenAKIS, Die Forderung nach Bildungsqualität, in: Bundesministerium für Familie, Senioren, Frauen und Jugend (Hrsg.), Auf den Anfang kommt es an!, 2003, S. 75 f.: „An erster Stelle gilt es, das Kind als Subjekt im Bildungsprozess anzuerkennen, es von Anfang an als ein kompetentes Kind zu betrachten, das seine Erziehung und Bildung 
Abgesehen davon, dass das Grundgesetz den Vorrang elterlicher vor staatlicher Erziehung garantiert, ${ }^{146}$ werden hier nicht belegte Behauptungen als sachlich richtige Informationen dargestellt, denn es gibt für Deutschland keine breit angelegten Studien, ${ }^{147}$ die einen empirisch nachweisbaren Zusammenhang zwischen der Betreuung im Kleinkindalter und der Vermeidung der beschriebenen negativen externen Effekte (in Bezug auf soziale Kosten und kindliche Fehlentwicklungen) bzw. der Erzielung der behaupteten positiven Effekte belegten. ${ }^{148}$

co-konstruiert. Kinder gestalten dabei von Anfang an Bildung und Entwicklung mit und übernehmen entwicklungsangemessen Verantwortung. [...] Erforderlich ist auch, eine angemessene Beteiligung des Kindes am Leben in der Tageseinrichtung sicherzustellen. [...] Schon das Kleinkind soll das Lernen lernen und so auf ein Leben vorbereitet werden, in dem beständiges Lernen unverzichtbar ist." $\mathrm{Zu}$ den Hintergründen dieser Entwicklung vgl. IlONA Ostner, Ökonomisierung der Lebenswelt durch aktivierende Familienpolitik?, in: Adalbert Evers/Rolf G. Heinze (Hrsg.), Sozialpolitik, Ökonomisierung und Entgrenzung, 2008, S. 49, 59; DiEs. (Anm. 85), RdJB 2009, S. 44 ff.

146 Art. 6 Abs. 2 S. 1 GG gewährt Eltern das Recht, die Pflege und Erziehung ihrer Kinder nach ihren eigenen Vorstellungen frei zu gestalten und räumt ihnen insoweit Vorrang vor anderen Erziehungsträgern ein, weil den Eltern ,,in aller Regel [...] das Wohl des Kindes mehr am Herzen liegt als irgendeiner anderen Person oder Institution" (BVerfG NJW 1983, S. 101).

147 Hans Bertram/Steffen Kohl, Zur Lage der Kinder in Deutschland 2010, hrsg. vom Deutschen Komitee für UNICEF, 2010, S. 37 f.: „Bedauerlicherweise gibt es in Deutschland mit einer einzigen Ausnahme keine Längsschnittuntersuchungen, die die kindliche Entwicklung in verschiedenen Altersstufen nachzeichnen. [...] Auch die Frage, ab wann Kinder sinnvollerweise in außerfamiliären Einrichtungen betreut und gebildet werden können und welche Effekte dort zu erwarten sind, lässt sich zumeist nur auf der Basis angelsächsischer Studien beantworten“. Auch hinsichtlich der deutlichen Erhöhung der Erwerbsbeteiligung der Mütter mit erheblichen Auswirkungen auf die familiäre Zeitstruktur könne „,nur auf angelsächsische Erfahrungen und Untersuchungen“ zurückgegriffen werden, wenn man ,,diese Entwicklungen in Bezug auf das kindliche Wohlbefinden und die Entwicklungschancen von Kindern einschätzen" wolle. Vgl. weiter Martin R. Textor, Die „NICHD Study of Early Child Care“ - ein Überblick, in: ders. (Hrsg.), Kindergartenpädagogik - Online-Handbuch (http://www.kindergartenpaedagogik.de/1602.html): „Deutlich wird hier das große Forschungsdefizit in der Bundesrepublik: In den letzten zwei Jahrzehnten wurden keine wissenschaftlichen (Längsschnitt-) Untersuchungen über unter Dreijährige durchgeführt, die entweder in der Familie, in einer Kinderkrippe, in Familientagespflege oder in einer weit altersgemischten Gruppe [...] aufwuchsen. Da derzeit die Betreuungsangebote für unter Dreijährige $[\ldots]$ stark ausgebaut werden, müssten $\mathrm{m}$. E. dringend Untersuchungen über die Konsequenzen einer sehr frühen Fremdbetreuung durchgeführt werden, wobei auch die Betreuungsdauer zu berücksichtigen wäre."

148 Auch an anderen Stellen wird dieser Zusammenhang (ohne entsprechende Nachweise) behauptet, vgl. etwa BT-Drucks. 15/3676, S. 24 zum bedarfsgerechten Ausbau der Tagesbetreuung für Kinder unter drei Jahren: „Jede Förderung, die Kindern in diesem Alter zugute kommt, wirkt sich positiv auf den weiteren Weg in Schule und Ausbildung aus und sichert damit Lebenschancen. Andererseits werden durch eine unzureichende Förderung von Kindern in dieser Altersgruppe die Weichen für Benachteiligung, Des- 
Studien aus den USA kommen sogar zu dem gegenteiligen Ergebnis, nämlich dass außerfamiliäre Betreuung unter Dreijähriger negative Effekte auf die sozioemotionale Entwicklung der Kinder haben kann. ${ }^{149}$ Dennoch wird propagiert, dass die Erziehungs-, Sozialisations- und Bildungsfunktion der Familie nur noch für die ersten Lebensmonate des Kindes bis zum Eintritt in die Krippe anerkannt werden könne, während sich danach die kindliche emotionale, soziale und kognitive Entwicklung besser außerhalb der Familie fördern lasse. ${ }^{150}$ Eltern (und vor allem solchen mit Migrationshintergrund oder aus bildungsfernen Milieus) wird dabei suggeriert, dass sie der Aufgabe einer frühkindlichen Förderung und Bildung ihrer Kinder nicht gewachsen seien und daher eine ergänzende „Bildungsbeteiligung“ in der Krippe erforderlich sei. ${ }^{151}$ Darüber hinaus wird

integration und Dissozialität gestellt." Vgl. weiter BT-Drucks. 17/2716, S. 10 (Antwort der Bundesregierung auf eine Anfrage der Fraktion BÜNDNIS 90/DIE GRÜNEN vom 5. August 2010) zur frühkindlichen Bildung unter Dreijähriger in Kindertageseinrichtungen: „Die Förderung in den ersten Lebensjahren ist grundlegend für alle weitergehenden Bildungserfolge. Sie entscheidet maßgeblich über Entwicklungs-, Teilhabe- und Aufstiegschancen und trägt damit zur sozialen Gerechtigkeit bei. Nur gute und passgenaue Förderung von Anfang an schafft faire Chancen für alle Kinder." Dazu insgesamt kritisch Vera Brünnagel/Barbara Henman, Kleinkindbetreuung: Wahlfreiheit durch subventionierte Krippenplätze?, Wirtschaftsdienst 2007, S. 309, 310 f. (insb. Fn. 11).

149 Dazu Rainer BöHm, Auswirkungen frühkindlicher Gruppenbetreuung auf die Entwicklung und Gesundheit von Kindern, Kinderärztliche Praxis 82 (2011), S. 316 ff. mit zahlreichen Nachweisen. Ergänzend dazu Aric Sigman, Mother Superior?, The biological effects of day care, The Biologist, Vol. 58 (2011), No. 3, S. 28 ff. (mit dem Hinweis auf S. 32, dass die Diskussion über die bestmöglichen Entwicklungsbedingungen von Kleinkindern von der Verwirklichung anderer politischer Ziele überlagert sei): „Unfortunately, understanding the effects of day care on the child continues to be discussed through the prism of adult sexual politics and women's rights. This has been a significant impediment, involving a serious conflict of interest: women's rights and self-fulfillment are not the same issue as child wellbeing and may often compete for precedence."

150 Vgl. auch Siebter Familienbericht, BT-Drucks. 16/1360, S. XXV, XXVII: „Vorrangige Handlungsfelder sind die vorschulische Kinderbetreuung, insbesondere der unter Dreijährigen, die frühe Förderung der Kinder [...]. Der Familienbericht sieht eine staatliche Förderung guter pädagogischer Betreuung ausdrücklich als, ökonomisch rational' und, sehr rentabel' an, da der spätere Nutzen die Kosten um ein Vielfaches übersteigt." Kritisch zur Skepsis gegenüber der elterlichen Erziehungskompetenz auch Ostner (Anm. 97), ZfS 2007, S. 385, 388. Vgl. weiter DIES. (Anm. 85), RdJB 2009, S. 44 ff., insb. 47 ff.

151 Vgl. Nationaler Bildungsbericht 2012 - Bildung in Deutschland und Stellungnahme der Bundesregierung vom 9. November 2012, BT-Drucks. 17/11465, S. 56 ff.: „Die zunehmende Bildungsbeteiligung der unter 3-Jährigen ist weiterhin das zentrale Thema der frühkindlichen Bildung. [...] Die Bildungsbeteiligung von Kindern unter 3 Jahren mit Migrationshintergrund liegt [...] in Westdeutschland bei $13 \%$ und damit deutlich unter der Beteiligung der Kinder ohne Migrationshintergrund (23\%). "Aus diesen Erkenntnissen des Berichts zieht die Bundesregierung folgende „Schlussfolgerungen“ (S. VI): „Frühe Förderung ist aus der Sicht der Bundesregierung nach wie vor der Schlüssel zu 
vor allem bildungsfernen Eltern und solchen mit Migrationshintergrund unterstellt, dass sie im Falle der Gewährung eines Betreuungsgeldes ihren Kindern „Bildung" vorenthalten würden, um in den Genuss der Geldzahlung zu kommen. ${ }^{152}$ Dabei ist diese, auf nicht bewiesene Behauptungen aufbauende Stigmatisierung bestimmter Familien völlig haltlos. Tatsächlich besuchen nämlich nur deshalb weniger Kinder mit Migrationshintergrund bzw. aus bildungsfernen Familien Krippen, weil die Auswahlkriterien der Einrichtungen diese Familien benachteiligen - wie im Dritten Zwischenbericht zur Evaluation des Kinderförderungsgesetzes nachzulesen ist: „Eltern mit Migrationshintergrund sowie Eltern in bildungsbenachteiligten Familien wünschen sich für ihre Kinder genauso häufig einen Betreuungsplatz, bekommen ihn aber seltener." ${ }^{\text {“53 }}$

Doch wie sieht die frühkindliche Betreuung der unter Dreijährigen aus und welche langfristigen Erfolge verspricht sie? Hier ist zunächst darauf hinzuweisen, dass die außerfamiliäre Kleinkindbetreuung konsequent als „frühkindliche Förderung“" oder ,frühkindliche Bildung“ bezeichnet wird und damit etwas verheißt, was nur außerhalb der Familie geleistet werden könne (zur Beeinflussung durch Verwendung positiv besetzter Begriffe siehe unten S. 46). Frühkindliche Förderung ist in den einschlägigen Gesetzen, den Gesetzesmaterialien, den Berichten der Bundesregierung und den Informationskampagnen des Bundesfamilienministeriums nicht näher definiert; ${ }^{154}$ gleichwohl bezeichnet die Bundesregierung die Betreuung in Kindertagesstätten und in der Tagespflege durchgängig als ,frühkindliche Bildung“. ${ }^{155}$ So findet sich etwa im Koalitions-

einer besseren Integration und schafft gleiche Startbedingungen für alle Kinder. Insbesondere die alltagsintegrierte sprachliche Bildung für alle Kinder sowie die Sprach- und Leseförderung muss quantitativ und qualitativ weiter ausgebaut werden. Auch bleibt es eine wichtige Aufgabe, bildungsferne Eltern mit und ohne Migrationshintergrund verstärkt zu informieren und einzubeziehen."

152 Die damalige Familienministerin Ursula von Der Leyen hat dies mit Nachdruck öffentlich verkündet; vgl. nur Angela Gareis, Die Pannen der Frau von der Leyen, Der Westen Online vom 29. Mai 2009, die die Ministerin mit folgenden Worten wiedergibt (http://www.derwesten.de/politik/die-pannen-der-frau-von-der-leyen-id331065. html): „Es ist eine bildungspolitische Katastrophe, wenn der kleine zweijährige Ahmed in den Kindergarten geht und seine Eltern hören, wir kriegen 150 Euro im Monat auf die Hand.“

153 Dritter Zwischenbericht zur Evaluation des Kinderförderungsgesetzes, BT-Drucks. 17/9850, S. 15.

154 Nach den Gesetzesmaterialien zum Kinderförderungsgesetz (BT-Drucks. 16/9299, S. 15) soll mit , der Bezeichnung, frühkindliche Förderung' $[\ldots]$ die spezifische Zielsetzung der Förderung dieser Altersgruppe hervorgehoben" werden. Außer diesem wenig aussagekräftigen Hinweis ist zu den Inhalten der frühkindlichen Förderung und Bildung in den Krippen und durch Tagesmütter nichts zu finden.

155 So zuletzt wieder im Nationalen Bildungsbericht 2012, BT-Drucks. 17/11465, S. IV ff.: „2011 konnten rund 517000 Kinder unter drei Jahren von einem Betreuungsangebot 
vertrag zwischen CDU, CSU und FDP vom 26. Oktober 2009 der Hinweis, dass die Bundesregierung darauf hinwirken werde, dass ,sich Bund und Länder auf gemeinsame Eckpunkte der frühkindlichen Bildung, insbesondere auch der Sprachförderung, einigen“. ${ }^{156}$ Im Dritten Zwischenbericht zur Evaluation des Kinderförderungsgesetzes für das Jahr 2011 wird darauf verwiesen, dass ,frühkindliche Sprachförderung“" zum festen Bestandteil der Kleinkindbetreuung gehöre und dass die Einrichtungen „Sprachförderung spielerisch durch Lieder, Musik und Bewegung in den Betreuungsalltag aller Kinder" integrierten. ${ }^{157}$

Der Vorstellung, dass Eltern von unter Dreijährigen zu Hause keine vergleichbare Sprachförderung betrieben bzw. dazu nicht in der Lage seien, steht die seit Jahrzehnten empirisch nachgewiesene Bildungsfunktion der Familie entgegen. ${ }^{158}$

profitieren. Das ist im Vergleich zu 2006 eine Steigerung um 80 Prozent. Ihre Bildungsbeteiligung stieg damit in Westdeutschland auf 20 Prozent und in Ostdeutschland auf 47 Prozent.“ Künftig sei diese „frühkindliche Bildung auch qualitativ weiter aus[zu]bauen.“

156 Koalitionsvertrag zwischen CDU, CSU und FDP „Wachstum. Bildung. Zusammenhalt." vom 26. Oktober 2009, S. 68 (http://www.cdu.de/sites/default/files/media/ dokumente/091026-koalitionsvertrag-cducsu-fdp.pdf). Konkrete Programme zur frühkindlichen Bildung scheinen noch nicht vorzuliegen; so heißt es im Nationalen Bildungsbericht 2012, BT-Drucks. 17/11465, S. 66: „Durch welche pädagogischen Konzepte Kinder beim (Zweit-)Spracherwerb am wirkungsvollsten unterstützt werden können, ist eine fachlich nach wie vor ungeklärte Frage [...]." Im Übrigen werden vor allem Qualifikationsmaßnahmen für Erzieher und Tagespflegepersonen genannt; vgl. nur die Antwort der Bundesregierung auf Kleine Anfragen der SPD sowie von BÜNDNIS 90/DIE GRÜNEN zu Stand und Zukunft des qualitativen und quantitativen Ausbaus der Kinderbetreuung, BT-Drucks. 17/714, S. 8, 10 ff. und BT-Drucks. 17/2716, S. $2,5 \mathrm{ff}$.

157 Dritter Zwischenbericht zur Evaluation des Kinderförderungsgesetzes, BT-Drucks. 17/9850, S. 5, 52.

158 Dazu etwa Martin R. Textor, Die „Bildungsmacht“ der Familie, in: Regiestelle E\&C der Stiftung Sozialpädagogisches Institut Berlin (Hrsg.), Fachforum Orte der Bildung im Stadtteil, Dokumentation zur Veranstaltung am 16. und 17. Juni 2005 in Berlin, 2005, S. 60 ff. (http://www.eundc.de/pdf/36000.pdf) unter Heranziehung mehrerer Studien der letzten Jahrzehnte: „Somit ist festzuhalten, dass der Einfluss der Familie auf den Schulerfolg größer ist als der Einfluss der Schule oder als der Einfluss von Kindmerkmalen. In ihren Familien erwerben Kinder die meisten psychomotorischen, sozialen, affektiven und sprachlichen Kompetenzen. [...] (Bildungs-)Politik und Bildungssystem müssen endlich die zentrale Bedeutung der Familie als Bildungsinstitution anerkennen." Vgl. weiter Вӧнм (Anm. 149), Kinderärztliche Praxis 82 (2011), S. 316, 321 unter Berufung auf die US-amerikanische „Study of Early Child Care and Youth Development" des National Institute of Child Health and Human Development (NICHD): „Eine wichtige Erkenntnis von NICHD ist, dass der Einfluss der Eltern auf die kindliche Entwicklung wesentlich höher ist als der von Betreuungseinrichtungen." $\mathrm{Zu}$ älteren Studien aus den USA vgl. Kevenhörster/Windhoff-Héritier (Anm. 19), ZfP 1981, S. 239, 250. Von Interesse ist insoweit auch der aktuelle Bildungsbericht 2012, der erstmals auch die Bildung von Kindern in der Familie in den Blick nimmt (BT-Drucks. 17/11465, S. 47 f.): „Während in den letzten Bildungsberichten die frühkindliche Bil- 
Zudem bleibt erklärungsbedürftig, warum für Kinder zwischen drei und sechs Jahren, die in Kindergärten betreut und drei Jahre lang für die Schule „,fit“ gemacht werden könnten - immerhin mehr als $93 \%$ aller Kinder dieser Altersgruppe in Deutschland (und $87 \%$ der Kinder mit Migrationshintergrund) ${ }^{159}$-, keine fruchtbaren Förderprogramme zur Verfügung stehen. ${ }^{160}$ Mit solchen Programmen könnten fast $90 \%$ der Kinder mit Migrationshintergrund bzw. aus bildungsfernen Elternhäusern vor Schulbeginn im Kindergarten sprachlich gefördert werden, zumal einschlägige Studien zu dem Ergebnis kommen, dass das letzte Kindergartenjahr auf den Schulerfolg Einfluss nehmen kann, während es für die Betreuung im Kleinkindalter keine entsprechenden (breit angelegten) Untersuchungen gibt. ${ }^{161}$

Wie wenig sich die frühkindliche Betreuung auf die schulischen Leistungen auswirkt, zeigt im Übrigen ein Blick auf die Kompetenzen der deutschen Schüler im Vergleich der Bundesländer. Obwohl die Kinder in den neuen Bundesländern seit Jahrzehnten in signifikant höherem Maße bereits im Kleinkindalter fremdbetreut werden, fallen die Kompetenzen dort nicht generell besser aus. ${ }^{162}$ Seit Jahren sind vier Bundesländer immer auf den ersten Plätzen, nämlich Baden-Württemberg und Bayern einerseits sowie Sachsen und Thüringen an-

dung in Tageseinrichtungen und Tagespflege im Zentrum stand, werden hier erstmals auch Lern- und Entwicklungsprozesse in der Familie einbezogen. [...] Die Familie spielt als primäre Sozialisationsinstanz und als Ort der Bildung eine zentrale Rolle für den Verlauf der Bildungsbiographie. Dies trifft in besonderer Weise auf die frühe Kindheit zu, gilt aber für das gesamte Kindes- und Jugendalter. [...] In der Familie werden nicht nur wesentliche basale Kompetenzen und Vorläuferfähigkeiten vermittelt, es finden [...] auch unterschiedliche Bildungsprozesse statt, die langfristig die Bildungsmotivation und -chancen der Kinder erheblich beeinflussen."

159 Statistisches Bundesamt (Hrsg.), Kindertagesbetreuung in Deutschland 2012, S. 11 f., 17 (für 2012).

160 Vgl. nur Textor (Anm. 147): „Auch Untersuchungen über die Entwicklung von Kindergartenkinder fehlen in Deutschland weitgehend. Die einzige deutsche Längsschnittstudie, die sich auf 422 Kinder aus 103 Kindergartengruppen in fünf Bundesländern bezog [...] ergab u.a., dass die pädagogische Qualität im Durchschnitt mittelmäßig war und zwischen den einzelnen Kindergärten stark variierte: Die Entwicklungsunterschiede bei Kindern, die auf die Qualität zurückgeführt werden konnten, entsprachen im Extremfall einem Altersunterschied von einem Jahr."

161 So Brünnagel/Henman (Anm. 148), Wirtschaftsdienst 2007, S. 309, 310 m.w.N.

162 Vgl. nur PISA-Konsortium Deutschland, PISA 2006 in Deutschland, Die Kompetenzen der Jugendlichen im dritten Ländervergleich, Zusammenfassung, 2008 (http:// www.pisa.ipn.uni-kiel.de/Zusfsg_PISA2006_national.pdf); Petra Stanat/Hans Anand Pant/Katrin Böhme/Dirk Richter (Hrsg.), Kompetenzen von Schülerinnen und Schülern am Ende der vierten Jahrgangsstufe in den Fächern Deutsch und Mathematik, Ergebnisse des IQB-Ländervergleichs 2011, 2012, S. 104, 106, 118 f. (http://www.iqb. hu-berlin.de/laendervergleich/LV2011/Bericht). 
dererseits. ${ }^{163}$ Nur am Rande sei erwähnt, dass ausgerechnet diese vier Länder seit rund zwei Jahrzehnten zunächst im Anschluss an das Bundeserziehungsgeld und seit $2007 \mathrm{im}$ Anschluss an das Elterngeld Landeserziehungsgeld gewähren und daher nach der von den Gegnern eines Betreuungsgeldes vorgetragenen Argumentation (das Betreuungsgeld verhindere die notwendige frühkindliche Bildung außerhalb der Familie) ${ }^{164}$ deutlich schlechter als andere Bundesländer abschneiden müssten. Auch wenn hier nicht behauptet werden soll, dass die durch die Gewährung von Landeserziehungsgeld in den genannten vier Bundesländern geförderte längere Betreuung der Kinder durch die Eltern die Ursache für bessere Schulerfolge ist, so lässt sich jedenfalls die These, dass eine längere Betreuung durch die Eltern zwangsläufig in einer ,,bildungspolitischen Katastrophe“" ende, nicht halten. ${ }^{165}$

Während positive Effekte frühkindlicher Fremdbetreuung in sämtlichen staatlichen Kampagnen besonders stark gemacht werden und das verwendete Vokabular (,frühkindliche Bildung“, „frühe Chancen“, „,Grundstein für den späteren Erfolg in Bildung und Beruf" usw.) ausschließlich positiv besetzt ist, werden Informationen in Bezug auf mögliche negative Folgen der Kleinkindbetreuung, insbesondere wissenschaftliche Studien, die vor einer zu frühen und zu langen Fremdbetreuung warnen, verschwiegen. Dies deutet darauf hin, dass Kinder und deren Wohl im Rahmen der neuen Familienpolitik nur insofern Platz haben, als es um eine Steigerung ihrer (schulischen) Leistungen geht. Darüber hinaus erweckt die Einseitigkeit sämtlicher Informationskampagnen den Eindruck einer gezielten Desinformationspolitik. ${ }^{166}$

163 PISA-Konsortium Deutschland, PISA 2003: Ergebnisse des zweiten Ländervergleichs, Zusammenfassung, 2005, S. 6 f., 9, 11, 13, 15 f., 38 (http://www.pisa.ipn.uni-kiel.de/ PISA2003_E_Zusammenfassung.pdf); ebenfalls beruhend auf der PISA-Studie 2003: http:// www.unicef.de/fileadmin/content_media/presse/fotomaterial/Kinderarmut/Grafik_3.pdf.

164 Die aktuelle Diskussion um das Betreuungsgeld zeigt zudem in aller Deutlichkeit, dass es längst nicht mehr primär darum geht, sämtliche Familien bei dem jeweils gewählten Modell der Vereinbarkeit von Familie und Beruf zu unterstützen, sondern klare Vorgaben für das ,richtige“"Familienleben zu machen.

165 So vor allem die Äußerungen der Opposition im Vorfeld der Einführung des Betreuungsgeldes, vgl. nur BT-Drucks. 17/1579, S. 1 (BÜNDNIS 90/DIE GRÜNEN): „Gerade für bildungsferne und zugleich einkommensschwache Eltern bietet das Betreuungsgeld einen starken Anreiz, ihren Kindern frühe Förderangebote in einer Kinderbetreuungseinrichtung vorzuenthalten und sich stattdessen für die Auszahlung einer Geldleistung zu entscheiden. [...] Das wäre eine bildungspolitische Katastrophe!" Vgl. weiter BTDrucks. 17/8201, S. 5 (SPD). Vgl. auch jüngst BT-Drucks. 17/9165 (BÜNDNIS 90/ DIE GRÜNEN).

166 Zur Einseitigkeit der Informationspolitik vgl. auch RaInER BöHM, Die dunkle Seite der Kindheit, FAZ vom 4. April 2012, S. 7. Zur Beurteilung dieser Politik in Bezug auf die Lebensbedingungen von Kindern vgl. die UNICEF-Studie von BERTram/KoHL (Anm. 147), S. 33: „Auch die jüngsten Veränderungen in der Familienpolitik durch 
Bei den ,,verschwiegenen“ Informationen handelt es sich um ein Bündel von möglichen Negativeffekten, die für die von den Eltern zu entscheidende Frage, ab wann, wo und in welchem Umfang ihr Kleinkind außerfamiliär betreut wird, von erheblicher Bedeutung sein dürften. So sollte das Verhältnis von Betreuer zu Kind für unter Dreijährige bei maximal 1 : 3 liegen, ${ }^{167}$ sodass eine Betreuung durch eine Tagespflegeperson zunächst attraktiver erscheint als eine Betreuung in einer Krippe, wo derzeit fast vier Kinder (Westdeutschland) bzw. fast sechs Kinder (Ostdeutschland) unter drei Jahren auf eine Erzieherin kommen. ${ }^{168}$ Allerdings betreuen Tagespflegepersonen zwar durchschnittlich nur drei Kinder; mehr als ein Viertel aller Tagespflegepersonen betreut jedoch fünf Kinder. ${ }^{169}$ Hinzu kommt,

Renate Schmidt und Ursula von der Leyen wären nicht möglich gewesen, wenn nicht gleichzeitig in der Öffentlichkeit ein Meinungsklima entstanden wäre - auch glaubwürdig vertreten durch die Politik - dass sich die außerfamiliäre Betreuung von Kindern unter drei Jahren positiv auf die kindliche Entwicklung auswirken kann und zugleich die Mütter, die sich so entschieden, das Gefühl vermittelt bekamen, sich auch im Interesse ihrer Kinder richtig zu entscheiden. “ An diesem Beispiel werde deutlich, „,dass Indikatoren, die diese subjektiven Komponenten“ (wie „Emotionen“ oder „,das Gefühl geliebt zu werden“ usw.) „nicht mitberücksichtigen, ungeeignet [seien], um wissenschaftliche Politikberatung zur positiven Entwicklung der Teilhabechancen von Kindern in der Gesellschaft zu ermöglichen“".

167 In Ulrike Horacek/Rainer Böhm/Renate Klein/Ute Thyen/Frank Wagner, Positionspapier der Deutschen Gesellschaft für Sozialpädiatrie und Jugendmedizin (DGSPJ) zu Qualitätskriterien institutioneller Betreuung von Kindern unter 3 Jahren (Krippen), in: Martin R. Textor (Hrsg.), Kindergartenpädagogik - Online-Handbuch (http://www. kindergartenpaedagogik.de/1897.html) wird folgende Empfehlung der Fachgesellschaft abgegeben: „für Säuglinge von 9 bis 12 Monaten: 1 Betreuerin für maximal 2 Kinder; für Kinder von 12 bis 24 Monaten: 1 Betreuerin für maximal 3 Kinder; für Kinder von 24 bis 36 Monaten: 1 Betreuerin für maximal 4 Kinder." Vgl. weiter die vom Österreichischen Institut für Familienforschung der Universität Wien in Auftrag gegebene Studie (http://www.oif.ac.at/fileadmin/OEIF/Working_Paper/wp_72_ausserfamiliale_ kinderbetreuung.pdf) von Sabine Buchebner-Ferstl/Sonja Dörfler/Michael Kinn, Kindgerechte außerfamiliale Kinderbetreuung für unter 3-Jährige, 2009, S. 37: „Demgemäß wäre für Krippen ein optimaler Betreuungsschlüssel von 1 (Betreuerin) : 3 (Kindern) einzufordern [...]. “ Ähnlich Theresia Herbst, Bindung und Bildung, Psychologie in Österreich 2012, S. 436, 444 (,Betreuer-Kind-Verhältnis von $1: 2$ bis maximal $1: 3$ für Kinder unter drei Jahren“). Hinzu kommt, dass Kleinkinder in der Eingewöhnungsphase einer besonders intensiven Begleitung durch die Erzieherinnen bedürfen; vgl. dazu die Leiter der Wiener Kinderkrippenstudie Maria Fürstaller/Antonia Funder/ Wilfried Datler, Wenn Tränen versiegen, doch Kummer bleibt, Über Kriterien gelungener Eingewöhnung in die Kinderkrippe, frühe Kindheit 2011, Heft 1 (http://ligakind.de/fruehe/111_datler.php).

168 Hinzu kommt erschwerend, dass von der Arbeitszeit der Erzieherinnen noch die Verfügungszeiten von $25 \%$ der Arbeitszeit abgezogen werden müssen (Dritter Zwischenbericht zur Evaluation des Kinderförderungsgesetzes, BT-Drucks. 17/9850, S. 43 f.).

169 Dritter Zwischenbericht zur Evaluation des Kinderförderungsgesetzes, BT-Drucks. 17/9850, S. 26. 
dass Tagespflegepersonen im Durchschnitt deutlich schlechter qualifiziert sind als Fachkräfte in Kindertageseinrichtungen; lediglich 32 \% der 2011 tätigen Tagespflegepersonen hatten eine pädagogische Ausbildung. ${ }^{170}$

Zudem belegt eine breit angelegte Studie des US-amerikanischen National Institute of Child Health and Human Development, dass unabhängig von der Qualität der außerfamiliären Betreuung von Kleinkindern negative Effekte im Bereich der sozio-emotionalen Entwicklung wahrscheinlich sind. ${ }^{171}$ Den leicht positiven Effekten auf die kognitive Entwicklung (bei einer vorausgesetzten hohen Qualität der außerfamiliären Betreuung) müssen somit negative Effekte aufgrund fehlender Bindung gegenüber gestellt werden. ${ }^{172}$ Zur derzeitigen Betreuungsqualität in Deutschland hat die 107. Jahrestagung der Deutschen Gesellschaft für Kinder- und Jugendmedizin e.V. (DGKJ) folgende Stellungnahme abgegeben:

„Die aktuell in Deutschland im U3-Bereich vorzufindenden Qualitätsniveaus liegen praktisch ausschließlich im niedrigen bis mittleren Bereich, was nicht nur in der konkreten Umsetzung begründet ist, sondern bereits in ungenügenden gesetzlichen Vorgaben. Durch diese Ausgestaltung der Betreuung sind aus kindlicher Perspektive in der Tendenz leicht negative und keine positiven Effekte zu erwarten. Es gibt ferner Hinweise, dass niedrige bis mittlere Betreuungsqualität sich auch negativ auf Verhalten und Befinden berufstätiger Eltern von U3-betreuten Kindern auswirkt." ${ }^{173}$

$1709 \%$ der Tagespflegepersonen besitzen keine formale Qualifikation, $33 \%$ haben einen Qualifikationskurs mit weniger als 160 Stunden absolviert und $26 \%$ haben nur an der empfohlenen Mindestqualifizierung von Tagespflegepersonen nach dem DJI-Curriculum im Umfang von 160 Stunden teilgenommen; Dritter Zwischenbericht zur Evaluation des Kinderförderungsgesetzes, BT-Drucks. 17/9850, S. 27, 34 ff., insb. S. 36. Vgl. auch Nationaler Bildungsbericht 2012, BT-Drucks. 17/11465, S. 60, 66.

171 Dazu Böнм (Anm. 149), Kinderärztliche Praxis 82 (2011), S. 316 f.: In Abhängigkeit vom zeitlichen Umfang der außerfamiliären Betreuung der Kinder zeigten diese später „dissoziales Verhalten“ („Streiten, Kämpfen, Sachbeschädigungen, Prahlen, Lügen, Schikanieren, Gemeinheiten begehen, Grausamkeit, Ungehorsam, häufiges Schreien“). „Bei den mittlerweile 15-jährigen Jugendlichen ergibt sich eine Verschiebung der Auffälligkeiten hin zu vermehrt impulsivem und risikoreichem Verhalten (Alkohol, Rauchen, Drogen, Waffengebrauch, Stehlen, Vandalismus)." Vgl. weiter Textor (Anm. 147).

172 Dass dies regelmäßig nicht geschieht, mag auch daran liegen, dass Bildung und Bindung unterschiedlichen Forschungszweigen zugeordnet sind. Vgl. weiter Herbst (Anm. 167), Psychologie in Österreich 2012, S. 436, 437 ff.: „Die frühe Bildung findet in der Interaktion [des Kleinkindes] mit seinen Bindungspersonen statt“ (S. 439). Zudem bringe die zunehmende „Gleichaltrigenorientierung“ ab der Krippe ,viele negative Effekte mit sich“ (S. 441): „Ohne die schützende Elternbindung seien Kinder potentiell gefährdeter, Mobbingopfer zu werden. Es leide die vertikale Kultur- und Wertevermittlung, wenn Kinder und Jugendliche überwiegend voneinander annehmen, was sie selbst können. Sie übertragen sich ihr unreifes Verhalten, ihre Wünsche, Motive, ihre fragmentierte Sprache usw."

173 Abstracts der 107. Jahrestagung der Deutschen Gesellschaft für Kinder- und Jugendmedizin e.V. (DGKJ), Monatsschrift Kinderheilkunde Supplement 3, 2011, S. 141, 
Obwohl auch dem Gesetzgeber diese Informationen bekannt sind, ${ }^{174}$ werden Eltern in den breit angelegten Werbekampagnen nicht auf diese möglichen negativen Effekte aufmerksam gemacht. ${ }^{175}$

Insgesamt lassen sich somit im Hinblick auf die Etablierung des Leitbildes der Zwei-Erwerbstätigen-Familie durch edukatorisches Staatshandeln drei Effektverstärkungen feststellen: erstens eine Kumulation von Edukationseffekten durch das Zusammenwirken mehrerer Gesetze, zweitens eine Intensivierung der Wirkung dieser Gesetze durch breit angelegte staatliche Informations- und Werbekampagnen und drittens eine Verstärkung der bezweckten Effekte durch gezielte Desinformation (einseitig ausgewählte und unvollständige Informationen) im Rahmen dieser Kampagnen.

142. Dort heißt es weiter: „Gegenüber Einrichtungen mit geringerer Qualität verbessert hohe Qualität einerseits etwas die späteren Lernleistungen. Andererseits kann hohe Qualität das Auftreten expansiven Problemverhaltens sowie unerwünschter Veränderungen des Cortisolprofils, die mit zunehmender Besuchsdauer von U3-Gruppenbetreuung auftreten, und das damit verbundene Risiko für die langfristige psychische Entwicklung nicht aufheben.“ Empfohlen wird daher, dass „elterliche Erziehung besonders in den ersten drei Lebensjahren unterstützt und gefördert" wird.

174 Vgl. nur Deutscher Bundestag, Ausschuss für Familie, Senioren, Frauen und Jugend, 74. Sitzung, Öffentliche Anhörung zu dem Entwurf eines Gesetzes zur Einfuihrung eines Betreuungsgeldes, Protokoll Nr. 17/74, S. 18 f., 50 ff.; Stellungnahme Rainer BöHm, Ausschussdrucksache 17(13)188d.

175 Zwar wird im Achten Familienbericht von 2012 nun erstmals nicht nur auf Chancen, sondern auch auf Risiken außerfamiliärer Betreuung für Kleinkinder hingewiesen, jedoch ist diese Information bislang nicht breit an die Öffentlichkeit weitergegeben worden; Achter Familienbericht, BT-Drucks. 17/9000, S. 75 ff. unter der Überschrift „Die Effekte außerfamiliärer Betreuung: Chancen und Risiken für Kinder“: „Die Forschungsresultate zu den Effekten institutioneller Kinderbetreuung sind nicht eindeutig. Die Mehrzahl der hauptsächlich im US-amerikanischen Raum durchgeführten Studien deutet auf eine positive Wirkung der frühkindlichen Kinderbetreuung auf kognitive und sprachliche Fähigkeiten [...] und gleichzeitig auf negative Auswirkungen auf soziale Kompetenzen hin. [...] Eine Metaanalyse zur Aufnahme von Erwerbsarbeit durch Mütter in den ersten drei Lebensjahren des Kindes (69 Studien aus den Jahren 1960 bis 2010) kommt zu dem Schluss, dass Kinder, deren Mütter schon vor dem dritten Lebensjahr an den Arbeitsplatz zurückkehren, später nicht häufiger Schul- oder Verhaltensprobleme zeigen als Kinder, deren Mütter zu Hause bleiben. [...] Andere Analysen zeigen jedoch, dass die Berufstätigkeit der Mütter mit negativen Entwicklungsergebnissen des Kindes zusammenhängt, wenn die Familien nicht in ökonomisch belastenden Situationen sind (Mittel- und Oberschichtfamilien). [...] Dem Kind entgeht also durch die außerfamiliäre Betreuung die Bildung und Erziehung durch eine gut gebildete und erziehungskompetente Mutter. Dieser Befund deckt sich mit Studien, nach denen Kinder aus niedrigen sozioökonomischen Lebenslagen am meisten von der Bildungsanregung der Kindertageseinrichtungen profitieren, jedoch auch nur dann, wenn diese eine gute Qualität aufweisen. Für Kinder aus der Mittel- und Oberschicht bleibt das Bildungsangebot in den Kindertageseinrichtungen hinter der familiären Bildungsanregung zurück." 
Dass dieses Bündel edukatorischer Maßnahmen einen Eingriff in die durch Art. 6 Abs. 1 und 2 GG geschützte Wahlfreiheit der Eltern darstellt, ist angesichts der ständigen Rechtsprechung des BVerfG zur Wahlfreiheit und zum staatlichen Neutralitätsgebot ohne Zweifel zu bejahen, ${ }^{176}$ zumal die Garantie der Wahlfreiheit auch beinhaltet, dass die Entscheidung für ein bestimmtes Familienmodell frei getroffen werden kann und nicht durch sachlich unrichtige und unvollständige staatliche Informationen manipuliert wird. Eine verfassungsimmanente Rechtfertigung eines solchen Eingriffs durch Art. 3 Abs. 2 S. 2 GG (wie ihn das BVerfG in seiner Entscheidung zu den Vätermonaten nahegelegt hat) ${ }^{177}$ ist nicht schon dann gegeben, wenn das vorliegende staatliche Handeln geeignet ist, die Gleichberechtigung der Geschlechter in der Gesellschaft durchzusetzen und die überkommene Rollenverteilung zu überwinden, ${ }^{178}$ denn das Grundgesetz geht davon aus, dass der Schutz von Ehe

176 BVerfGE 6, S. 55, 81 f.; BVerfGE 10, S. 59, 84 ff.; BVerfG NJW 1984, S. 1523; BVerfGE 87, S. 234, 258 f. Der Staat muss danach die unterschiedlichen Lebensentwürfe in der Familie respektieren und Rahmenbedingungen schaffen, damit die jeweiligen Entwürfe auch gelebt werden können. So ausdrücklich BVerfGE 99, S. 216, 231, 234: „Art. 6 Abs. 1 GG garantiert als Abwehrrecht die Freiheit, über die Art und Weise der Gestaltung des ehelichen und familiären Zusammenlebens selbst zu entscheiden [...]. Deshalb hat der Staat die Familiengemeinschaft sowohl im immateriell-persönlichen als auch im materiell-wirtschaftlichen Bereich in ihrer jeweiligen eigenständigen und selbstverantwortlichen Ausgestaltung zu respektieren [...]. Demgemäß dürfen die Eltern ihr familiäres Leben nach ihren Vorstellungen planen und verwirklichen und insbesondere in ihrer Erziehungsverantwortung entscheiden, ob und in welchem Entwicklungsstadium das Kind überwiegend von einem Elternteil allein, von beiden Eltern in wechselseitiger Ergänzung oder von einem Dritten betreut werden soll. [...] Neben der Pflicht, die von den Eltern im Dienst des Kindeswohls getroffenen Entscheidungen anzuerkennen und daran keine benachteiligenden Rechtsfolgen zu knüpfen, ergibt sich aus der Schutzpflicht des Art. 6 Abs. 1 GG auch die Aufgabe des Staates, die Kinderbetreuung in der jeweils von den Eltern gewählten Form in ihren tatsächlichen Voraussetzungen zu ermöglichen und zu fördern. [...] Der Staat hat dementsprechend dafür Sorge zu tragen, daß es Eltern gleichermaßen möglich ist, teilweise und zeitweise auf eine eigene Erwerbstätigkeit zugunsten der persönlichen Betreuung ihrer Kinder zu verzichten wie auch Familientätigkeit und Erwerbstätigkeit miteinander zu verbinden." Zur Wahlfreiheit vgl. auch Matthias Pechstein, Familiengerechtigkeit als Gestaltungsgebot für die staatliche Ordnung, Zur Abgrenzung von Eingriff und Leistung bei Maßnahmen des sog. Familienlastenausgleichs, 1994, S. 195 ff.; Stefan Huster, Die Unterscheidung von politischen Zielen und verfassungsrechtlichen Argumenten, Eine Untersuchung am Beispiel des Ehe- und Familienschutzes im deutschen Verfassungsrecht, in: Christian Hiebaum/Peter Koller (Hrsg.), Politische Ziele und juristische Argumentation, 2003, S. 47, 49 f., 57 ff., 61 ff.; Ders. (Anm. 74), S. 529 ff.; Schumann (Anm. 83), S. 444, 479 ff. jeweils m.w.N.

177 BVerfG FamRZ 2011, S. 1645, 1646 f.

$178 \mathrm{Ob}$ die vorliegenden Maßnahmen zur Überwindung der traditionellen Rollenverteilung überhaupt geeignet sind, muss allerdings bezweifelt werden. Denn durch die vorlie- 
und Familie (gerade auch unter Beachtung der Wahlfreiheit der Eltern und des Neutralitätsgebots des Staates) und der Gestaltungsauftrag des Art. 3 Abs. 2 S. 2 GG zwei gleichrangige Prinzipien sind, die bezogen auf die Vereinbarkeit von Familie und Beruf nicht in Widerspruch stehen müssen ${ }^{179}$ und jedenfalls in einen Ausgleich zu bringen sind. ${ }^{180}$ Daher ist $\mathrm{zu}$ fragen, ob im vorliegenden

gende Einschränkung der Wahlfreiheit sind zwar überwiegend Mütter, aber auch alle kinderbetreuenden Väter betroffen. Der Gesetzgeber will auch nicht mehr Männer zu „Hausmännern“" machen (also gleichsam die Rollen tauschen) oder sie dazu bringen, die Familienarbeit mit der Mutter gleichmäßig zu teilen, vielmehr möchte er erreichen, dass betreuende Eltern ihre Kinder möglichst früh außerfamiliär betreuen lassen und die Unterbrechung der Erwerbstätigkeit möglichst kurz halten. Eine rein formale „Gleichstellung" soll somit unter Missachtung des Wertes der Familienarbeit und der Betreuung der eigenen Kinder dadurch erreicht werden, dass Eltern Familienaufgaben erheblich einschränken. Im Übrigen impliziert diese Auffassung des Gesetzgebers, dass die Familienarbeit, insbesondere die Betreuung von Kindern, ein „bestehender Nachteil“ im Sinne von Art. 3 Abs. 2 S. 2 GG ist, den es zu beseitigen gilt.

179 Etwa BVerfGE 88, S. 203, 260 f.: „Der [...] Schutzauftrag für Ehe und Familie (Art. 6 GG) und die Gleichstellung von Mann und Frau in der Teilhabe am Arbeitsleben [...] verpflichten den Staat und insbesondere den Gesetzgeber, Grundlagen dafür zu schaffen, daß Familientätigkeit und Erwerbstätigkeit aufeinander abgestimmt werden können und die Wahrnehmung der familiären Erziehungsaufgabe nicht zu beruflichen Nachteilen führt. Dazu zählen auch rechtliche und tatsächliche Maßnahmen, die ein Nebeneinander von Erziehungs- und Erwerbstätigkeit für beide Elternteile ebenso wie eine Rückkehr in eine Berufstätigkeit und einen beruflichen Aufstieg auch nach Zeiten der Kindererziehung ermöglichen. [...] Weiter hat der Staat dafür zu sorgen, daß ein Elternteil, der sich unter Verzicht auf Erwerbseinkommen der Erziehung eines Kindes widmet, für die ihm hieraus erwachsenden versorgungsrechtlichen Nachteile eine angemessenen Ausgleich erhält.“ Ähnlich auch BVerfGE 105, S. 1, 10 f.: „Art. 6 Abs. 1 in Verbindung mit Art. 3 Abs. 2 GG schützt die Ehe als eine Lebensgemeinschaft gleichberechtigter Partner [...], in der die Ehegatten ihre persönliche und wirtschaftliche Lebensfuhrung in gemeinsamer Verantwortung bestimmen [...]. Zur selbstverantwortlichen Lebensgestaltung gehören neben der Entscheidung, ob die Ehegatten Kinder haben wollen, insbesondere auch die Vereinbarung über die innerfamiliäre Arbeitsteilung und die Entscheidung, wie das gemeinsame Familieneinkommen durch Erwerbsarbeit gesichert werden soll. [...] Dabei steht es den Ehepartnern frei, ihre Ehe so zu führen, dass ein Ehepartner allein einer Berufstätigkeit nachgeht und der andere sich der Familienarbeit widmet, ebenso wie sie sich dafür entscheiden können, beide einen Beruf ganz oder teilweise auszuüben und sich die Hausarbeit und Kinderbetreuung zu teilen oder diese durch Dritte durchführen zu lassen." Vgl. auch schon BVerfGE 3, S. 225, $241 \mathrm{f}$.

180 Zum Verhältnis von Art. 6 Abs. 1 GG und Art. 3 Abs. 2 GG vgl. auch Huster (Anm. 74), S. 537 ff., insb. S. 547 f.; Peter Badura, in: Theodor Maunz/Günter Dürig (Begr.), Grundgesetz, Bd. 2, 66. Ergänzungslieferung 2012, Art. 6 GG Rn. 27 ff.; Arnd Uhle, in: Volker Epping/Christian Hillgruber (Hrsg.), Beck'scher Online-Kommentar GG, Edition 17, Stand 01.01.2013, Art. 6 GG Rn. 7; Christian Starck, in: Hermann von Mangoldt/Friedrich Klein/Christian Starck (Hrsg.), Kommentar zum Grundgesetz, Bd. 1, 6. Aufl. 2010, Art. 3 GG Rn. 309; Frauke Brosius-Gersdorf, Demografischer Wandel und Familienförderung, 2011, S. 365 ff. 
Bereich das mit Art. 3 Abs. 2 S. 2 GG verfolgte Ziel einer Überwindung der traditionellen Rollenverteilung in der Familie auch durch andere Maßnahmen, die in die Wahlfreiheit der Eltern weniger stark eingreifen, aber im Hinblick auf die Verwirklichung der Gleichberechtigung der Geschlechter genauso effektiv sind, zu erreichen wäre.

So heißt es beispielsweise im Achten Familienbericht (2012) zu den WunschArbeitszeiten von Müttern und Vätern:

„Beide Elternteile sind mit dieser Aufgabenverteilung nicht unbedingt zufrieden. Befragungen zu den tatsächlichen und gewünschten Arbeitszeiten zeigen immer wieder dieselbe Tendenz: Väter wollen den Umfang ihres zeitlichen Arbeitseinsatzes reduzieren und Mütter wünschen sich oft Arbeitszeitarrangements, die es ihnen ermöglichen, in der vollzeitnahen Teilzeit zu arbeiten. [...] Überwiegend bevorzugen Eltern eine flexible Gestaltung ihrer Arbeitszeiten. [...] Zwischen Familie, Beruf und Pflege kommt es oft zu subjektiv empfundener und objektiv belegbarer Zeitknappheit von Familienmitgliedern. Zwei Drittel der Väter und ein Drittel der Mütter haben zu wenig Zeit für ihre Kinder. Kinder nehmen diesen Mangel meist genauso wahr wie ihre Eltern." ${ }^{181}$

181 Achter Familienbericht, BT-Drucks. 17/9000, S. 45. Vgl. weiter S. 90: „Flexible Arbeitszeiten und entsprechende Arbeitskonten werden von Eltern als besonders bedeutsam für eine verbesserte Vereinbarkeit von Beruf und Familie erachtet. Dies gilt insbesondere für Führungskräfte [...]. Der Ravensburger Elternsurvey zeigt sehr deutlich, dass junge Eltern ein sequenzielles Modell der Erwerbstätigkeit präferieren, d.h. eine berufliche Aktivität, die sich während des Aufwachsens der Kinder zunächst so gestaltet, dass Raum für Zeit mit der Familie bleibt und sich allmählich ausweitet. Er widerspricht damit der teils geäußerten Vermutung, eine Vollzeittätigkeit beider Elternteile auch bei unter 3-Jährigen entspräche den Wunschvorstellungen der Mehrheit. So wünschen sich vor allem vollzeitarbeitende Väter eine Reduzierung ihrer Wochenarbeitszeit, während teilzeitarbeitende Mütter vielfach ihr Arbeitsvolumen aufstocken möchten [...]. Insgesamt bewegen sich die Arbeitszeitwünsche aufeinander zu und pendeln sich beim Modell einer, vollzeitnahen Teilzeit" [...] ein, d.h. etwa zwischen 25 und 35 Stunden." Dies bestätigt auch die neue Eltern-Studie „Wenn Eltern die Wahl haben“ vom 9. April 2013 (forsa, Familie und Wahl, Ergebnisbericht, 2013, S. 18, 20 f.; http://www.eltern.de/c/ images/pdf/forsa_ergebnisbericht\%202013.pdf): Danach bevorzugen $40 \%$ der Befragten „eine Arbeitsteilung zwischen Mann und Frau, bei der der Mann Vollzeit und die Frau Teilzeit arbeitet und sich vorrangig um Hausarbeit und Kinder kümmert. $38 \%$ präferieren die Variante, dass sowohl Mann als auch Frau die Arbeitszeit auf 30 Stunden pro Woche reduzieren und sich die Hausarbeit und die Kinderbetreuung gleichermaßen aufteilen. Dass beide Elternteile Vollzeit arbeiten und sich Hausarbeit und Kinderbetreuung gleichermaßen aufteilen, finden lediglich 13 Prozent eine gute Lösung. " Tatsächlich weichen die praktizierten Modelle von den bevorzugten Modellen zum Teil erheblich ab; so können derzeit nur $6 \%$ aller befragten Eltern das zweite Modell (beide Eltern arbeiten 30 Stunden und teilen Hausarbeit und Kinderbetreuung gleichermaßen auf) realisieren, wobei die Gründe für das Nicht-Praktizieren des Wunschmodells überwiegend ökonomischer Natur sind (zu geringes Einkommen, zu unterschiedliche Gehälter, Befürchtung von Nachteilen im Beruf oder für die Karriere) oder in den arbeitsrechtlichen Rahmenbedingungen liegen (fehlendes Einverständnis des Arbeitgebers). 
Würde der Gesetzgeber die Rahmenbedingungen entsprechend den Wünschen der Mehrzahl aller Eltern gestalten (anstatt ökonomische und bevölkerungspolitische Zielsetzungen in den Vordergrund zu stellen), ${ }^{182}$ so müssten Anreize gesetzt werden, dass die Wirtschaft für Männer und Frauen mehr vollzeitnahe Teilzeittätigkeiten mit flexibleren Arbeitszeiten schafft (zudem dürften solche Arrangements keine negativen Auswirkungen auf die Karriere haben). ${ }^{183}$ Da Eltern sich mehrheitlich solche Rahmenbedingungen wünschen, dürften die Effekte - wie im Übrigen auch die Entwicklung im Öffentlichen Dienst belegt ${ }^{184}$ - im Hinblick auf eine Überwindung überkommener Rollenverteilung mindestens genauso effektiv sein wie die derzeitigen Maßnahmen, die einseitig auf eine Vollerwerbstätigkeit beider Eltern nach kurzer Babypause und eine außerfamiliäre Betreuung von Kleinkindern abzielen. Die Förderung verschiedener Modelle einer Vereinbarkeit von Familie und Beruf würde zudem dem staatlichen Auftrag aus Art. 6 Abs. 1 und 2 GG deutlich besser gerecht. ${ }^{185}$

\section{Fazit}

Am Beispiel der Durchsetzung des neuen Familienleitbildes konnte gezeigt werden, wie im Rahmen edukatorischen Staatshandelns zur Erreichung eines Bewusstseinswandels Gesetzgebung und staatliche Informationssteuerung mit-

182 So auch Auth (Anm. 83), S. 81, 100; Seiler (Anm. 99), NVwZ 2007, S. 129, 133 f.

183 Auth (Anm. 83), S. 81, 87 ff. weist zudem darauf hin, dass die derzeitigen Rahmenbedingungen der neoliberalen Arbeitsmarktpolitik (Förderung eines Niedriglohnsektors, Abbau von Arbeitsschutzrechten, Reduzierung der sozialen Absicherung, fehlende finanzielle Planungssicherheit, die erwartete Bereitschaft zu nahezu grenzenloser räumlicher und zeitlicher Flexibilität) Rückwirkungen auf familiäre Entscheidungen hätten. Vgl. weiter Achter Familienbericht, BT-Drucks. 17/9000, S. 90 ff.

184 Dazu Ursula KöBl, Welche Maßnahmen empfehlen sich, um die Vereinbarkeit von Berufstätigkeit und Familie zu verbessern?, JZ 1994, S. 840, 845 ff.

185 Art. 6 Abs. 1 GG verpflichtet den Staat nämlich auch zur Schaffung von Rahmenbedingungen für eine Rückkehr in die Berufstätigkeit und einen Aufstieg nach Zeiten der Kindererziehung sowie zur Setzung von Anreizen zur Einrichtung flexibler Arbeitszeitmodelle, aber auch zur Anerkennung (und damit auch zur rechtlichen und ökonomischen Absicherung) des Wunsches von Eltern, bei der Versorgung der Familie (Kindererziehung) das Ernährer-Modell zu praktizieren. So ausdrücklich BVerfGE 88, S. 203, 260 f. (siehe oben Anm. 179). Unter den gewünschten familienpolitischen Maßnahmen nimmt die Gewährleistung von Wahlfreiheit einen hohen Stellenwert ein, wie die neuste Eltern-Studie „Wenn Eltern die Wahl haben“ vom 9. April 2013 zeigt (forsa, Familie und Wahl, Ergebnisbericht, 2013, S. 6; http://www.eltern.de/c/images/pdf/forsa_ergebnisbericht $\% 202013$.pdf): Danach sind $74 \%$ der Befragten der Ansicht, dass der Staat dafür zu sorgen habe, ,dass Familien die Möglichkeit haben, das Betreuungsmodell für ihre Kinder zu wählen, das am besten zu den eigenen Bedürfnissen passt“. 
einander kombiniert werden: So werden seit gut zehn Jahren staatliche Empfehlungen und Appelle dahingehend abgegeben, dass eine möglichst frühzeitige Entfamilisierung des Kindes gut sei für dessen Sozialisation und Bildung. Gleichzeitig werden vor allem die sogenannten bildungsfernen Schichten und Familien mit Migrationshintergrund stigmatisiert, weil diese (angeblich) ihren Kindern die frühkindliche Förderung und Sozialisation außer Haus vorenthalten, was zu kindlichen Fehlentwicklungen und sogar zu späterer Delinquenz führen könne.

Insgesamt wird Eltern vermittelt, dass sie sich bei Befolgung sämtlicher Zielvorgaben für das ,richtige“ Familienleben entscheiden, wobei sich der Staat insbesondere mit der Gewährung eines „Rechtsanspruchs“ auf einen Krippenplatz den Eltern als leistender und nicht als lenkender Staat präsentiert. Für Eltern, die dieses ,richtige“ Familienleben nicht praktizieren wollen, ist die aufgrund des bereits herbeigeführten gesellschaftlichen Erwartungsdrucks zu überwindende Schwelle besonders hoch, ${ }^{186}$ denn diese Erwartungshaltung erzeugt die soziale Pflicht, sich für ein (vermeintlich) an Gemeinwohlinteressen ausgerichtetes Familienleben zu entscheiden.

Sämtliche unter Ziff. II beschriebenen Gefahren edukatorischen Staatshandelns (staatliche Bewusstseinsbeeinflussung, Prägung von Werten und Menschenbildern durch den Staat, Meinungsbildungsprozess von oben nach unten, Manipulation durch Desinformation, Sozialkontrolle des Privaten, mangelnde Rechtsschutzmöglichkeiten bei ,weichem“ Staatshandeln, Aufhebung der Trennung von Recht und Moral) lassen sich somit anhand des gewählten Beispiels nachweisen.

Hinzu kommt, dass sich auch hier - wie auf den anderen Feldern edukatorischen Staatshandelns - die Frage aufdrängt, ob denn die staatliche Erziehung überhaupt das halten kann, was der Staat sich von ihr verspricht. Die von Seiten des Staates beanspruchte (den Eltern überlegene) Kompetenz erweist sich nämlich keineswegs als die für jede Familie und jedes Kind „richtige“ Lösung. Zudem stehen im Mittelpunkt dieser Familienpolitik nicht das Wohl der Kinder und die Wünsche ihrer Eltern, sondern (im Hinblick auf den besonderen staatlichen Schutz der Familie in Art. 6 Abs. 1 GG zweckfremde) ökonomische Interessen. ${ }^{187}$

$186 \mathrm{Zu}$ diesem Gedanken vgl. auch Lüdemann (Anm. 1), S. 104 ff., 123.

187 Darauf weisen Bertram/Kohl (Anm. 147), S. 32 f. in der neuesten UNICEF-Studie zur Lage der Kinder in Deutschland 2010 in aller Deutlichkeit hin. Die Verfasser der Studie gehen unter der Überschrift „Das Bild von Kindern in Wissenschaft und Politikberatung“ der Frage nach, ,warum bei der Diskussion um die Zukunft von Kindern und ihrer Teilhabemöglichkeiten in der Gesellschaft fast ausschließlich Aspekte der schulischen Leistungsfähigkeit oder der ökonomischen Benachteiligung thematisiert werden“. Dies habe „nicht nur damit zu tun, dass die Medien und die Politik sich nur für diese Dinge interessieren, sondern auch mit der Forschung selbst und mit der wissen- 
So konnte gezeigt werden, dass die positiven Effekte im Bereich der ,frühkindlichen Bildung“" von Ein- und Zweijährigen eher gering und nur bei sehr hoher Betreuungsqualität (die in Deutschland regelmäßig nicht vorliegt) zu erreichen sind. Im Hinblick auf Bildungserfolge wäre somit zu prüfen, ob die Effekte nicht größer wären, wenn die immensen staatlichen Subventionen in die Bildung etwas älterer Kindergartenkinder bzw. in die gezielte Förderung von leistungsschwachen Schulkindern investiert würden. ${ }^{188}$ Es konnte weiter gezeigt werden, dass der Vorwurf, bildungsferne Familien und Migrantenfamilien würden ihren Kindern frühkindliche Bildungsangebote vorenthalten, völlig haltlos ist und $\mathrm{zu}$ einer höchst bedenklichen Stigmatisierung dieser Familien führt (die sich inzwischen sogar in Forderungen nach Gutscheinen statt Geldleistungen niederschlägt und Ausdruck eines nicht gerechtfertigten Misstrauens

schaftlichen Politikberatung in Deutschland und Europa“, wobei die Verfasser für diese Entwicklung vor allem die von der OECD geförderten internationalen Vergleichsstudien in der pädagogischen Forschung verantwortlich machen. So sei es irritierend, „dass die OECD in ihrer jüngst vorgelegten Studie zum kindlichen Wohlbefinden zwar die ökonomische Situation der Kinder, ihre Wohnungssituation und Bildungssituation, ihre Gesundheit und Sicherheit erfasst, aber ausgerechnet die Beziehungen zu Freunden und zu den Eltern und die Erfragung des subjektiven Wohlbefindens der Kinder aus dem Indikatorentableau ausschließt“. Damit befinde sich die OECD ,in klarem Widerspruch zur UNO-Kinderrechtskonvention [...], die explizit die Kinder selbst und ihre eigene Lebenseinschätzung des eigenen Wohlbefindens als Indikator der Verwirklichung der Kinderrechte betont“. Die Beziehungen zu den Eltern stellten einen ,zentralen Bestandteil verschiedener Artikel der Kinderrechtskonvention dar“. Zudem stelle ,sich die OECD in diesem Punkt in einen klaren Widerspruch zur Amerikanischen Akademie der Wissenschaften, die gerade die Bedeutung der Beziehungen der Kinder zu ihren Eltern als ein wichtiges Element der kindlichen Entwicklung" betone. Die OECD unterstelle mit dem von ihr gezeichneten „ökonomistische[n] Menschenbild“, „dass Kinder in ihrer Entwicklung mehr oder minder dem Modell des ,homo oeconomicus" folgen“" und gehe „davon aus, dass die Kinder bei entsprechenden positiven Umweltanreizen den vorgegebenen gesellschaftlichen Zielen folgen“, während „Emotionen und Gefühle, subjektive Einschätzungen, das Gefühl, Teil der Gesellschaft zu sein, oder das Gefühl geliebt zu werden [...], bei dieser Betrachtung nicht“ vorkämen. „Ohne die Einbeziehung der subjektiven Reaktionen von Kindern und Jugendlichen auf ihre Stellung in der Gesellschaft, auf ihre persönliche Einschätzung von Schule, Freundschaften und Familienbeziehungen, [werde] das Kindeswohl verkürzt auf eine Verengung der wohlfahrtsstaatlichen Perspektive“.

188 Wie gering die gezielte Unterstützung von Schulkindern berufstätiger und/oder bildungsferner Eltern bei den Hausaufgaben ausfältt, belegen die aktuellen Zahlen zu den Plätzen in der Hortbetreuung von Schulkindern bis zum Alter von 14 Jahren: Während für Kinder unter drei Jahren (und damit im Wesentlichen für zwei Jahrgänge) 780.000 Plätze bis 2013 geschaffen wurden, stehen derzeit für acht Jahrgänge von Schulkindern im Alter von 6 bis 14 Jahren insgesamt 440.000 Hortplätze deutschlandweit zur Verfügung; dazu Kirsten Fuchs-Rechlin, Es wird eng - zur aktuellen Dynamik der Kitas, Kommentierte Daten der Kinder- und Jugendhilfe, 2011, Heft 3, S. 1, 2 f. 
ist). ${ }^{189}$ Schließlich wird die im Hinblick auf mögliche negative Effekte der auBerfamiliären Betreuung unter Dreijähriger (bezogen auf die sozioemotionale Entwicklung) ausgesprochene Empfehlung der Deutschen Gesellschaft für Kinder- und Jugendmedizin, dass ,elterliche Erziehung besonders in den ersten drei Lebensjahren unterstützt und gefördert werden " sollte, ${ }^{190}$ weitgehend ignoriert.

Bedenklich ist schließlich auch die Herabsetzung des Wertes von Familienarbeit, denn ohne die innerhalb der Familie täglich erbrachten (regelmäßig unbezahlten) Erziehungs- und Pflegeleistungen würde der Sozialstaat kollabieren. Dies gilt sowohl für die Betreuung von Kleinkindern, die bei einer außerfamiliären Betreuung das Drei- bis Vierfache der familiären Betreuung kostet (und die bei einer außerfamiliären Betreuung aller Kinder unter drei Jahren zusätzlich 12 Mrd. Euro jährlich an reinen Betriebskosten verursachen würde), als auch für die Pflege von Angehörigen, deren Wert derzeit mindestens $44 \mathrm{Mrd}$. Euro jährlich beträgt. ${ }^{191}$ Bei einem Bundeshaushalt von ca. 300 Mrd. Euro würde ein Weg-

189 Dass deutsche Eltern „,relativ viel in Bildungsgüter für ihre Kinder zu investieren“ scheinen, heben die Verfasser der UNICEF-Studie zur Lage der Kinder in Deutschland 2010, Bertram/Kohl (Anm. 147), S. 15, auch deshalb besonders hervor, ,,weil in der öffentlichen Debatte häufig der Eindruck entsteh[e], dass die Eltern die finanziellen Unterstützungsleistungen nicht für ihre Kinder, sondern für ihre eigenen Bedarfe verwenden“. Insgesamt seien in Deutschland, ,die familiären Investitionen in Bildungsgüter aus der Sicht der Kinder besser als in anderen europäischen Ländern“.

190 Abstracts der 107. Jahrestagung der Deutschen Gesellschaft für Kinder- und Jugendmedizin e.V. (DGKJ), Monatsschrift Kinderheilkunde Supplement 3, 2011, S. 141, 142. Vgl. weiter BöHm (Anm. 149), Kinderärztliche Praxis 82 (2011), S. 316, 321: „Die derzeitigen Planungen zum Krippenausbau sind vor allem von ökonomischen Aspekten bestimmt und ignorieren weitgehend gesundheitliche Aspekte. Für eine gesunde Entwicklung brauchen Kinder jedoch besonders in den ersten 3 Lebensjahren die Liebe und die Zeit ihrer Eltern."

191 Achter Familienbericht, BT-Drucks. 17/9000, S. 100: „Es wird geschätzt, dass der Umfang der familiären Pflegearbeit ca. 3,2 Millionen Erwerbsarbeitsplätzen bzw. einer Wertschöpfung von ca. 44 Mrd. Euro pro Jahr entspricht, wenn ein mittleres Lohnniveau unterstellt wird." Der Familienbericht bezieht sich hier auf die Studie von GERtrud M. Backes/Ludwig Amrhein/Martina Wolfinger, Gender in der Pflege, Herausforderungen für die Politik, Expertise im Auftrag der Friedrich-Ebert-Stiftung, 2008, S. 3, in der es weiter zur häuslichen Pflege heißt: „Die Absicherung für diese Arbeit ist völlig unzureichend, denn über die Pflegeversicherung werden pro Tag nur 0,5 bis 1,8 Stunden Pflegearbeit finanziert. Das Verhältnis der privat Pflegenden zu den professionell Pflegenden beträgt drei zu eins." Der Familienbericht (S. 100 f.) kommt zu dem Ergebnis, dass ,auch in Zukunft ein nicht unerheblicher Teil der Pflege unentgeltlich durch Familienangehörige und freiwillig Tätige geleistet werden [muss] - dies allein schon aufgrund der steigenden Anzahl pflegebedürftiger Menschen: Derzeit sind 2,34 Millionen Menschen [...] pflegebedürftig [...]. Schätzungen zufolge werden im Jahre 2030 ca. 3,4 Millionen Menschen, im Jahre 20504 Millionen Menschen pflegebedürftig sein [...]." Zur Problematik auch Heinz Rothgang/Jeanine Staber, Pflege durch Angehörige - aktueller Stand und Reformdiskussion, FPR 2012, S. 48 ff. 
fall der Familienarbeit eine zusätzliche Belastung von mehr als einem Sechstel des gesamten Haushaltes bedeuten. Würden somit alle Eltern ihre Kleinkinder außerfamiliär betreuen lassen und würden alle pflegebedürftigen Angehörigen außerfamiliär untergebracht, so wäre dies überhaupt nicht finanzierbar. Abgesehen davon, dass unsere Gesellschaft auch aus ökonomischen Gründen nicht auf Familienarbeit verzichten kann, entspricht die familiäre Betreuung der eigenen Kinder unter drei Jahren ebenso wie die familiäre Pflege von Angehörigen auch dem Wunsch der Mehrheit der Familien. ${ }^{192}$

Führt man familiäre Wünsche und haushaltspolitische Notwendigkeiten zusammen, so müssten flexiblere Arbeitszeiten und Teilzeittätigkeiten für beide Eltern mit einer besseren finanziellen Anerkennung von Familienarbeit kombiniert werden, wobei dies nicht nur die Wahlfreiheit nach Art. 6 Abs. 1 und 2 GG stärker gewährleisten würde, sondern auch positive Effekte auf die Rollenverteilung zwischen den Geschlechtern hätte. ${ }^{193}$ Was spräche dagegen, wenn der Gesetzgeber beispielsweise die Auszeiten für Familie stärken (Erweiterung statt Kürzung von Elternzeit und Pflegezeit ${ }^{194}$ sowie Verhinderung von negativen Auswirkungen von Eltern-/Pflegezeit auf den Wiedereinstieg in den Beruf und auf die weitere Karriere) und verbindliche Ansprüche gegen den Arbeitgeber auf Teilzeittätigkeit bei Vorhandensein von minderjährigen Kindern und pflegebedürftigen Angehörigen einführen würde? Letztlich doch wohl nur ein höherer

192 Vgl. nur Institut für Demoskopie Allensbach, Monitor Familienleben 2010, Einstellungen und Lebensverhältnisse von Familien, Ergebnisse einer Repräsentativbefragung, 2010, S. 35, 48 (http://www.ifd-allensbach.de/uploads/tx_studies/7550_Monitor_Familienleben_2010.pdf) zur Vereinbarkeit von Familie und Beruf (wenngleich dort wenig Verständnis für den Wunsch aufgebracht wird, Kinderbetreuung und Angehörigenpflege selbst zu übernehmen): „53 Prozent der betroffenen Eltern denken, eine stärkere finanzielle Förderung der Familien würde gegen ihre Probleme mit der Vereinbarkeit helfen. In Intensivinterviews begründen die Befragten diese auf den ersten Blick sonderbar [sic!] anmutende Erwartung häufig damit, dass mehr finanzielle Förderung den empfundenen Erwerbsdruck verringern und ihnen erlauben würde, weniger Stunden zu arbeiten und mehr Zeit zusammen mit ihren Kindern zu verbringen. [...] 60 Prozent [der berufstätigen] Väter und 41 Prozent dieser Mütter würden etwas weniger Wochenstunden arbeiten, wenn sie es sich aussuchen könnten." Und weiter zur Pflege von Angehörigen, S. 38 f.: „41 Prozent der Bevölkerung insgesamt halten es deshalb für sehr wichtig, Berufstätigen die Pflege ihrer Angehörigen zu erleichtern, weitere 46 Prozent finden es wichtig. [...] Dahinter steht die verbreitete Vorstellung, dass Pflegebedürftige wo möglich am besten von ihren Angehörigen gepflegt werden sollten (65 Prozent der Gesamtbevölkerung)." Vgl. jetzt auch Bundesministerium für Familie, Senioren, Frauen und Jugend, Politischer Bericht zur Gesamtevaluation der ehe- und familienbezogenen Leistungen, 2013, S. 6 ff.

193 Ähnlich Böнm (Anm. 166), FAZ vom 4. April 2012, S. 7.

194 So wird im Achten Familienbericht, BT-Drucks. 17/9000, S. 126 eine Kürzung der Elternzeit auf zwei Jahre aufgrund der Belastungen für die Unternehmen vorgeschlagen (siehe oben Anm. 102). 
Organisationaufwand für die Unternehmen. Unter dem besonderen staatlichen Schutz der Verfassung steht jedoch nicht die Wirtschaft, ${ }^{195}$ sondern die Familie - auch wenn dem Gesetzgeber dies in den letzten zehn Jahren nicht immer bewusst gewesen zu sein scheint. ${ }^{196}$

195 In diesem Zusammenhang sei darauf hingewiesen, dass ein Bericht des Bildungsausschusses der OECD (OECD, Starting Strong. Early Childhood Education and Care, 2001) wesentlich zu dem beschriebenen Perspektivwechsel in Deutschland beigetragen hat. Dazu Schumann (Anm. 83), S. 444, 446 ff., 472; Ostner (Anm. 85), RdJB 2009, S. 44 ff. m.w.N.

196 In diesem Sinne mahnt auch Paul Kirchnof, \21 Grundrechtsinhalte und Grundrechtsvoraussetzungen, in: Detlef Merten/Hans-Jürgen Papier (Hrsg.), Handbuch der Grundrechte in Deutschland und Europa, Bd. 1: Entwicklung und Grundlagen, 2004, S. 807, 838 (Rn. 46): „Der gegenwärtige Hang des Staates, die Erziehungsverantwortung für das Kind schon in allerersten Jahren - aus Gründen des Arbeitsmarktes und der Gleichberechtigung - in öffentliche Hand zu übernehmen, hat die Frage veranlaßt, ob Ehe und Familie heute nicht mehr vor dem Staat als durch den Staat geschützt werden müssten." 